\title{
Untersuchungen über die Phytoplanktonblüte in der westlichen Ostsee ${ }^{1}$
}

\author{
WOLFGANG HICKEL ${ }^{2}$ \\ Institut für Meereskunde (Planktonlabor) der Universität Kiel, Kiel
}

\begin{abstract}
Investigations on the phytoplankton bloom in the western Baltic. Initiation and limitation of phytoplankton blooms in spring and autumn, occurring under complex hydrographic conditions in the brackish stratified waters of the western Baltic (Belt Sea), were investigated. Daily quantitative observations of plankton and environmental factors were made for a period of 5 to 6 weeks during March and April 1961 and 1962 as well as in September and October 1961 from the light-vessel "Flensburg" in the outer Flensburg Fjord. The diatom outburst appeared at the end of February 1961 during a calm weather period. In March 1962, when water temperature was quite low, the flowering of Skeletonema and Tbalassiosira occurring in two separate clouds took place three weeks later. These clouds were found at the surface and at $10 \mathrm{~m}$ depth after stabilization by a halocline in 7.5 to $10 \mathrm{~m}$. In both cases the end of this first bloom was caused by turbulence. The effect of the disappearance of a thermohaline stratification on the plankton succession was observed in September 1961, when, three days after complete mixing of the water column and with the onset of a calmwind period, a vigorous bloom of Ceratium fusus started; it stopped with the occurrence of a nutrient-devoid low-saline water mass at the surface. In the Belt Sea the main limiting factor for plankton flowering is considered to be wind turbulence coupled with high seston values and low compensation depths $(2$ to $11 \mathrm{~m}$ ). Plankton blooms, as understood here, occur in the form of unevenly distributed clouds in the euphotic layer during periods of at least 4 to 6 weeks in spring, and of 8 weeks in autumn. They are controlled by turbulence and last until a long period of calm weather allows the depletion of nutrients in the upper layer of the stratified water.
\end{abstract}

\section{EINLEITUNG}

\section{Bisherige Untersuchungen und Aufgabenstellung}

Die Erscheinung der „Phytoplanktonblüten“, also plötzlicher Massenentwidklungen von Planktonalgen, ist seit längerer Zeit bekannt. Im Jahresgang der Planktonverteilung in Meeren gemäßigter und höherer Breiten sind solche Wucherungen zu bestimmten Jahreszeiten regelmäßig zu beobachten. Sie spielen eine bedeutende Rolle in

${ }^{1}$ Herrn Prof. Dr. Friedrich Krüger zum 65. Geburtstag am 18. August 1967 in Verehrung gewidmet.

Gekürzte und veränderte Fassung der Dissertation des Verfassers (Kiel 1965). Die Arbeit wurde mit Unterstützung durch die Deutsche Forschungsgemeinschaft durchgeführt.

2 Neue Adresse: Biologische Anstalt Helgoland, Meeresstation, Helgoland. 
W. HICKEL

der Gesamtproduktion des Meeresplanktons. Zudem sind sie für die Untersuchung ökologischer und physiologischer Probleme besonders interessant. Gerade die Beobachtung der auslösenden und begrenzenden Faktoren für das Planktonwachstum ermöglichte das Verständnis der Primärproduktion im Meer.

Von den vielen Arbeiten, die sich mit der Erscheinung der Planktonblïten befaßt haben, können hier nur einige der wichtigsten erwähnt werden: MARsHall \& ORR (1929/30) untersuchten die Frühjahrsblüte in einem schottischen „Loch" mehrere Jahre lang. Sie fanden starke Skeletonema-Wucherungen, die zwei Wochen lang anhielten und zu erheblicher Verschlechterung des Lichtklimas im Wasser führten. GraN (1930) beobachtete den Beginn der Frühjahrsblüten vor der norwegischen Küste und setzte ihn in Beziehung zu den Schmelzwasserzufüssen. RrLeY $(1942,1943,1947)$ stellte umfangreiche Beobachtungen über die Diatomeenblüte in Beziehung zu deren begrenzenden Faktoren an und beschrieb die physiologischen Aspekte des Lebensablaufs der Diatomeen in situ und in Kultur.

Sverdrup (1953) machte das Problem der Entstehung der Planktonblite der mathematischen Behandlung zugänglich, indem er die wichtigsten begrenzenden Faktoren in einer Formel zusammenfaßte, mit der er den Eintritt der Planktonentfaltung vorhersagen konnte. GILLBRICHT (1955) untersuchte den Ablauf der Phytoplanktonwucherung in einem abgeschlossenen Hafenbecken. RYTHER et al. (1958) erfaßten die Veränderungen einer dichten Diatomeenblüte in Landnähe während 40 Stunden. Pomeroy, Haskin \& Ragotzkie (1956) und Ragotzkie \& Pomeroy (1957) stellten Messungen an Dinoflagellaten-Blüten an. McAllister, Stephens \& Strickland (1961) und ANTIA et al. (1963) erzeugten in einem großen, im Meer verankerten Plastikballon eine Planktonblüte. Cusming (1962) konnte die Sverdrup-Methode zur Berechnung des Eintritts einer Planktonwucherung verbessern. Schließlich sind GinLBRICHTS (Diss. 1951) produktionsbiologische Untersuchungen auf der Flensburger Förde zu erwähnen, die manche Grundlage für die hier vorgelegte Arbeit geben.

Nach den bisher bekannten Ergebnissen sind in der Beltsee eine Frïhahrs- und Herbstblüte des Phytoplanktons meist gut ausgebildet. Im Frihjahr wird vor allem durch steigendes Lichtangebot der Beginn der Wucherung ermöglicht, die nahezu ausschließlich von Diatomeen gebildet wird und bald durch Nährstofferschöpfung ihr Ende findet. Mit den absinkenden Planktonzellen wird der salzarmen Oberschicht auch der Nährstoff-Vorrat entzogen; daher bleibt im Sommer die Planktonproduktion gering. Erst im Herbst, wenn durch Stürme die Schichtung zerstört wird und die remineralisierten Nährstoffe wieder in die euphotische Schicht gelangen, kann eine zweite Planktonblüte im Jahresgang stattfinden. Ob diese Vorstellungen zur Deutung der beobachteten Erscheinungen ausreichen oder ob sie ergänzt werden müssen, wird im folgenden erörtert.

\section{Untersuchungsgebiet und seine Hydrographie}

Die Frühjahrs- und Herbstentfaltung des Phytoplanktons wurde von einem festen Punkt aus mit Hilfe täglicher Probenserien in engen vertikalen Abständen erfaßt. Als fester Punkt diente das Feuerschiff „Flensburg“, das an einer geschützten Po- 
sition in der Flensburger Außenförde liegt (Abb. 1). Die Wassertiefe beträgt hier $28 \mathrm{~m}$, die schmalste Stelle der Förde ist $7 \mathrm{~km}$ breit.

Die Beltsee, das Übergangsgebiet zwischen Nord- und Ostsee, zeichnet sich durch außerordentlich unruhige hydrographische Verhältnisse aus, über die durch WATTENBERG $(1941,1949 a, b)$ und andere Autoren hinreichend Klarheit geschaffen wurde.

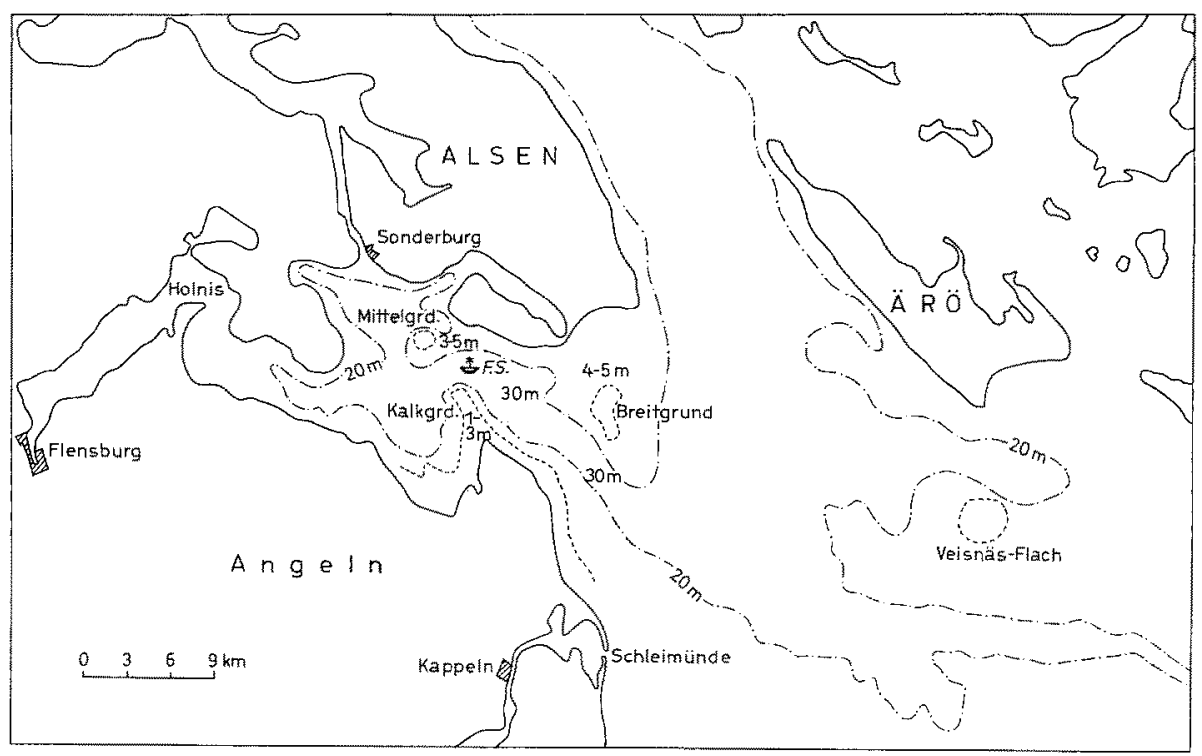

Abb. 1: Lage des Untersuchungsgebietes. (F.S.: Feuerschiff Flensburg)

Dort wird über den Wasseraustausch, die hydrographischen Fronten zwischen beiden Meeren und die hier so wichtigen Schichtungsverhältnisse (WeIdemann 1948, Dietrich 1950, KäNDLER 1951) berichtet. In diesem Meeresgebiet muß die Flensburger Außenförde als relativ gut geeignet gelten für planktologische Untersuchungen, da sie Windschutz von drei Seiten hat und abseits vom Hauptwasseraustausch zwischen den Meeren liegt. Der Baltische Strom nimmt seinen Weg durch den Großen Belt und den Sund, nur wenig fließt durch den Kleinen Belt. Wassertiefen von über $30 \mathrm{~m}$ verbinden jedoch das Bodenwasser der Förde mit dem Rinnensystem der westlichen Ostsee und ermöglichen die gleichen Schichtungsverhältnisse in der Förde wie in der ganzen Beltsee.

Sind die starken Strömungen der Ostseeausgänge im. Untersuchungsgebiet auch nicht zu erwarten, so spielen doch die windbedingten Wasserstandsänderungen der westlichen Ostsee eine große Rolle und machen sich als Ein- oder Ausstrom in der Förde bemerkbar. Diese Strömungen können Trübungswolken von den nahen Flachs des Kalkgrundes und Breitgrundes sowie von den Küsten her bewegen. Unter extremen Bedingungen kann sich auch der Einfluß des Innenförde-Wassers, das stark eutrophiert ist, bis zum Feuerschiff erstrecken (Abb. 1). Man muß also damit rechnen, daß nur bei günstigen hydrographischen Bedingungen Aussagen über die Entwicklung einer identischen Planktonpopulation über mehrere Tage oder Wochen gemacht werden können. Die hydrographische Lage muß daher für jeden Tag bekannt sein. 


\section{METHODEN}

\section{Probenahme und chemische Bestimmung des Sestons und Planktons}

Die Wasserproben wurden mit einem 5-1-Wasserschöpfer mit Plastikröhre (Firma Hydro-Bios, Kiel) gewonnen, der einen guten Durchfluß gewährleistet und Verunreinigungen durch Korrosionsprodukte verhindert. Meist wurde täglich eine Probenserie geschöpt in vertikalen Abständen von $2,5 \mathrm{~m}$ bis 1,5 beziehungsweise $1 \mathrm{~m}$ über Grund. Dazu wurden einige "gezielte" Proben je nach Tiefenlage der Sprungschicht genommen. Qualitative Planktonfänge mit einem Netz von $56 \mu$ Maschenweite wurden alle zwei Tage als Vertikalzüge durch die ganze Wassersäule oder nur in der Oberschicht gemacht.

Temperaturmessungen wurden mit einem Umkippthermometer am Schöpfer auf $1 / 100^{\circ} \mathrm{C}$ genau durchgeführt. Im Herbst wurde die Temperatur außerdem mit dem Bathythermographen gemessen $\left( \pm 0,5^{\circ} \mathrm{C}\right)$. Der Salzgehalt wurde refraktometrisch an Bord, im Frihjahr 1962 im Institut auf 0,1 bzw. 0,05\% Genauigkeit bestimmt. Er wird auf $\pm 0,1 \%$ angegeben.

Von jeder Wasserprobe wurde ein Teil für die Bestimmung des Sestons, ein weiterer für die Chlorophyllanalyse durch gehärtete Papierfilter mit angegebener mittlerer Porengröße von 1 bis $2 \mu$ (Schleicher $\&$ Schüll No. 575) filtriert $(0,25$ bis 11 ). Die Bestimmung des Sestongewichtes wurde nach Trocknung der Filter nach der Methode von KREY (1950) auf $\pm 0,2 \mathrm{mg} / 1$ durchgeführt. Das Trockengewicht des Detritus (nach KreY, s. Diskussion) erhält man durch Abzug des Plankton-Trockengewichtes, wie es sich aus der Eiweißbestimmung errechnet, vom Sestontrockengewicht. Der Eiweißgehalt der lebenden organischen Substanz wurde von den Sestonfiltern mit der BiuretMethode nach Krey bestimmt (Krey 1952; KreY, Banse \& Hagmener 1957). Die Methode erfaßt Eiweißkörper bis herab zu den Tripeptiden; sie werden als Albuminäquivalente (Eichung mit Albumin aus Eiern) kolorimetrisch bestimmt ( $\pm 15 \mu \mathrm{g} / 1$ $\mathrm{Alb}$. Aqu. nach LENZ 1963). Statt von Albuminäquivalenten wird im folgenden von Eiweiß geredet.

Chlorophyll a wurde nach KREY (1939) bestimmt. Der Methanolauszug des auf einem Filter angereicherten Planktons wurde im Elko II (Zeiss) mit dem Filter I 66,2 photometriert. Dieses Filter erfaßt den Extinktionsschwerpunkt von Chlorophyll a und dessen Abbauprodukte. Die Genauigkeit beträgt nach LENZ $\pm 0,3 \mu \mathrm{g} / 1$. Die Vollständigkeit der Extraktion wurde hier allerdings nur am Diatomeenplankton der Frühjahrsproben untersucht, indem bereits extrahierte und mehrfach gespülte Chlorophyllfilter erneut 1- bis 4mal mit kaltem und heißem Methanol behandelt und dessen. Extinktion wie vorher gemessen wurde (maximal bis 3 Tage Extraktionszeit). Dabei wurden Werte von 0,2 bis $0,6 \mu \mathrm{g}$ Chlorophyll bei chlorophyllreichen Proben gefunden, was maximal 1 bis $2 \%$ des ersten Extraktes ausmacht. Diese niedrigen Beträge schließen nicht aus, daß besonders bei besserem Aufschluß von dickschaligen Peridineen (z. B. durch Ultraschall) weit mehr Chlorophyll gefunden werden kann.

An filtrierten Wasserproben wurde der Phosphatgehalt bestimmt nach der Vorschrift von WATTENBERg (1937) als Phosphormolybdänsäure mit $\mathrm{SnCl}_{2}$ als Reduk- 
tionsmittel. Die Blaufärbung wurde mit einem Pulfrich-Photometer und $15 \mathrm{~cm} \mathrm{Kü-}$ vetten gemessen. Diese Bestimmung war wenige Stunden nach der Probenahme abgeschlossen, womit Veränderungen im $\mathrm{PO}_{4}$-Gehalt vermieden wurden. Für die Angabe der Konzentration wurde wie bei Chlorophyll und Eiweiß $\mu \mathrm{g} / 1$ gewählt.

\section{Planktonzählung und Volumenberechnung \\ Tabelle 1}

Gezählte Arten und Gruppen des Phytoplanktons und deren mittleres Plasmavolumen. Bei mehreren Zahlenangaben hintereinander gelten diese für die drei Beobachtungszeiträume (Reihenfolge: März 1961, September 1961, März 1962)

Vergrößerung $8 \times 40$

Skeletonema costatum

Chaetoceras, kleine Arten (C. socialis, bolsaticus, gracilis)

Thalassiosira, kleine, und Verwandte, 5-15 $\mu \varnothing$

Flagellaten, kleine (nackte Flagellaten, 5-10 $\mu$ lang, kleinste Dinoflagellaten)

Vergrößerung $8 \times 16$

Thalassiosira, große (und kleine Coscinodiscus) 50-100 $\mu \varnothing$

Thalassiosira, mittlere (T. baltica und Verwandte, Lauderia) $20-50 \mu \varnothing$

Chaetoceras, große (C. borealis, brevis) $40 \mu$ breit

Chaetoceras, mittlere

Leptocylindrus danicus

Thalassiothrix nitzschioides

Bodendiatomeen, große (meist Pleurosigma)

Bodendiatomeen, kleine (meist Navicula)

Peridineen, große (Prorocentrum, große Gymnodinium) 30-55 $\mu$ lang

Peridineen, mittlere (Gymnodinium, Peridinium triquetrum) $20 \mu$ lang

Distephanus speculum

Rhizosolenia fragilissima

Nitzschia

Cyanophyceen (Aphanizomenon)

Vergrößerung $8 \times 2,5$

Ceratium tripos typ.

Ceratium fusus

Ceratium lineatum

Ceratium longipes

Dinophysis, große

Dinophysis, mittlere

Peridinium, große

Peridinium, kleine

Rhizosolenia, große

Rhizosolenia, mittlere ( $R$. alata)

Biddulphia (B. aurita)

Ceratanlina

Coscinodiscus, sehr große

Coscinodiscus, große

Coscinodiscus, mittlere
Plasmavolumen einer

Zelle in $\mu^{3}$

150

100

100

200

17000

1700

900

$450 ; \quad 200 ; \quad 400$

200

800

10000

$1000 ; \quad 300 ; \quad 1000$

$10000 ; 10000 ; \quad 6000$

$700 ; 1000 ; 1000$

1400

4000

300

1 Kette: $\quad 30000$

100000

25000

40000

80000

100000

20000

$100000 ; 140000 ; 100000$

$10000 ; 15000 ; 10000$

30000

5500

4000

4000

800000

200000

75000 
Von den mit Lugolscher Lösung fixierten Seewasserproben $(100 \mathrm{ml})$ wurden 5 bis $25 \mathrm{ml}$ nach der Methode von UtermöHL (1958) und BraARUd (1958) mit dem umgekehrten Mikroskop ausgezählt. Bestimmt wurde nur das Phytoplankton; da das Ziel eine Volumenbestimmung war, wurden verschiedene Gattungen und Größengruppen so zusammengefaßt, daß für sie ein mittleres Volumen angegeben werden konnte. Um den Zählaufwand möglichst gering zu halten, wurde im Sinne von GILLBRICHT (1962) verfahren. Er findet, daß das Plankton einer Probe im Mittel 15 bis $25 \%$ um den wirklichen Planktongehalt des Wassers streut und empfiehlt, je nach Heterogenität des Planktons nur bis zu 35 bis 15 Einheiten einer Art zu zählen, womit bei mäßigem Zählaufwand eine Genauigkeit von \pm 10 bis $15 \%$ erreicht wird.

Zum Summieren und Vergleichen von Planktonarten können Zellzahlen kein brauchbares Maß bilden. Seit LoHManN (1908) die bislang gebräuchlichen Methoden zur „quantitativen“ Planktonbestimmung einer Kritik unterzog und das Rechenvolumen einführte, wurden noch oft Fehler durch die Verwendung von Zellzahl, Verdrängungs- oder gar Absetzvolumen als Maß gemacht. Das hier verwendete „Rechenvolumen" LoHmanNs entspricht dem Volumen der lebenden organischen Substanz und wird hier etwas vereinfacht als "Plasmavolumen" der Plankter bezeichnet. Mit diesem Maß kann die dem Stoffumsatz dienende Substanz ganz unterschiedlicher Planktonformen (wie der Diatomeen und Peridineen) verglichen werden. Trotz starker Streutung des Volumens selbst einer Art kommen Hagmeier (1960) wie auch PaAsche (1960) zu dem Ergebnis, daß nur auf diesem Wege eine biologisch sinnvolle Summierung der gezählten Plankter erfolgen kann. Das Rechenvolumen hält auch BANSE (1962) für die bei den großen Diatomeen-Vakuolen wohl beste rechnerische Annäherung an die organische Substanz der Plankter.

Fehlermöglichkeiten und Genauigkeit der Umrechnung können aus der gründlichen Arbeit von HAGMEIER (1960) ersehen werden. Die für die getrennten Arten und Gruppen verwendeten Volumina wurden aus Angaben von LoHmanN (1908), Gillbricht (1951) und vor allem Hagmeier (1960) zusammengestellt (Tab. 1). Zellgrößenmessungen, Mikrophotographien und Vergleich mit den formolfixierten Netzfängen dienten zur Ermittlung des Zellvolumens und Sicherung der Artbestimmung.

\section{Lichtmessungen}

Da sich mit dem Gehalt an Seston und gelösten Stoffen (Gelbstoff) die Lichtdurchlässigkeit des Wassers rasch ändert, ist man gerade in Küstennähe auf häufige Wiederholung der Lichtmessungen angewiesen. Auch die spektrale Zusammensetzung des Unterwasserlichtes verschiebt sich mit dem Landeinfluß und erschwert den Vergleich mit Messungen in ähnlichen Seegebieten (JERLov 1955). Es wurde hier daher aus verschiedenen Literaturangaben eine Methode zusammengestellt, um das Strahlungsangebot an das Plankton für jeden Tag aus Messungen der Transparenz des Wassers zu berechnen.

Aus zahlreichen Arbeiten geht hervor, daß nur der sichtbare Bereich des Strahlungsspektrums im Wasser eine wesentliche Rolle spielt, da das Ultraviolett (300 bis $380 \mathrm{~nm}$ ) wie auch das Ultrarot $(750$ bis $3000 \mathrm{~nm}$ ) besonders im getrübten Küstenwasser 
in den obersten Zentimetern absorbiert werden. Das tiefer eindringende "Licht", also Strahlung von 380 bis $720 \mathrm{~nm}$ Wellenlänge, kommt auch nur für die Photosynthese der Planktonalgen in Frage. Viele Versuche über die Ausnutzung der verschiedenen Wellenlängen durch Phytoplankter (RABINowrTch 1951) zeigen, daß man bei ökologischen Arbeiten das sichtbare Licht als gleichmäßig wirksam annehmen darf (STRICKLAND 1958). Bei dem unterschiedlichen Pigmentgehalt und der verschiedenen chromatischen Adaptation der Plankter einer gemischten Population ist die für die Praxis am besten geeignete Größe die Gesamtstrahlung im genannten Bereich.

Licht- und Planktonmessungen im Meer wurden erst ab 1932 miteinander verknïpft, um die Lichtabhängigkeit der Planktonphotosynthese zu erforschen (PETTERson, Höglund \& Landberg 1934, Höglund \& Landberg 1936, Jenkin 1937). STrickland (1958) gibt eine Zusammenstellung der veröffentlichten Ergebnisse über Licht im Meer mit besonderer Berücksichtigung der Lichtwirkung auf das Plankton. Es wird hier nach seinen Ergebnissen die Gesamtstrahlungsenergie zwischen 380 und $720 \mathrm{~nm}$ als das beste Maß für die zur Photosynthese verwendbare Energie für das Phytoplankton angenommen.

\section{Energiebedarf des Pbytoplanktons}

Aus der Literatur werden Werte über den Energiebedarf der Planktonalgen zusammengestellt, um Kompensationsenergie, optimale Energie (Lichtsättigung) und Lichtschädigungsenergie zu finden, wie sie für das Plankton unseres Gebietes in Frage kommen (Tab. 2). Die „Kompensationsenergie“ (Petterson, Höglund \& Landberg 1934) ist die Energiemenge, die kurzfristig - zum Beispiel während eines einstündigen Experiments - zur Kompensation der Atmungsverluste durch die Assimilation ausreicht, so daß sich Stoffproduktion und Stoffabbau genau die Waage halten. Dies bezeichnet Gessner (1960) als "physiologischen Kompensationspunkt", der nur auf die Zeit der Assimilationstätigkeit zu beziehen ist.

Die Energiemenge, die zur Kompensation während 24 Stunden, also einer Hellund Dunkelphase, ausreicht, ist nach Marshall \& ORR (1928) am „Kompensationspunkt" vorhanden und dient als Bezug bei ökologischer Auswertung einer Planktonverteilung. Während einer längeren Beobachtungsperiode ist also die Tiefe, in der die Energie für eine Kompensation während 24 Stunden ausreicht, maßgebend für die Planktonproduktion, während die kurzzeitige Kompensationstiefe zur Erklärung der Planktonverteilung an einzelnen Tagen bekannt sein muß. Weiter ist der Begriff der kritischen Tiefe wichtig als der Tiefe, in der pro $\mathrm{m}^{2}$ Oberfläche die Gesamtproduktion gleich dem Gesamtverlust an organischer Substanz des Phytoplanktons ist. Sie kann das 5- bis 10fache der Kompensationstiefe betragen (Gran \& BraArud 1935) und dürfte in unserem Gebiet oft den Boden erreichen.

In Tabelle 2 sind einige Angaben aus Beleuchtungswerten (Lux) umgerechnet worden. Die Kompensationstiefe entspricht ungefähr der Tiefe mit 0,5 bis $1 \%$ des einfallenden Oberflächenlichts (STRICKLand 1958, Steemann Nielsen \& HANsen 1959). Zusammenfassend werden mit STRICKLAND folgende Werte angenommen: 
$0,18 \mathrm{cal} / \mathrm{cm}^{2} / \mathrm{h}=$ wahrscheinliche kurzzeitige Kompensationsenergie für natürliche Phytoplanktonpopulationen.

$0,13 \mathrm{cal} / \mathrm{cm}^{2} / \mathrm{h}=$ desgleichen für ausgeprägtes Schattenplankton.

$5 \mathrm{cal} / \mathrm{cm}^{2} / \mathrm{Tag}=$ Kompensationsenergie für 24 Stunden. Da im Frühjahr Schattenformen vorherrschen, wird man ab ungefähr $15 \mathrm{cal} / \mathrm{cm}^{2} / \mathrm{h}$ mit dem Beginn der Lichtschädigung rechnen können.

Tabelle 2

Energiebedarf des Phytoplanktons

\begin{tabular}{|c|c|c|}
\hline \multicolumn{2}{|c|}{$\begin{array}{l}\text { I. Kompensationsenergie } \\
0,18 \mathrm{cal} / \mathrm{cm}^{2} / \mathrm{h} \\
\text { oder }\end{array}$} & Autoren: \\
\hline $\begin{array}{l}5 \mathrm{cal} / \mathrm{cm}^{2} / \mathrm{Tag} \\
0,13 \mathrm{cal} / \mathrm{cm}^{2} / \mathrm{h}\end{array}$ & $\begin{array}{l}\text { Natürliche Planktonpopulationen } \\
\text { (während des Tages) Coscinodiscus- } \\
\text { Kulturen (Schattenalgen) }\end{array}$ & $\begin{array}{l}\text { STRICKLAND } 1958 \\
\text { JENKIN } 1937\end{array}$ \\
\hline $\begin{array}{l}0,14-0,18 \mathrm{cal} / \mathrm{cm}^{2} / \mathrm{h} \\
0,18-0,36 \mathrm{cal} / \mathrm{cm}^{2} / \mathrm{h}\end{array}$ & $\begin{array}{l}\text { (24-h-Mittel) Gemischte Populationen } \\
\text { (Kurzzeitige Kompens.-Energie) Ver- } \\
\text { suche an versch. Planktongruppen }\end{array}$ & $\begin{array}{l}\text { PetTERson et al. } 1934 \\
\text { Ryther } 1956\end{array}$ \\
\hline $0,072-0,163 \mathrm{cal} / \mathrm{cm}^{2} / \mathrm{h}$ & $\begin{array}{l}\text { "Kompensationspunkt" für Schatten- } \\
\text { plankton }\end{array}$ & $\begin{array}{l}\text { STEEMANN NIELSEN } \\
\& \text { HANSEN } 1959\end{array}$ \\
\hline $0,22-0,43 \mathrm{cal} / \mathrm{cm}^{2} / \mathrm{h}$ & $\begin{array}{l}\text { "Kompensationspunkt" für Sonnen- } \\
\text { plankton }\end{array}$ & $\begin{array}{l}\text { STEEMANN NIELSEN } \\
\& \text { HANSEN } 1959 \\
\end{array}$ \\
\hline $\begin{array}{l}\text { I1. Optimale Energie } \\
9 \mathrm{cal} / \mathrm{cm}^{2} / \mathrm{h} \\
4,2-9 \mathrm{cal}^{2} / \mathrm{cm}^{2} / \mathrm{h} \\
9,7-11,6 \mathrm{cal} / \mathrm{cm}^{2} / \mathrm{h}\end{array}$ & $\begin{array}{l}\text { Cichtsättigungsenergie) } \\
\text { Gemischte Phytoplanktonpopulation } \\
\text { Diatomeen und Dinoflagellaten } \\
\text { in Kultur }\end{array}$ & $\begin{array}{l}\text { STRICKLAND } 1958 \\
\text { RYTHER } 1956 \\
\end{array}$ \\
\hline $\begin{array}{l}\text { III. Lichtschädigung } \\
30 \mathrm{cal} / \mathrm{cm}^{2} / \mathrm{h}\end{array}$ & $\begin{array}{l}\text { Beginn deutlicher Schwächung und } \\
\text { Schädigung }\end{array}$ & STRICKLAND 1958 \\
\hline $\begin{array}{l}10 \mathrm{cal} / \mathrm{cm}^{2} / \mathrm{h} \\
30 \mathrm{cal} / \mathrm{cm}^{2} / \mathrm{h}\end{array}$ & $\begin{array}{l}\text { Coscinodiscus-Kulturen (Schattenalgen) } \\
\text { Diatomeen nur noch wenige } \% \text { der } \\
\text { optimalen Assimilation }\end{array}$ & JENKIN 1937 \\
\hline oder: $3,9 \mathrm{cal} / \mathrm{cm}^{2} / \mathrm{h}$ & $\begin{array}{l}\text { Dinoflagellaten } 40-50 \% \text { der optimalen } \\
\text { Assimilation } \\
\text { mehr als Lichtsättigung = Schädigung } \\
\text { bei allen Planktongruppen }\end{array}$ & $\begin{array}{l}\text { RYTHER } 1956 \\
\text { RYTHER } 1956\end{array}$ \\
\hline
\end{tabular}

\section{Prinzip wnd Praxis der Messungen}

Um die Strahlungsenergie in den verschiedenen Wassertiefen festzustellen, sind Direktmessungen der Energie bis heute mit vielen Schwierigkeiten verbunden und können nicht zu den Routineuntersuchungen zählen (SAUberER 1962). Man berechnet die Energie daher besser indirekt mit genügender Genauigkeit nach einer Methode, die JENKIN 1937 ausführte und für ihre bekannte Arbeit über Lichtabhängigkeit der Photosynthese bei Coscinodiscus verwandte. Diese Methode empfiehlt auch der ICES. Bei SAuberer (1962) findet man die Energieberechnung näher erklärt. Das Prinzip ist folgendes: 
(1) Mit einem UW-Photometer wird in drei Spektralbereichen (blau, grün, rot) innerhalb des sichtbaren Lichts (380-780 nm) durch Relativmessungen der vertikale Extinktionskoeffizient $\left(\mathrm{EK}_{\mathrm{v}}\right)$ in diesen Bereichen festgestellt.

(2) Die Gesamtstrahlungsenergie über Wasser (Integral für eine bestimmte Zeit) muß ermittelt werden.

(3) Ist dazu noch die Energieverteilung, die sich mit Sonnenhöhe und Bewölkung ändert, für die Strahlung über Wasser bekannt, kann man die Strahlungsenergie für bestimmte Spektralbereiche in jeder Wassertiefe für einen bestimmten Zeitraum berechnen.

Bei Messungen des Tageslichtes kommt nur die Ermittlung des „vertikalen Extinktionskoeffizienten" in Frage, der von ATkINs \& POOLE (1933) in die Meeresoptik eingeführt wurde (siehe auch Josepr 1949). Er bezeichnet die Schwächung eines diffusen Lichtstromes beim Durchgang durch eine Wasserschicht einer bestimmten Dicke (meist $1 \mathrm{~m}$ ). Gemessen wird die Beleuchtungsintensität an der oberen und unteren Grenze einer Wasserschicht; die Angabe erfolgt meist als Durchlässigkeit (Transparenz) in $\% / \mathrm{m}$. Die Genauigkeit der Transparenzmessung reicht nicht aus zur Erfassung feiner Unterschiede in der optischen Schichtung. Hier sollen auch nur mittlere Verhältnisse gemessen werden, wie sie auf einen Plankter im Laufe des Tages einwirken. Daher wurden die erhaltenen Werte der einzelnen Serien im Frühjahr für die ganze Wassersäule, im Herbst für die Oberschicht und Unterschicht (unter der Sprungschicht) gemittelt. Wenn wegen starken Windes an einigen Tagen nicht mit dem Photometer gemessen werden konnte, wurden Sichttiefenmessungen zur Charakterisierung der optischen Eigenschaften herangezogen.

Zur Beobachtung des Lichtangebotes im. Wasser wurden an Bord folgende Messungen durchgeführt: (1) Globalstrahlungsenergie über Wasser mit dem Aktinographen; (2) Unterwasser-Beleuchtungsmessungen mit Selen-Photoelementen; (3) Messungen der Sichttiefe mit der Sechischeibe.

(1) Ein Aktinograph nach Robitzsch-Fuess wurde auf dem Feuerschiff aufgestellt. Das Gerät registriert kontinuierlich den zeitlichen Verlauf der auf eine horizontale Empfängerfläche fallenden Globalstrahlungsenergie (Sonnen- und Himmelsstrahlung). Für März 1962 wurden - da der Aktinograph im Sturm zerstört worden war - Registrierungen von einem gleichen Gerät von Wyk auf Föhr verarbeitet, die sich als gut vergleichbar erwiesen.

(2) Ein Unterwasser-Photometer (B-Gerät), wie es bei JosEPH \& WATTENBERG (1944) beschrieben ist, fand Verwendung. Drei Selen-Photoelemente, von denen je eins mit einem blauen, grünen und roten Filter bedeckt war, waren im druckdichten Gehäuse unter einer gemeinsamen Glasplatte eingeschlossen. Es wurden Elemente der Fa. Lange, Berlin, und Schott-Glasfilter $(2,0 \mathrm{~mm})$ benutzt. Die spektrale Empfindlichkeit der Maßanordnungen setzt sich aus der des Filters und der des Elements zusammen. JOSEPH (1946) gibt für die verwendeten Meßanordnungen folgende Bereiche an:

$\begin{array}{ll}\text { blau: } & \text { Element }+ \text { Filter BG } 12 \\ \text { grün: } & \text { Element + Filter VG } 9 \\ \text { rot: } & \text { Element + Filter RG } 1\end{array}$

Optischer Schwerpunkt

$$
\begin{aligned}
& 380-480 \mathrm{~nm} \\
& 480-600 \mathrm{~nm} \\
& 600-720 \mathrm{~nm}
\end{aligned}
$$

$445 \mathrm{~nm}$

$533 \mathrm{~nm}$

$648 \mathrm{~nm}$ 
Der Photostrom der drei für verschiedene Spektralbereiche empfindlichen Elemente wurde an Deck mit einem Mikroampèremeter gemessen. Eine Proportionalität Photostrom zu Beleuchtungsstärke ist nur bei sehr niedrigen Innenwiderständen des Meßgerätes und niedriger Beleuchtungsintensität (unter 1000 Lux) gegeben. Daher wurden bei der Messung hohe Intensitäten vermieden und die abgelesenen Werte aus verschiedenen Meßbereichen durch Eichung vergleichbar gemacht. Die Schwerpunktverschiebung einer Meßanordnung, die durch das zusätzliche „Farbfilter" des Wassers hervorgerufen und durch die relativ große Bandbreite der Schott-Filter ermöglicht wird, konnte nicht berücksichtigt werden. Die anderen Fehlerquellen (SAUBERER 1962) spielen eine geringe Rolle. Der Einfluß des Schiffsschattens (Joserh \& WatTENBERG 1944) wurde vermieden, indem das Photometer über einen $4 \mathrm{~m}$ langen Ausleger am Heck des Schiffes jeweils zur Sonnenseite hin ausgebracht wurde. Gemessen wurde nur beim Fehlen rascher Schwankungen in der Einstrahlung (Wolken), und zwar von unten $(20-10 \mathrm{~m})$ nach oben, abgelesen bei jedem Meter.

(3) Die Sichttiefe einer 30-cm-Secchischeibe wurde täglich 1-4mal bestimmt. Diese als Zusatzmessung oft bewährte Methode erlaubt eine Schätzung der Durchlässigkeit des Wassers im Bereich maximaler Transparenz (hier grïn) und damit der Kompensationstiefe. Nach STRrckland (1958) und Banse (1957) gilt: Sichttiefe $\times 1,5=$ Kompensationstiefe. Beobachtungen der Bewölkungsart und Bedeckung, von Wind und Seegang dienten zur Berechnung der Energieverteilung und der Reflexion. Die meteorologischen und hydrographischen Beobachtungen der Feuerschiffsbesatzung (alle 4 Stunden) wurden mitverwendet („Beobachtungen auf den deutschen Feuerschiffen der Nord- und Ostsee“, DHI, Hamburg).

\section{Energieberechnungen}

Mit den so gewonnenen Werten wurden nach dem genannten Prinzip Energicberechnungen vorgenommen. Die spektralen Durchlässigkeits-Messungen sagen noch nichts aus über die tatsächliche spektrale Zusammensetzung der Strahlung im Wasser, da sie ja unter der Annahme einer energiegleichen Strahlung über das gesamte Spektrum gemacht wurden. Während in der Luft Messungen der Änderung eines Spektralbereiches gut proportional der Anderung des gesamten Spektrums sind, geht unter Wasser die Proportionalität rasch verloren, da ja die Intensität jedes Spektralbereiches unabhängig geschwächt wird. So wird das Gesantlicht mit der Tiefe nicht nur schwächer, sondern auch - in unserem Gebiet - grüner.

Die Spektralverteilung der Energie unter Wasser wird aus derjenigen der eindringenden Strahlung und der spektralen Durchlässigkeit des Wassers gefunden. Neben der Strahlungsenergie für den ganzen Tag wurden im März und Herbst 1961 auch noch die Werte für die hellste Tagesstunde und die Stunde der Probenahme berechnet. Der Gang der Berechnung ist folgender:

(1) Die Energieeinstrahlung über Wasser wurde z. B. als Tagessumme (cal/ $\mathrm{cm}^{2} /$ Tag) aus den Aktinographen-Aufzeichnungen ermittelt.

(2) Der Anteil der Globalstrahlung, der in den Bereich von 380-720 nm als der photosynthetisch wirksamen, eindringenden Strahlung fällt, wurde mit 50\% der Globalstrahlung, wie sie der Aktinograph mißt, angenommen (nach STRickLand). 
Phytoplanktonblüte in der Ostsee

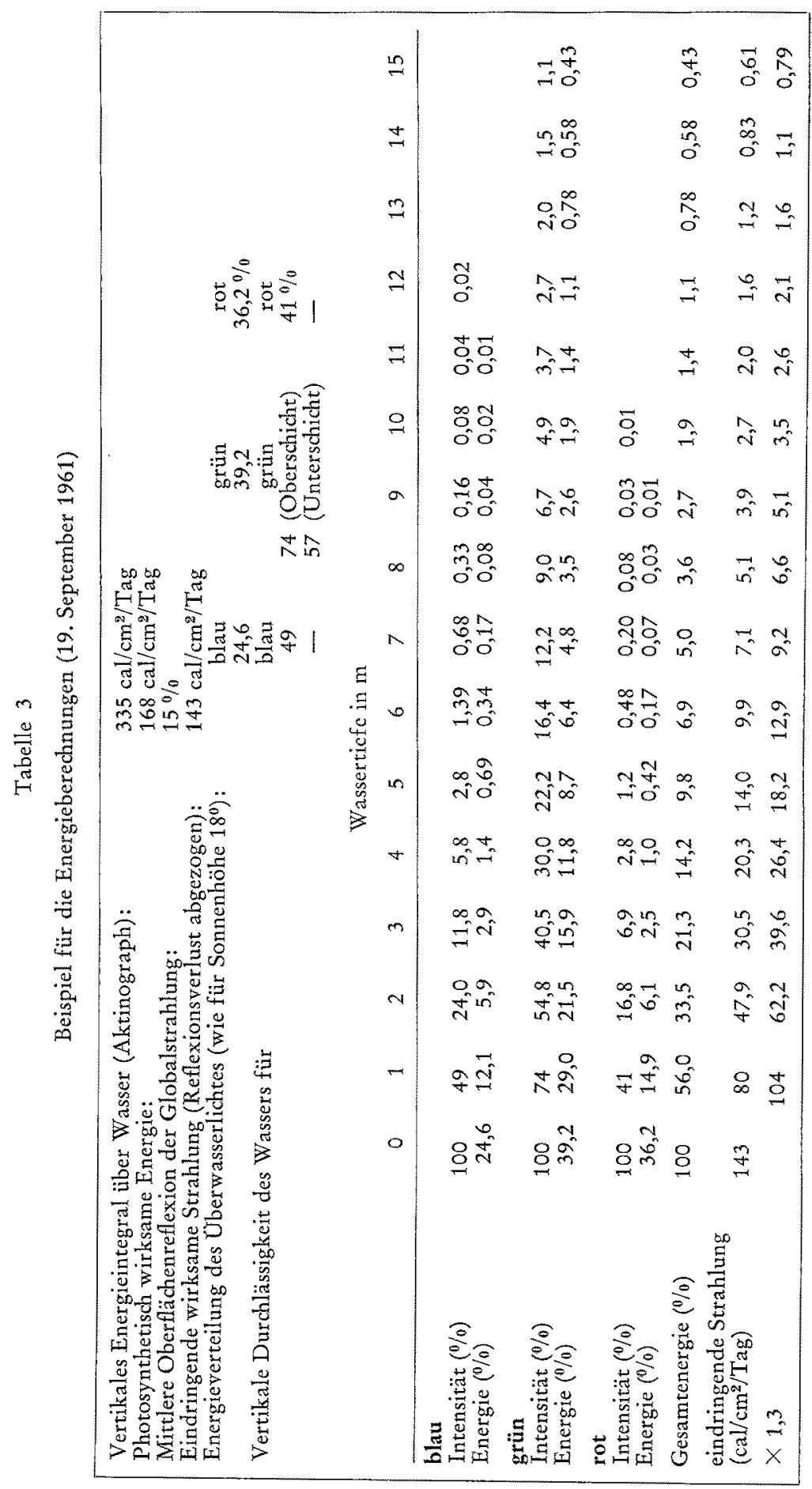


(3) Davon wurde der Reflexionsverlust abgezogen und so die eindringende, wirksame Strahlung gefunden. Die mittlere Oberflächenreflexion der Globalstrahlung wurde aus der Literatur unter Verwendung eigener Daten über Bewölkung, Seegang und mittlere Sonnenhöhe ermittelt (Sauberer 1962, Poole 1938, Atxins \& Poole 1936).

(4) Die Energieverteilung des Oberwasserlidates wurde nach Werten von SAUBERER (1962) bestimmt, der Kurven aufstellt für die mittlere absolute Intensität in den einzelnen Spektralbereichen bei wolkenlosem und bedecktem Himmel für $48^{\circ}$ nördlicher Breite.

(5) Die vertikale Durchlässigkeit für die drei Spektralbereiche wurde eingesetzt.

(6) Die Energieanteile jedes Spektralbereiches wurden mit den Intensitäten der Beleuchtungsstärke in jeder Tiefe multipliziert, wodurch man die Schwächung der Energie in jedem Spektralbereich erhält.

(7) Summiert man die so berechneten Energieprozentsätze, ergibt sich die eindringende Gesamtenergie in Prozent des Oberflächenwertes.

(8) Da der Oberflächenwert absolut bekannt ist aus den Aktinographendaten, kann man jetzt für jede Tiefe das Oberlicht in absoluten Energieeinheiten angeben, indem man die Gesamtenergie (\%) der verschiedenen Tiefen mit dem Energieintegral an der Oberfläche multipliziert.

(9) $\mathrm{Da}$ ein Plankter im Wasser aber nicht nur die vertikale Komponente des Tageslidhtstromes (Oberlicht) erhält, sondern auch den Streulichtanteil von den Seiten und von unten (Seiten- und Unterlicht), erhöht sich der Wert des hier bestimmten Oberlichtes um einen ziemlich konstanten relativen Betrag. Dieser wurde von JERLov (1951) für vergleichbares Küstenwasser mit 1,3 ermittelt. Jeder berechnete Energiewert ergibt also $\times 1,3$ den wirklichen Strahlungsempfang eines Plankters.

\section{DARSTELLUNG DER BEOBACHTUNGEN}

Für jeden der drei Beobachtungszeiträume werden zunächst hydrographische Lage, Licht- und Nährstoffangebot aufgezeigt, dann die Komponenten des Planktons dargestellt. Da hierbei weder auf die Anschaulichkeit des Isoplethendiagramms, noch auf die Genauigkeit der Vertikalkurven verzichtet werden konnte, werden möglichst beide Darstellungsarten nebeneinander gebracht. Das verwertete Probenmaterial ist aus Tabelle 4 zu ersehen.

Daten über Oberflächenstrom, Wind und Oberflächensalzgehalt wurden zur Ergänzung aus den „Beobachtungen auf deutschen Feuerschiffen der Nord- und Ostsee", DHI, Hamburg, entnommen.

März 1961

Hydrograpbie

Eine haline Schichtung ist meist vorhanden. Die Zunahme des Salzgehaltes von 3 bis $4 \%$ zum Boden erfolgt vom 2. bis 15 . März meist ohne, manchmal mit schwach 
Tabelle 4

Verwendetes Probenmaterial (Anzahl der ausgewerteten Proben)

\begin{tabular}{|lccc|}
\hline Art der Bestimmung & $\begin{array}{c}\text { Frïhjahr 1961 } \\
\text { (2. März bis } \\
\text { 6. April) }\end{array}$ & $\begin{array}{c}\text { Herbst 1961 } \\
\text { (6. September bis } \\
\text { 16. Oktober) }\end{array}$ & $\begin{array}{c}\text { Frühjahr 1962 } \\
\text { (1. März bis } \\
\text { 3. April) }\end{array}$ \\
\hline Temperaturmessungen & 300 & 280 & 307 \\
Salzgehaltsbestimmungen & 300 & 280 & 307 \\
Sestonbestimmungen & 300 & 240 & 320 \\
Chlorophyllbestimmungen & 300 & 240 & 320 \\
Eiweißbestimmungen & 300 & 240 & 320 \\
Planktonzählungen & 216 & 230 & 196 \\
Phosphatbestimmungen & & 126 & 170 \\
Bathythermograph-Registrierg. & & 30 & \\
UWW-Beleuchtungsmessungen: & & & \\
Vertikalserien & 27 & 19 & 50 \\
(gemessen an 15 bzw. 16 Tagen) & 31 & 83 & \\
Sichtscheibenmessungen & & & \\
\hline
\end{tabular}

ausgeprägter Sprungschicht (Abb. 2a). Schwache bis mäßige Westwinde und Ausstrom an der Oberfläche (bis $10 \mathrm{~cm} / \mathrm{sec}$ ) herrschen vor. Am 12. März bringt auffrischender Westwind kurz kräftigen Ausstrom (Abb. 2b). Salzreiches Bodenwasser, das am 13. März schon vom Schöpfer erfaßt wurde, steigt vom 16. bis 21. März von 22,5 auf $17,5 \mathrm{~m}$ an (Abb. 2a, 3). Eine scharfe Salzgehaltssprungschicht mit Gradienten von $2 \%$ pro 2,5 $\mathrm{m}$ und mehr ist ausgebildet. Am 18. März verursacht steifer Wind einen starken Ausstrom (Abb. 2b). Vom 21. bis 26. März ist eine ausgeprägte Salzgehaltsschichtung mit einer tief gelegenen Sprungschicht in 17,5 bis $20 \mathrm{~m}$ anzutreffen, in der Gradienten bis 2,5\% pro 2,5 m vorkommen (Abb. 3). Am 26. und 27. März bedingen stürmische Winde aus westlichen Richtungen bei starkem Ausstrom die Zerstörung der Schichtung. Anfang April wird eine erneute Stabilisierung durch eine aufsteigende Sprungschicht beobachtet (Abb. 2, 3). Der Salzgehalt an der Oberfläche steigt gleichmäßig an von $18 \%$ Anfang März bis auf 22,5\% Anfang April und erreicht damit den höchsten Wert des Jahres 1961 (Abb. 2b). Dreimal ist der Beginn einer thermischen Schichtung durch Erwärmung des Oberflächenwassers zu beobachten: vom 7. bis 11. März, 15. bis 17. März und 6. April (Abb. 3). Diese Schichtung wird durch die Windtage am 12. und 18. März zerstört. Die Wassertemperatur liegt, verglichen mit den Mitteln der Vorjahre, $2,2^{\circ} \mathrm{C}$ zu hoch. Sie steigt von 3,50 Anfang März auf 4 bis $5^{\circ} \mathrm{C}$ Anfang April.

Die hydrographische Lage ist also wie folgt zu charakterisieren: Bis Mitte März ist bei schwachen westlichen Winden und geringem Ausstrom an der Oberfläche keine starke Sprungschicht ausgebildet. In der zweiten Märzhälfte fließt bei stärkerem Westwind und Ausstrom an der Oberfläche salzreiches Bodenwasser ein und bedingt eine scharfe Dichteschichtung (Abb. 2). Der Salzgehalt des Fördewassers steigt Anfang März langsam, ab Mitte des Monats schneller durch Aufsteigen des Bodenwassers an den Küsten. Zwei kurze (12. und 18. März) und eine längere (26. bis 28. März) stark windige Periode zerstören die thermische, Ende März auch die haline Schichtung und dürften für die biologischen Ereignisse bedeutsam sein.

Bei den ruhigen Strom- und Windverhältnissen ist die Oberschicht bis Mitte März 


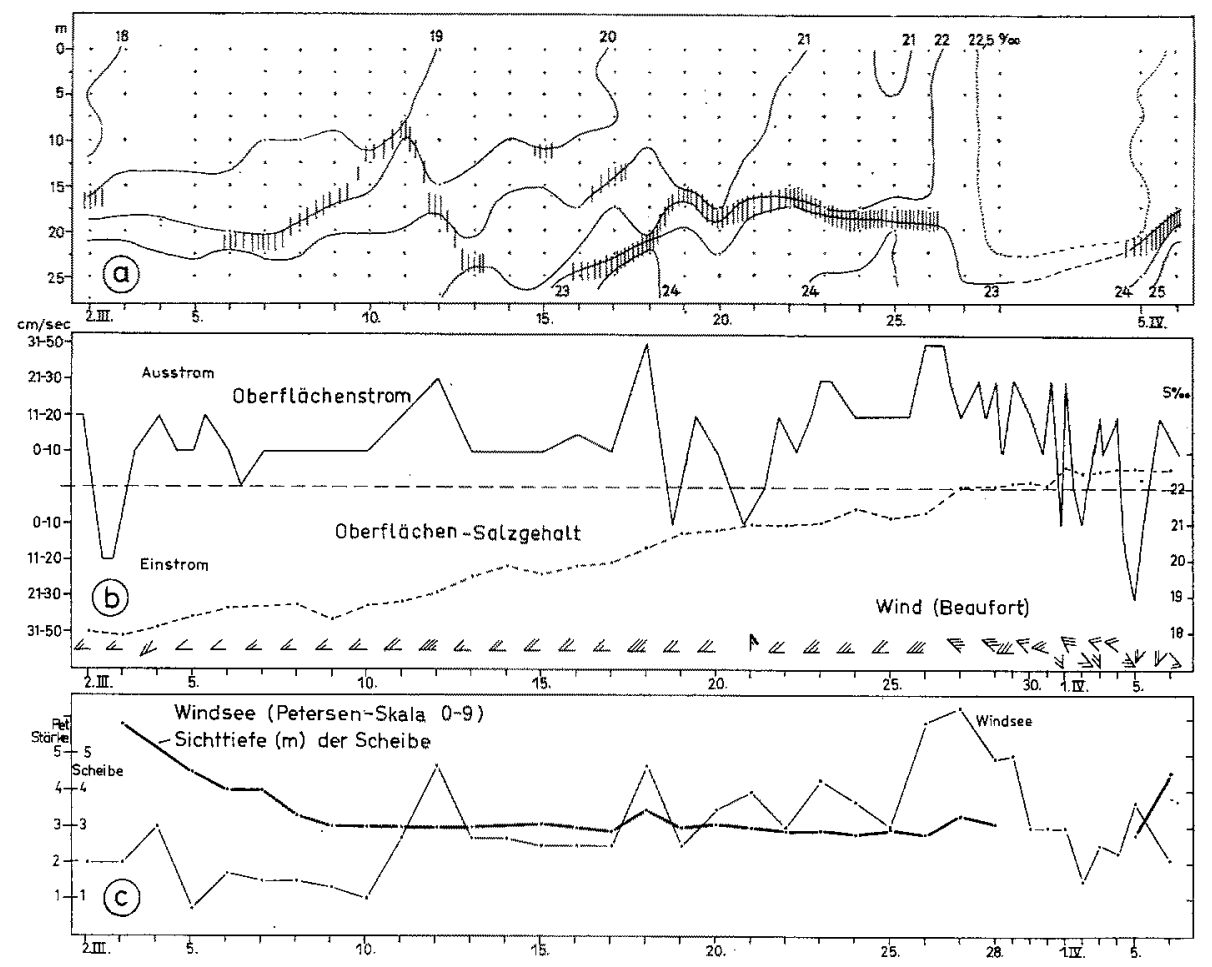

Abb. 2: März 1961: Hydrographie. (a): Isoplethen des Salzgehaltes. Senkrechte Striche: Salzgehalts-Sprungschicht. Je dichter die Striche, um so schärfer ausgebildet ist die Sprungschicht. (b): Strom und Salzgehalt an der Oberfläche, Windrichtung (woher) und Geschwindigkeit (BEAUforT). (c): Windsee und Sichttiefe

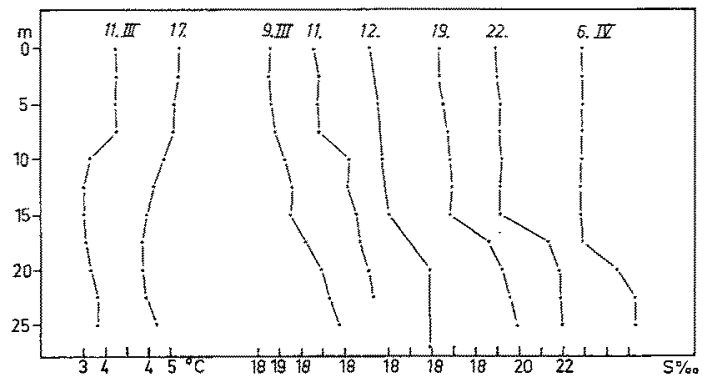

Abb. 3: März 1961: Vertikalkurven von Temperatur und Salzgehalt

ein bedingt vergleichbarer Wasserkörper. Keine plötzlichen Einschübe anderer Wassermassen stören, doch erfolgt langsam und kontinuierlich eine Zumischung salzreicheren Bodenwassers. Die Schichtung in der zweiten Märzhälfte läßt die Oberschicht besser vergleichbar erscheinen. Ein Dichtesprung trennt sie vom Bodenwasser, das biologisch noch keine Bedeutung hat. 


\section{Licht}

Der Kompensationspunkt liegt im Frühjahr 1961 sehr hoch (Abb. 4). Das Wasser ist trübe und zeigt oft eine milchig-grüne Vegetationsfärbung, die schon eine starke Planktonblüte erkennen läßt. Die Werte für die Sichtscheibe geben bereits einen Einblick in die optischen Verhältnisse (Abb. 2c). Am Anfang der Blüte fällt die Sichttiefe von 6 auf $3 \mathrm{~m}$, einen selbst für unser Gebiet sehr niedrigen Wert, der bis zum Ende der Blüte bleibt und erst Anfang April wieder auf 4,5 $\mathrm{m}$ ansteigt. Stärkere Windsee beeinflußt die Sichttiefe nicht wesentlich, nur am 6. April ist eine Abhängigkeit zu vermuten (Abb. 2c).

Entsprechend den niedrigen Sichtwerten findet sich auch der Kompensationspunkt in der geringen Tiefe von 2 bis $4 \mathrm{~m}$. Während des ganzen März sind $3 \mathrm{~m}$ die häufigste, $4 \mathrm{~m}$ die maximale und $2 \mathrm{~m}$ an dunklen Tagen die minimale Kompensationstiefe. Erst

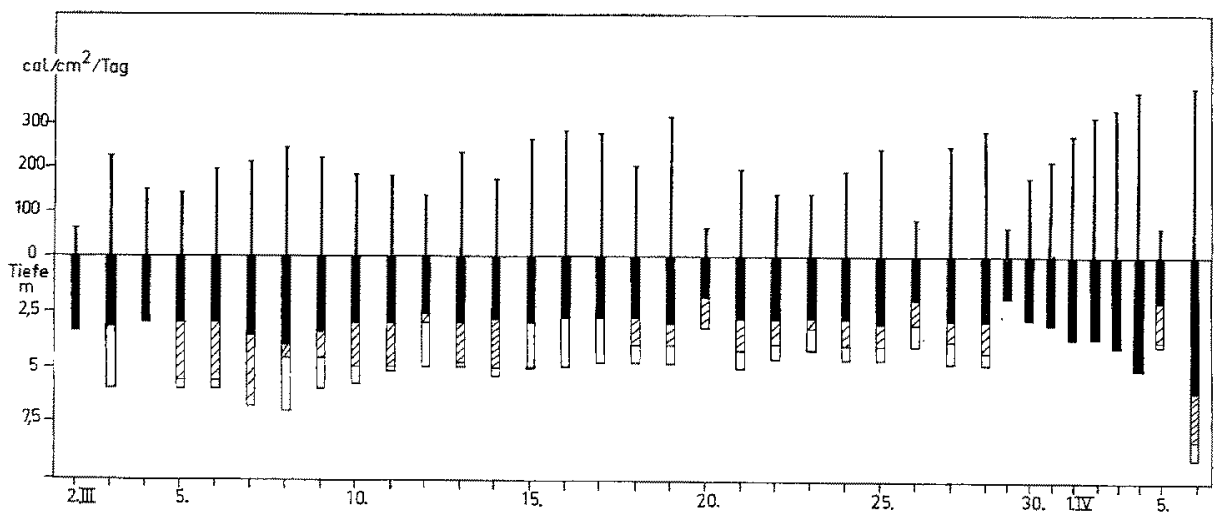

Abb. 4: März 1961: Globalstrahlung (über dem Strich). Kompensationstiefe (unter dem Strich): schwarze Säule: für 24 Std.; gestrichelte Säule: für Zeit der Schöpfprobennahme; weiße Säule: für hellste Tagesstunde

am 6. April werden $6 \mathrm{~m}$ erreicht. Die Kompensationsenergie zur hellsten Tagesstunde wird im März meist um $5 \mathrm{~m}$, maximal 7 und minimal $3 \mathrm{~m}$ gefunden; am 6. April reicht sie bis $9 \mathrm{~m}$ hinab (Abb. 4). Da die Transparenz sich nicht stark ändert, hängt die Kompensationstiefen-Änderung hier fast nur von der Oberflächenbeleuchtung $a b$, für die folgende Abschnitte bezeichnet werden können (Abb. 4): 3. bis 12. März ziemlich hell, Mittelwert $192 \mathrm{cal} / \mathrm{cm}^{2} /$ Tag; 13. bis 19. März hell, Mittel $253 \mathrm{cal} / \mathrm{cm}^{2} /$ Tag und 20 . bis 28. März dunkler und stark wechselnd, $162 \mathrm{cal}$ im Mittel.

Während der Unterbrechung der Planktonbeobachtungen wurde starke Einstrahlung registriert. Am 5. und 6. April findet man die beiden extremen Strahlungsunterschiede nebeneinander, deren Auswirkungen auf die Kompensationstiefe man erkennt. Die Tiefe optimaler Energie beträgt nur 1 bis $1,5 \mathrm{~m}$; Lichtschädigung darf nicht erwartet werden. Wenn die dafür angegebenen Lichtwerte an der Oberfläche erreicht werden, dringen sie an den hellsten Tagen bei dem triben Wasser doch nur wenige Dezimeter tief und können sich bei der stets herrschenden Turbulenz nicht auf das Plankton auswirken. 


\section{Vertikalverteilung des Sestons und Planktons}

Die Sestonisoplethen sind unübersichtlich und lassen erkennen, daß man in diesem Gebiet wenig Ubereinstimmung der Seston - mit der Planktonverteilung erwarten darf (Abb. 6). Die dichten Planktonwolken der Oberschicht zeigen sich hier nicht (8. März) oder nur gering (11., 16. März). Insgesamt werden hohe Sestongehalte beobachtet, besonders an windigen Tagen in Bodennähe.
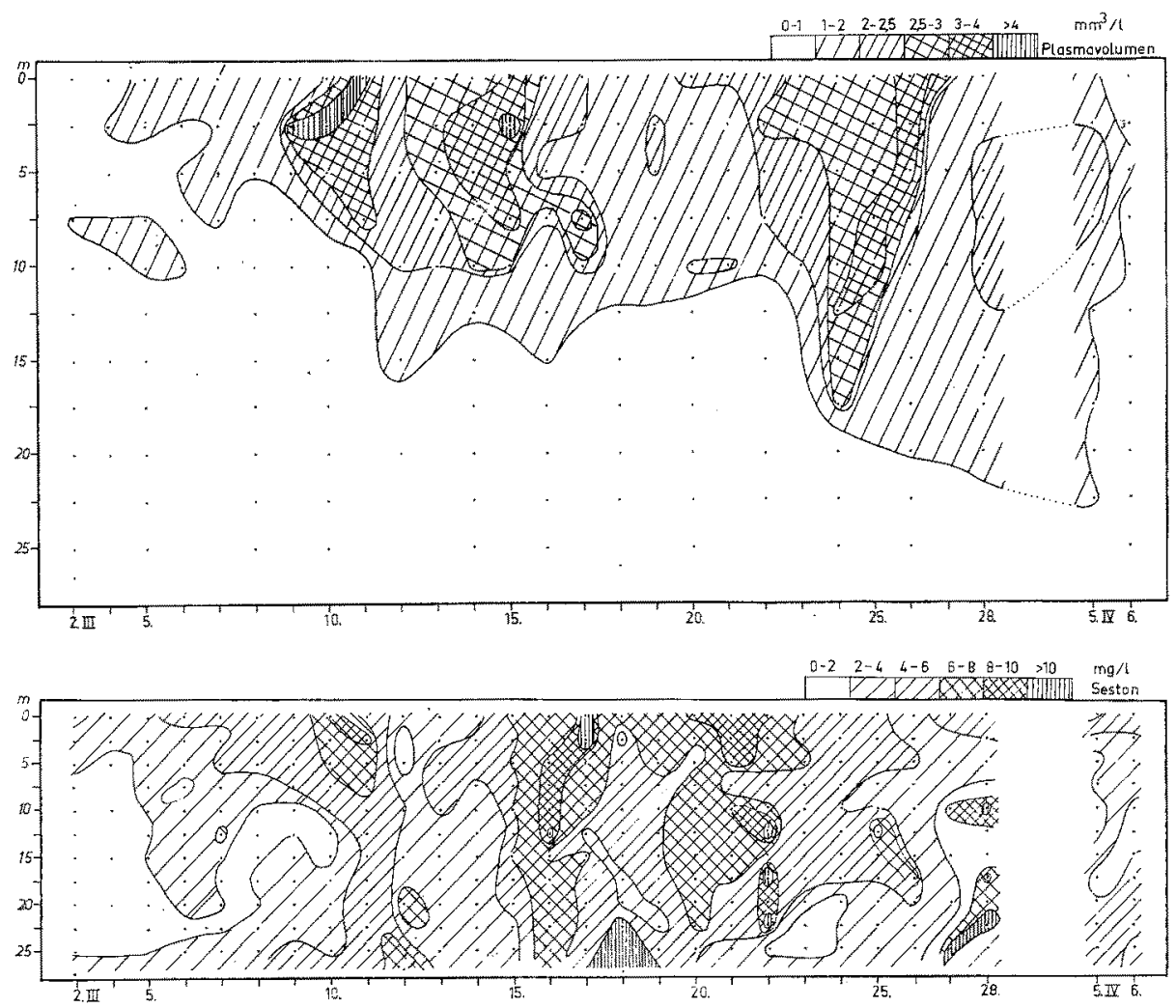

Abb. 5: (oben) März 1961: Plasmavolumen des Phytoplanktons, Isoplethen Abb. 6: (unten) März 1961: Seston-Isoplethen

Die Eiweiß- und Chlorophyll-Isoplethendiagramme sind einander ähnlich. Schon am 7. und 8. März werden die ersten Maxima nahe der Oberfläche erreicht (Abb. 7a, 8a). Die folgenden Planktonwolken (mit Werten über $25 \mu \mathrm{g}$ Chlorophyll/1) sind am 10. bis $11 ., 15$. bis 16. und 22. bis 23. März ständig absinkend zu beobachten und sowohl im Eiweiß- wie im Chlorophyllgehalt ausgeprägt. Die Chlorophyll-Isoplethen lassen einen gleichmäßig hohen Pigmentgehalt über $20 \mu \mathrm{g} / 1$ während der Periode mit geschichtetem Wasser von der Oberfläche bis zur Sprungschicht erkennen (Abb. 7b). Die Wucherungen am 10. und 11. lassen sich wegen des Windes am 12. März nicht mehr verfolgen, der wie am 18. die Vertikalverteilung beeinflußt. Ab 19. erkennt man den 
gleichmäßigen Chlorophyllgehalt der Oberschicht und die starken Gradienten zum Bodenwasser. Die Eiweißvertikalkurven zeigen in großen Zügen das gleiche, sind aber weit unregelmäßiger. Einzelwerte weichen oft erheblich von denen der entsprechenden Chlorophyllwerte ab (Abb. 8b). Das Plasmavolumen des Phytoplanktons stimmt weniger gut mit den chemischen Werten überein (Abb. 5). Die höchsten Zählplanktonwerte finden sich höher und auch später als die Chlorophyllmaxima, die nur bis zum 11. März in 0 bis $5 \mathrm{~m}$, also oberhalb der kurzzeitigen Kompensationstiefe (mit $0,13 \mathrm{cal} / \mathrm{cm}^{2} / \mathrm{h}$ ),
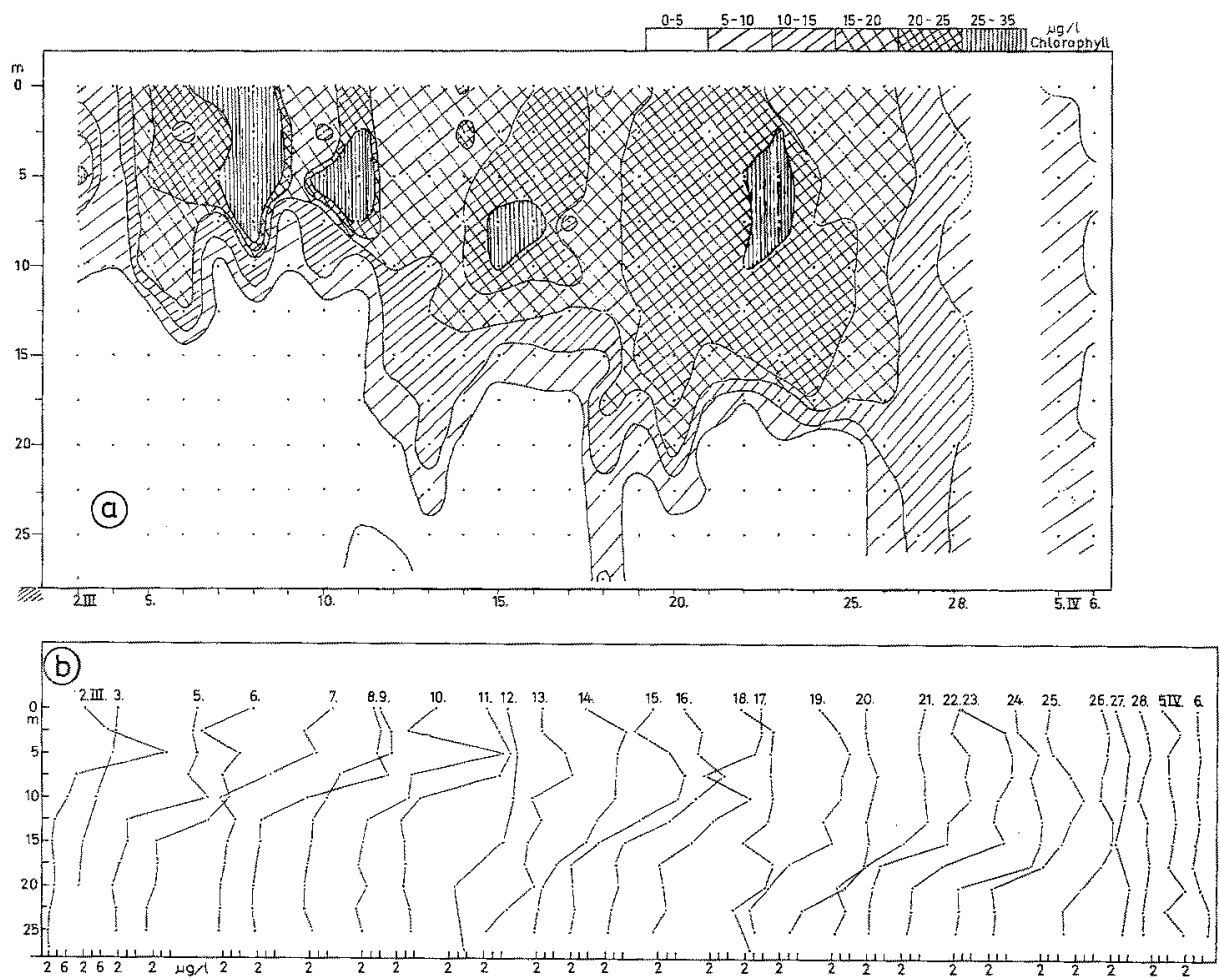

Abb. 7: März 1961: (a) Chlorophyll-Isoplethen; (b) Chlorophyll-Vertikalkurven

anzutreffen sind. Primäre Planktonansammlungen, also solche, die durch rege Zellteilung bei optimalen Lebensbedingungen entstanden sind, werden durch Chlorophyllund Plasmavolumenwerte in der ersten Märzhälfte in der euphotischen Schicht angezeigt. Sie reichern sich durch dauerndes Absinken an der Untergrenze der durchleuchteten Zone an und sinken bald aus ihr heraus.

\section{Prozentanteile der Planktongruppen}

Diatomeen und Peridineen, die beiden Hauptgruppen des Phytoplanktons, müssen für ökologische und produktionsbiologische Untersuchungen getrennt werden, da die 

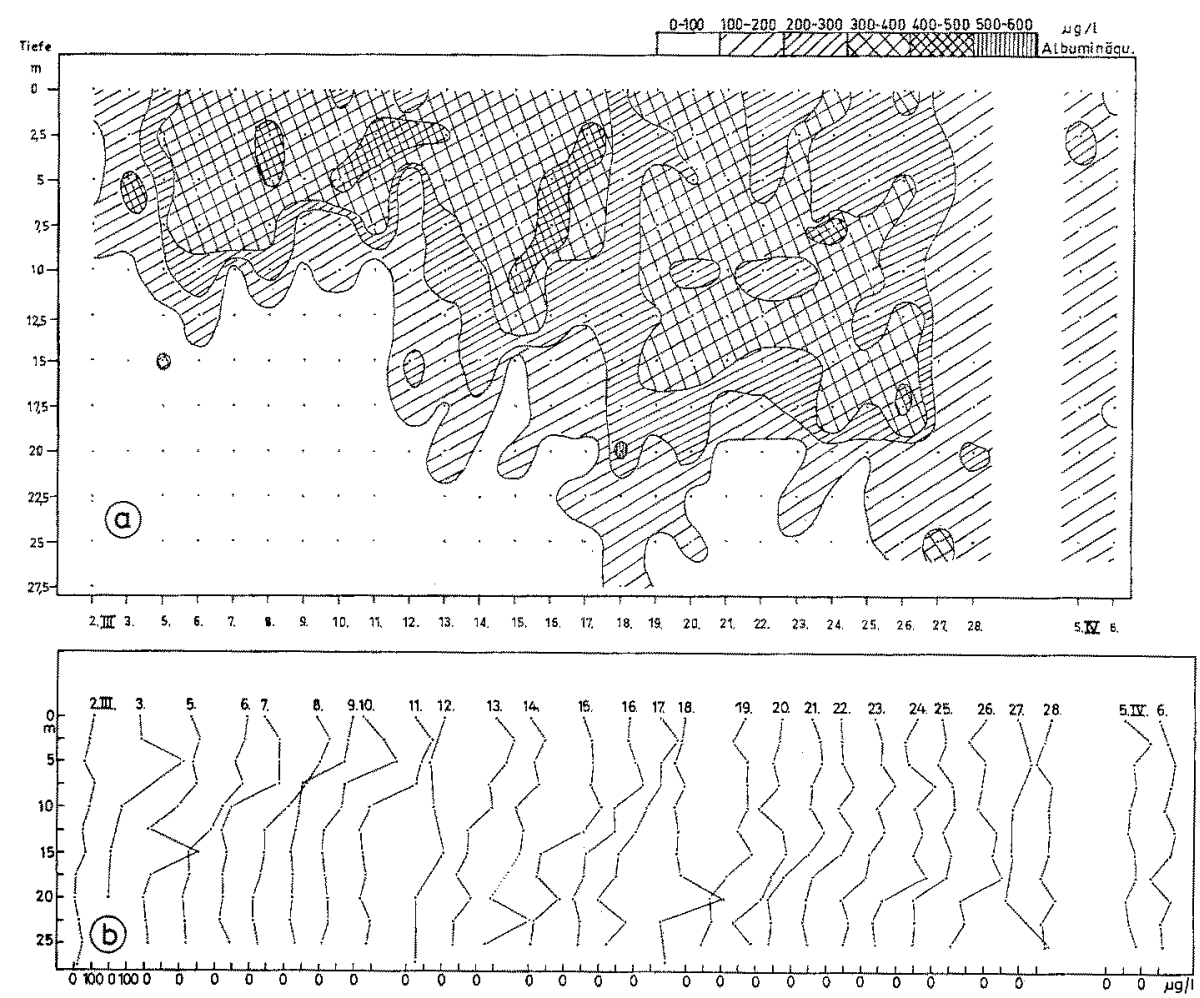

Abb. 8: März 1961: (a) Eiweiß (Albuminäquivalent) - Isoplethen; (b) Eiweiß-Vertikalkurven

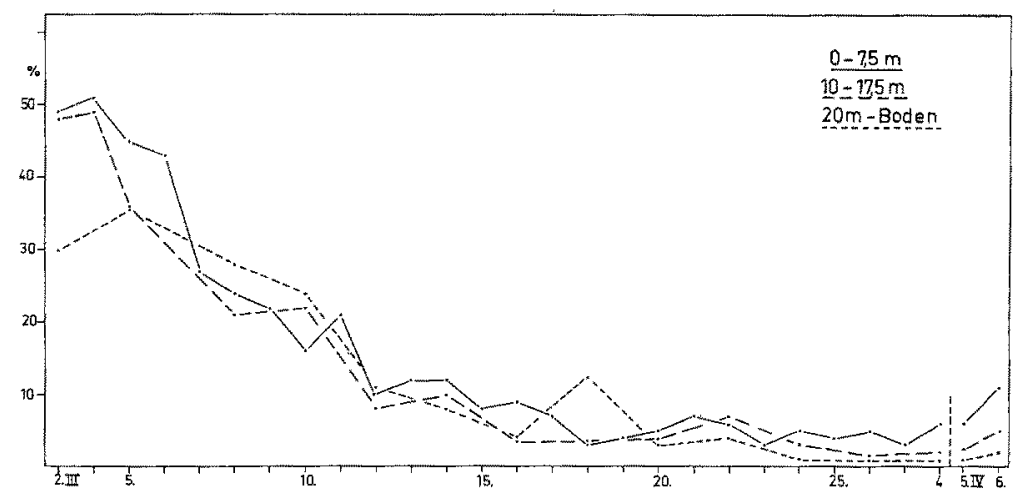

Abb. 9: März 1961: Anteil (Plasmavolumen) der Peridineen am Phytoplankton

Peridineen zur Bewegung befähigt sind, im Gegensatz zu der Hauptmasse der Diatomeen (zentrische Diatomeen). Die Erklärung der Vertikalverteilung setzt also die Trennung der "kinetischen" und der „akinetischen" Formen voraus. Beide Gruppen sind überdies in ihrer chemischen Zusammensetzung (Chlorophyll, Eiweiß) und ihren morphologischen und physiologischen Eigenschaften (Vakuolen, Plasma, Panzer, LichtAssimilationskurve) sehr voneinander verschieden. 
Der Anteil der Peridineen am Volumen des Phytoplanktons wird in Abbildung 9 für drei Schichten dargestellt. Von 50\% Anfang März fällt der Peridineenanteil bis zum 12. März rasch auf $10 \% \mathrm{ab}$. Am 16. März bilden sie nur noch $5 \%$ des Phytoplanktonbestandes und werden damit für produktionsbiologische Gesichtspunkte unbedeutend. Die drei Schichten zeigen sehr ähnliche Werte.

Ferner wird der Anteil der wichtigsten Arten am Phytoplankton in Prozent als Kreissektoren gezeichnet (Abb. 10), wobei sich der zunehmende Anteil von Skeletonema im Verlauf des März zeigt, der jedoch 60\% nicht übersteigt. Diese Art beherrscht also trotz ihrer Kleinheit das Plasmavolumen. Die zweitwichtigste Gruppe sind Thalassio-

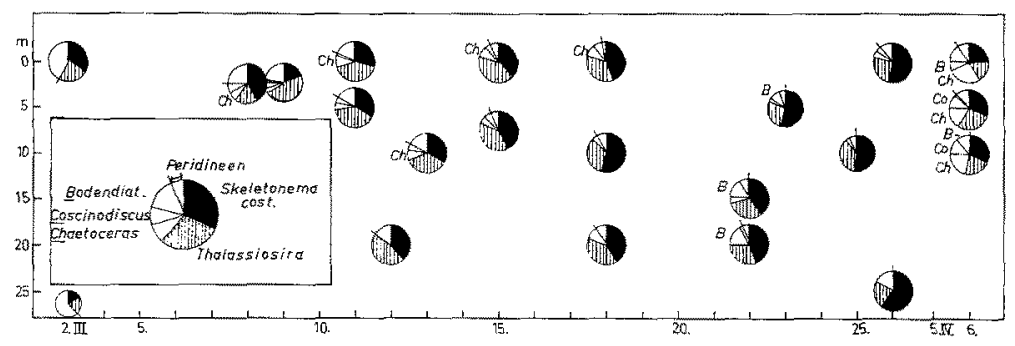

Abb. 10: März 1961: Artzusammensetzung (Plasmavolumen-Anteile) des Phytoplanktons

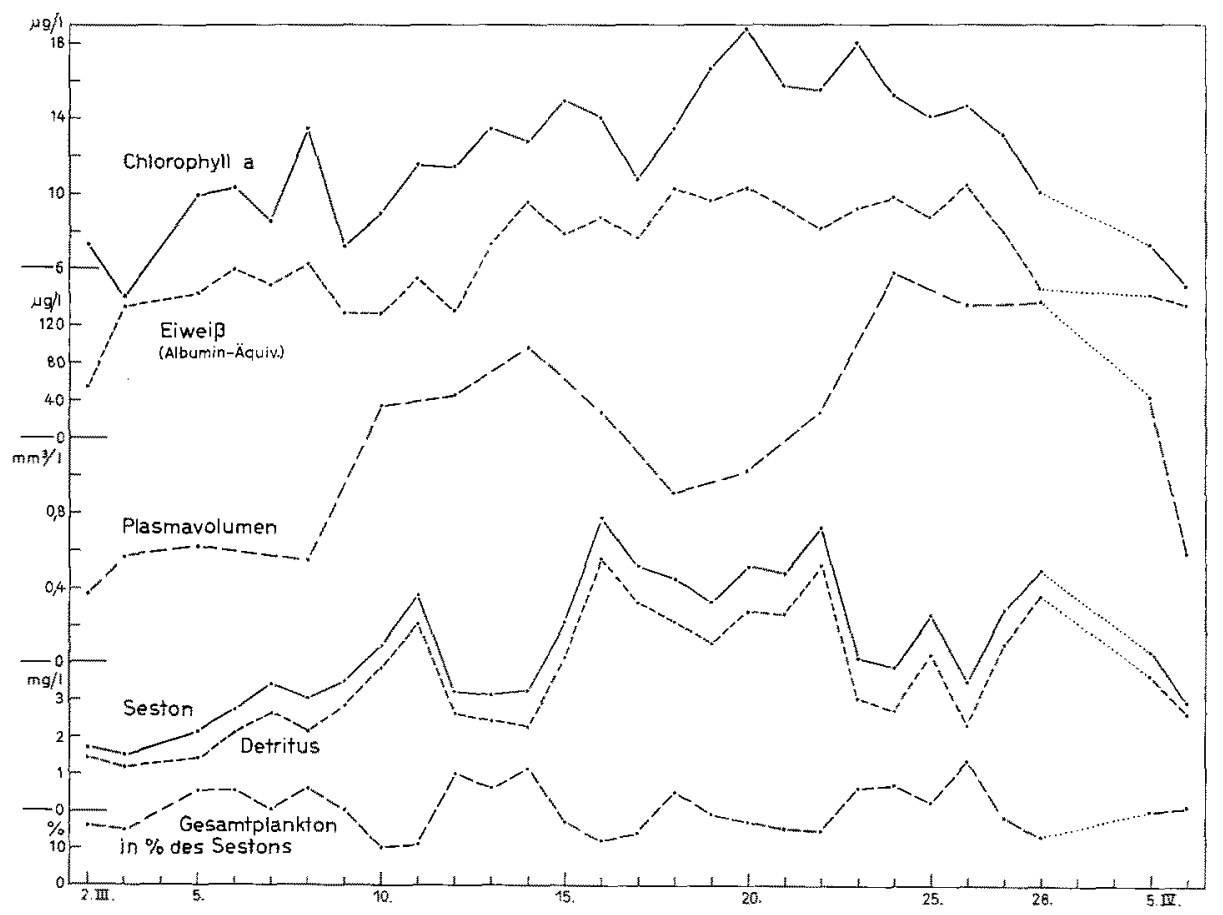

Abb. 11: März 1961: Mittelwerte gemessener und berechneter Komponenten in der Wassersäule 
sira-Arten und -Verwandte. Einige Bedeutung haben Chaetoceras-Arten, Thalassiothrix und Bodendiatomeen. Unter den Peridineen ist am Anfang Ceratium tripos wichtig, später Gymnodinien und kleine Flagellaten (die hier mit zu den Peridineen gezählt werden). Große Formen (Coscinodiscus), bei deren Volumenschätzung die größten Fehler gemacht werden, tragen nur selten wesentlich zum Gesamtvolumen bei.

\section{Kurven der Mittelwerte}

Die absolute Höhe der gemessenen Komponenten des Sestons und Planktons wird hier durch die Mittelwerte in der ganzen Wassersäule dargestellt (Abb. 11). Dazu wird der Prozentanteil des Gesamtplanktons am Seston, wie er sich aus dem Eiweißwert errechnet, und der Detritusanteil am Seston aufgetragen. Den Detritus (hier: organischer Detritus + mineralische Teilchen; siehe Diskussion) erhält man aus der Differenz von Gesamtplankton und Seston. Die Mittelwerte wurden als integrierte mittlere Konzentration (IMK) berechnet, wobei der Oberflächenwert mit $1 / 2$ eingesetzt wurde.

Chlorophyll und Eiweiß steigen noch bis zum 20. März an und erreichen die hohen Beträge von 16 bis $19 \mu \mathrm{g}$ und 240 bis $270 \mu \mathrm{g} / 1$. Plasmavolumenwerte von $1,7 \mathrm{~mm}^{2} / 1$ werden um Mitte und Ende März, später als die Chlorophyllmaxima, bèobachtet. Die Sestonkurve zeigt einen gegensätzlichen Verlauf zum Plasmavolumen; mit meist über 4 bis $5 \mathrm{mg} / \mathrm{l}$ werden auch für unser Gebiet hohe Werte erreicht. Maximal 30, meist um $20 \%$ bildet das Plankton am Sestongewicht der Wassersäule, wobei die getrennte Berechnung für das Bodenwasser ein starkes Ansteigen des Planktonanteils gegen Ende März ergibt.

\section{Herbst 1961}

\section{Hydrographie}

Durch die vorangegangene Wetterlage strömte bei schwachen östlichen Winden salzärmeres Wasser in die Förde ein, wobei der Salzgehalt um $3 \%$ fiel, die Temperatur um $2^{0} \mathrm{C}$ stieg. Ein zu Beginn der Beobachtungszeit schwacher, später sehr starker Salzgehaltssprung in 15 bis $10 \mathrm{~m}$ fällt mit einem Temperatursprung zusammen. Während am Boden tiefe Temperaturen bis $9^{\circ} \mathrm{C}$ beobachtet werden, liegen sie an der Oberfläche mit 15 bis $16^{\circ} \mathrm{C}$ um $2^{\circ} \mathrm{C}$ über dem langjährigen Mittel.

Bis zum 17. September herrschen mäßige Westwinde und schwacher Strom. Am 19. September beginnt eine langanhaltende Periode mit Südostwinden, die nur kurz am 25./26. aufhören, dann aber wieder auf 6 bis 8 Windstärken zunehmen und zum Verschwinden der stabilen, spätsommerlichen Schichtung führen. Die Südostrichtung ist die ungeschützteste für das Feuerschiff „Flensburg“, so daß es bei Winden aus dieser Richtung zu hohem Seegang und tiefreichender Turbulenz kommt (Abb. 12c). Die Sprungschicht sinkt in dieser Periode ständig ab und wird am 3. Oktober nicht mehr vom Schöpfer erfaßt (Abb. 12a, 13a). Offensichtlich wird salzreiches Oberflächenwasser in die Förde gedrückt und füllt sie bald ganz aus, wie am Absinken der 16\%0-Isohaline 
zu sehen ist. Auch die t-S-Diagramme (Abb. 13c) sprechen dafür, daß die Turbulenz nicht in der Lage war, die Sprungschicht zu zerstören, sondern daß das salzreiche, kalte Bodenwasser aus der Förde gedrückt wurde (siehe auch $\mathrm{PO}_{4}$-Werte). Zwar dürfte etwas vom salzreicheren Wasser vermischt worden sein, doch bleibt dies für die Veränderung des Oberflächenwassers unbedeutend. Die t-S-Charakteristik des Oberflächenwassers vor und des Wassers nach dem Verschwinden der Schichtung bleibt die gleiche (Abb. 13c). Die starken Gradienten beim Absinken der Sprungschicht sind aus den Vertikalkurven zu ersehen (Abb. 13a, b).
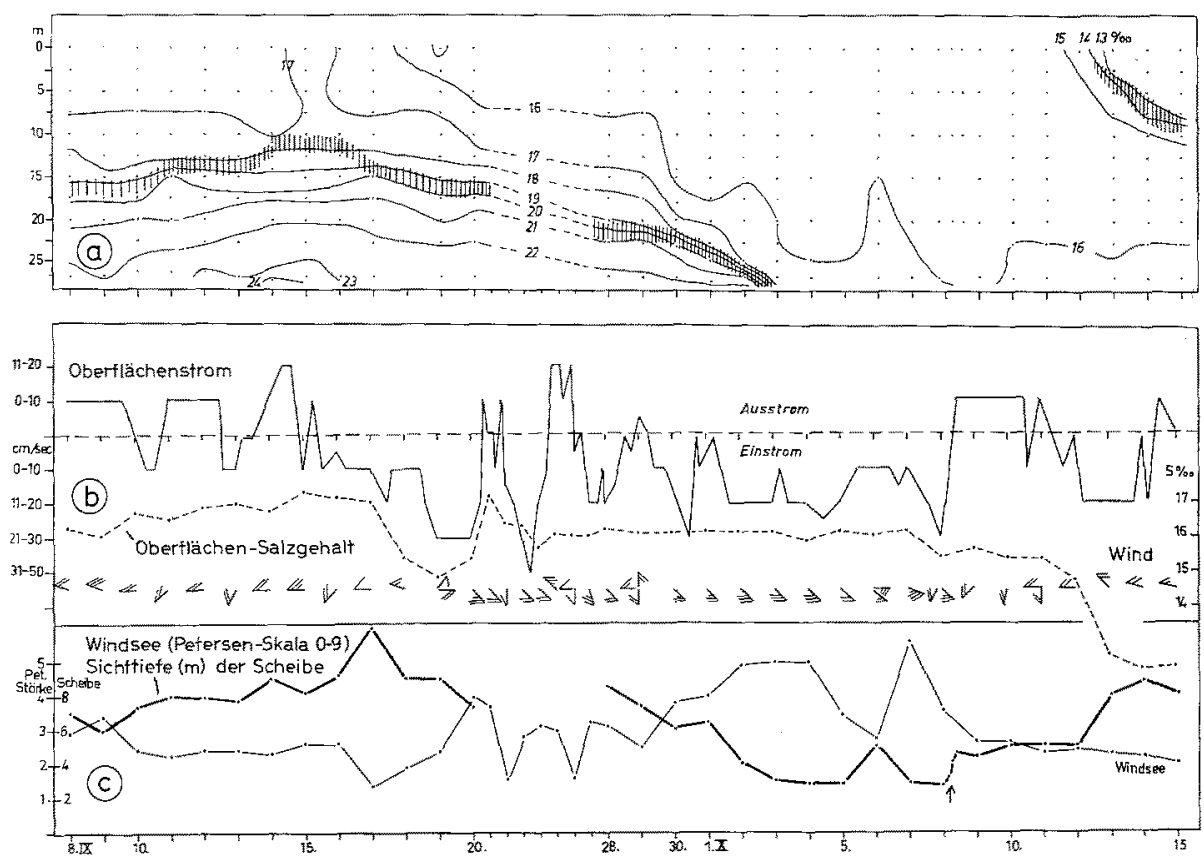

Abb. 12: Herbst 1961: Hydrographie. (a) Isoplethen des Salzgehaltes. Sprungschichtbezeichnung wie bei Abb. 2; (b) Strom und Salzgehalt an der Oberfläche, Wind (s. Abb. 2); (c) Windsee und Sichttiefe

Während nach den Schöpfproben am 3. Oktober schon völlig homothermes und homohalines Wasser gefunden wird, machen die Vertikalmessungen mit dem Bathythermographen (Abb. 13b) bis kurz über den Boden deutlich, daß sich kaltes Bodenwasser in einer dünnen Schicht noch länger vorfinder. Diese Schicht mag beim Feuerschiff nur wenige Dezimeter dick sein; in der nördlich vom Feuerschiff gelegenen, bis $32 \mathrm{~m}$ tiefen Rinne können dann noch $4 \mathrm{~m}$ dieses Wasserkörpers vorhanden sein. Am 12. Oktober beginnt der Einstrom eines salzarmen und kälteren Wasserkörpers aus Ost an der Oberfläche. Wurden im März die höchsten, so werden jetzt die niedrigsten Salzgehalte des Jahres mit 12\% erreicht (Abb. 12b). Die Uberschichtung mit diesem Wasserkörper stabilisiert die Wassersäule erneut.

In der Stromkurve fällt ein plötzlicher Richtungswechsel am 8. Oktober auf (Abb. 12b). Die Beobachtung vom Feuerschiff erklärt eine aufschlußreiche Erscheinung 
dieses Tages: Der Südostwind hatte am 8. Oktober eine Zunge stark getrübten Wassers zum Feuerschiff gebracht. Bei Abflauen des Windes und folgender Windstille lag das Feuerschiff inmitten dieser Wasserzunge, die sich durch ihre Färbung auffällig von dem klaren Wasser unterschied, das $600 \mathrm{~m}$ nördlich und $1500 \mathrm{~m}$ südlich zu sehen war (s. Abb. 1). Um 13.30 h setzte plötzlich Südwestwind 3 bis 4 ein. Der Strom kenterte,

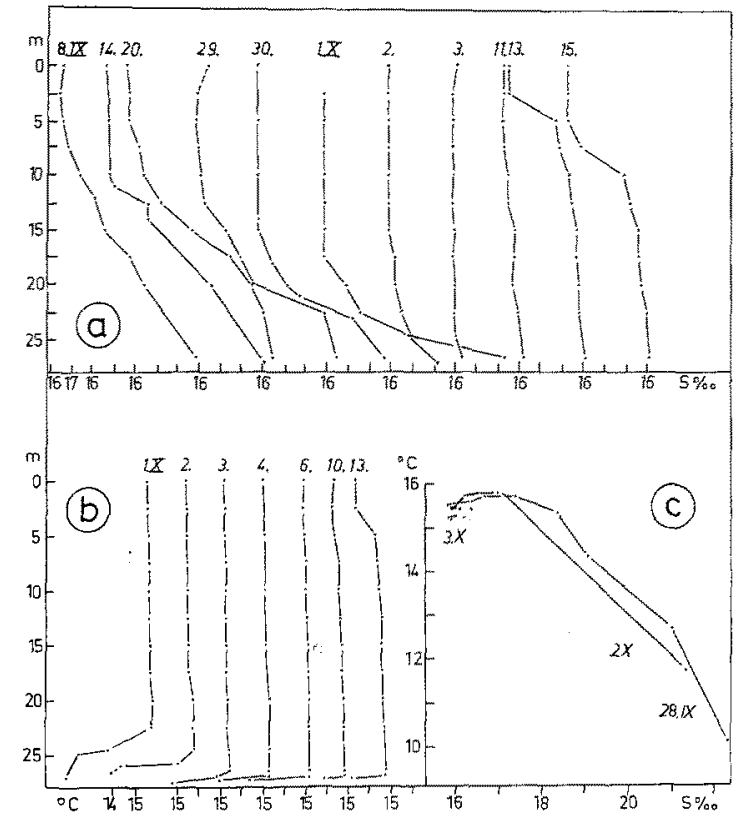

Abb. 13: Herbst 1961: Hydrographie. (a) Salzgehalt-Vertikalkurven; (b) Temperatur-Vertikalkurven (Thermometer + BT-Messung); (c) t-S-Diagramme

und die auf 1-2 $\mathrm{m}$ scharf ausgeprägte Grenze zwischen dem trïben und dem klaren Wasser, die 1 bis $2 \mathrm{sm}$ westlich vom Feuerschiff angelangt war, kam nach Osten zurück. Mit zwei kurzen Serien wurden die Unterschiede dieser beiden Wasserkörper erfaßt. Wenige $100 \mathrm{~m}$ vor dem Eintreffen des klaren Wassers beim Feuerschiff wurden in $0,5,10,20 \mathrm{~m}$ Proben genommen, desgleichen noch einmal nach dem Durchzug der Front $50 \mathrm{~m}$ von ihr entfernt im klaren Wasser. Nach einer Stunde folgte ein weiterer Wasserkörper von Westen, der wieder trüber und der vielleicht von der Innenförde beeinflußt war. Drei Wasserkörper hatten sich also erst beim Südostwind nach West, dann nach dem Umspringen des Windes wieder nach Ost zurückbewegt. Sie unterschieden sich nicht im Salzgehalt, sondern nur in der Trübung, wie die Sichttiefenwerte zeigen (Abb. 12c, Pfeil). Auf die biologischen Unterschiede wird noch eingegangen.

Es ist dies ein gutes Beispiel für die Beeinflussung des Sestongehaltes des Wassers durch Landeinfluß (Zunge trüben Wassers von der Küste her) für das Hin- und Herschieben der Wasserkörper in der Förde sowie für die Tatsache, daß deren Charakterisierung durch den Salzgehalt allein of nicht ausreicht. Auch WYRTKI (1950) unterschied durch Trübungsmessungen mehr Wasserkörper als durch Salzgehaltsunterschiede. 
Derartige Erscheinungen entziehen sich meist der Beobachtung von fahrenden Schiffen aus. Untersuchungen auf Feuerschiffen haben den Vorteil, daß man solche sichtbaren Ereignisse über längere Zeit verfolgen und danach gezielte Proben nehmen kann.

Es wird also das Verschwinden einer starken, spätsommerlichen, thermohalinen Schichtung, wie sie im Gebiet für diese Zeit typisch ist, beobachtet (Abb. 12a). Das Bodenwasser, hier von besonderer biologischer Bedeutung wegen seines sehr hohen Nährstoffgehaltes, wird aber nicht von der Turbulenz erfaßt, sondern beim kräftigen Einstrom in den höheren Schichten aus der Förde hinausgetrieben, wobei allerdings Reste in den tiefsten Senken erhalten bleiben dürften. Nach 10 Tagen setzt erneute Stabilisierung durch Einstrom leichteren Wassers an der Oberfläche von Osten her ein. Die Oberschicht ist bis 17. September vergleichbar, die Störung am 15. September muß beachtet werden. Das homogene Wasser scheint zwar nach dem Salzgehalt identisch, doch zeigt das Beispiel vom 8. Oktober, daß dabei erhebliche Unterschiede im Schwebstoffgehalt vorkommen können.

\section{Licht}

Anfang September werden die optischen Verhältnisse der spätsommerlich geschichteten Wassermassen angetroffen (Abb. 14). Die bei den schwachen Strömen, der geringen Turbulenz und der starken Schichtung sehr niedrigen Schwebstoffgehalte der Oberschicht haben hohe Lichtdurchlässigkeit zur Folge. So werden bis zum 18. September

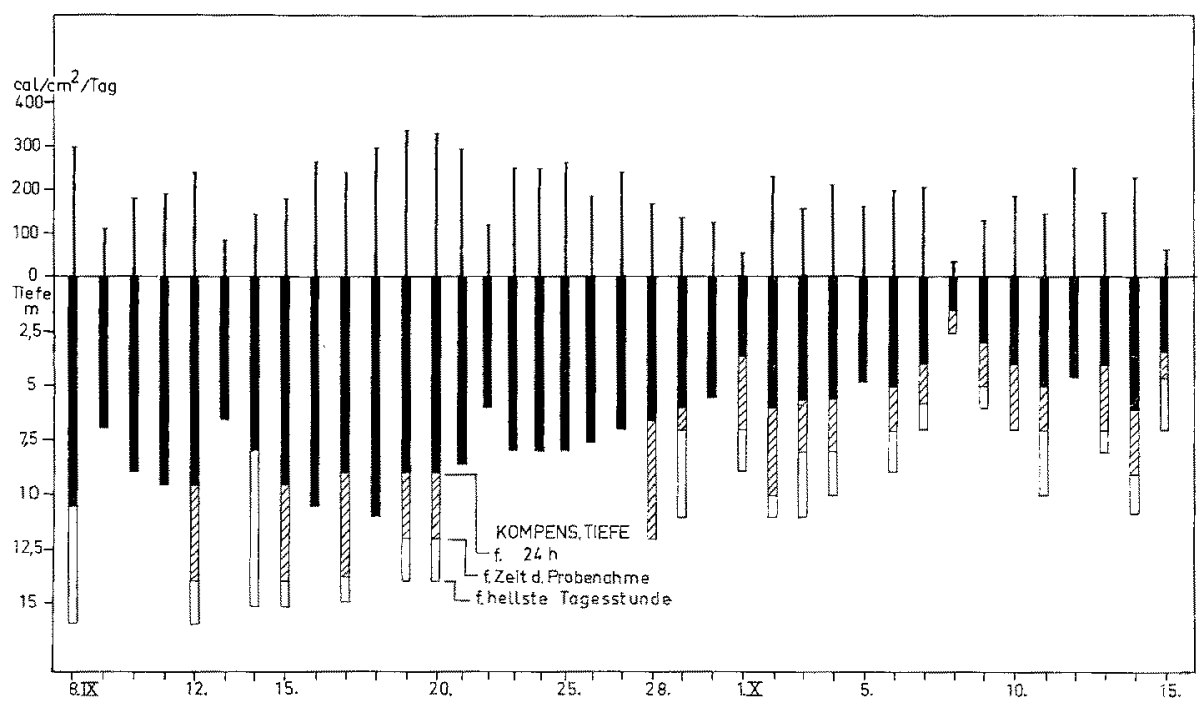

Abb. 14: Herbst 1961: Globalstrahlung und Kompensationstiefe

mehrfach 24-h-Kompensationstiefen von 10 bis $11 \mathrm{~m}$ berechnet, wobei die entsprechenden Mittagskompensationstiefen nur 14 bis $16 \mathrm{~m}$ tief reichen, weil sie bis unter die Sprungschicht und damit in das weit trübere Bodenwasser hinabgehen, in dem dann die Strahlung rasch geschwächt wird. Immerhin darf man in und unter der Sprung- 
schicht auch an hellen Tagen nur während der Mittagsstunden eine positive Produktionsbilanz erwarten.

Die Sichttiefen steigen Anfang September bis auf $12 \mathrm{~m}$ und zeigen auch im folgenden guten gegensätzlichen Verlauf zur Windseekurve, was hier die Abhängigkeit der optischen Bedingungen von der winderzeugten Turbulenz deutlich macht (Abb. 12c). Beim Auffrischen des Windes ab 20. September sinkt auch die Kompensationstiefe auf 6 bis $8 \mathrm{~m}$, nach dem Verschwinden der Schichtung Anfang Oktober auf meist 4 bis $5 \mathrm{~m}$, mittags auf 6 bis $10 \mathrm{~m}$, wobei die Sichtscheibenwerte oft die vom Frühjahr erreichen. Die niedrigste Kompensationstiefe wird mit 1,5 m errechnet. Beim Abflauen des Windes steigen durch Absinken der Sestonpartikel rasch die Sichttiefenwerte. Die Störung am 8. Oktober macht sich in der Kompensationstiefe besonders bemerkbar (Abb. $12 c, 14)$.

Die Globalstrahlungswerte schwanken stark. Im ersten Teil dieser Untersuchungsperiode wird ein Mittel von 220 , im zweiten von $170 \mathrm{cal} / \mathrm{cm}^{2} /$ Tag errechnet (Abb. 14). Die Schicht, in der Lichtsättigung für Peridineen anzunehmen ist, wie RyTHER (1956) sie im Versuch ermittelte, reicht kaum tiefer als $2 \mathrm{~m}$ im Anfang und 1 bis $2 \mathrm{~m}$ am Ende der Beobachtungszeit. Lichtschädigung kann hier auch bei klarem Wasser im September wie im März keine Rolle spielen, da sie den Verbleib der Plankter in den obersten Dezimetern voraussetzen würde.

\section{Phosphat-Phosphor}

Das Isoplethendiagramm des Phosphors zeigt die erwartete Ahnlichkeit mit der Dichteschichtung (Abb. 15a). Die Vertikalkurven lassen erkennen, daß sich das Bodenwasser sehr stark (bis über $100 \mu \mathrm{g} / 1$ ) mit gelöstem Phosphat angereichert hat, während in der Oberschicht Werte von $O$ bis $1 \mu \mathrm{g} / 1 \mathrm{zu}$ finden sind (Abb. 15b). Die Störung am
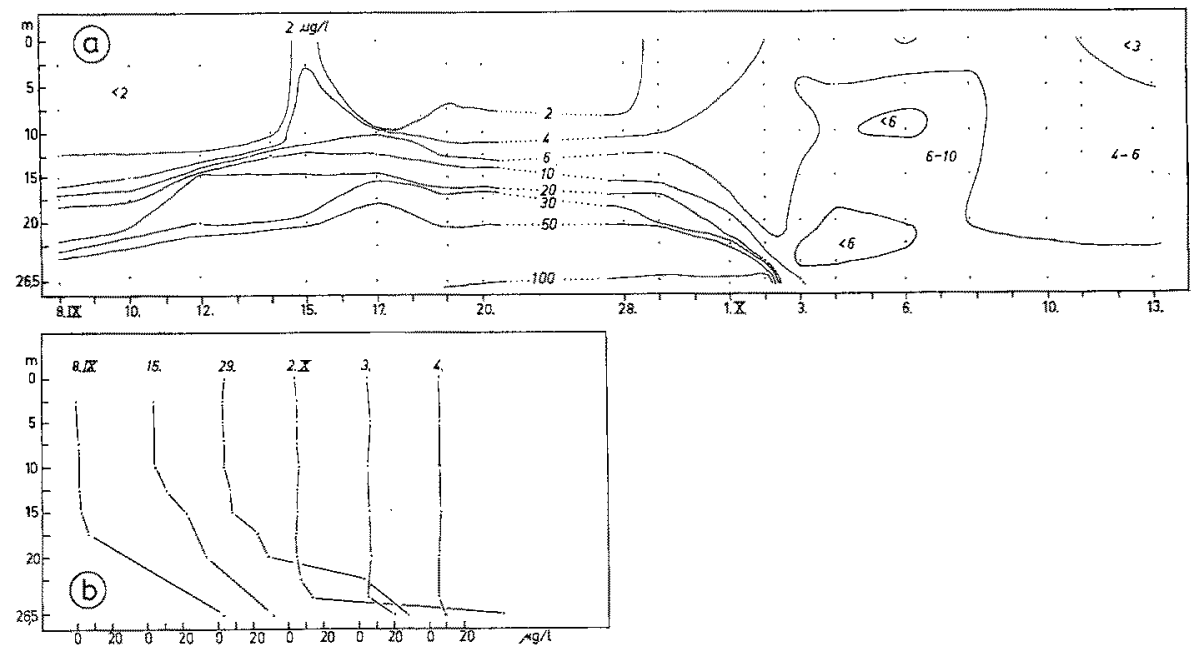

Abb. 15: Herbst 1961 : Phosphat-Phosphor. (a) Isoplethen; (b) Vertikalkurven 
15. September tritt hier nodh deutlicher hervor. $\mathrm{Da}$ am 14. kräftiger Ausstrom herrscht und gleichzeitig der Phosphatgehalt ansteigt, kann hier der Einfluß der Innenförde eine Rolle spielen. Es kann aber auch die Windturbulenz die hochgelegene Sprungschicht erreichen und Phosphat in die Oberschicht bringen, wie es auch nach den Salzgehaltsisoplethen wahrscheinlich wird.

KÄNDLER (1963) beschreibt die hydrographischen Verhältnisse der Innenförde zur gleichen Zeit; seine Darstellungen machen es wahrscheinlich, daß sich der "düngende" Einfluß der Innenförde sowohl im Boden- wie auch im Oberflächenwasser bis zum Feuerschiff bemerkbar machen kann. Das muß bei der scharfen Schichtung natürlich Folgen auf die Planktonproduktion haben. Die hohen Phosphatwerte am Boden könnten also zum Teil aus der eutrophierten Innenförde stammen, da Bodenwasser an der Enge von Holnis absinkt und bei Einstrom an der Oberfläche Ausstrom am Boden diese Nährstoffmengen mit nach Osten abführt. Eher als den Salzgehalt vermag die Turbulenz die Phosphatverteilung zu beeinflussen; steigen doch Ende September die Phosphatwerte an der Oberfläche und die Isoplethen rücken auseinander. Der Gradient in der Sprungschicht wird aber wie beim Salzgehalt stärker.

Die Frage nach dem Verbleib des Bodenwassers ist für die Phosphatverteilung natürlich von besonderer Bedeutung. Normalerweise kann man die Herbstwucherung des Planktons erst nach Zerstörung der thermohalinen Schichtung erwarten, weil dann die am Boden durch Remineralisation der toten Plankter frei gewordenen $\mathrm{PO}_{4}$-Ionen wieder in der euphotischen Schicht für die Assimilation zur Verfügung gestellt werden. Zur Verdeutlichung werden hier die Mittelwerte des Phosphats für die gesamte Wassersäule und einzelne Schichten aufgeführt.

Die Mittelwerte während der Schichtung ergeben die winterlichen Phosphatmengen von 20 bis $30 \mu \mathrm{g} / 1$, wie sie dem Plankton bei der Frühjahrsblüte zur Verfügung stehen. Daß diese Werte hier für die Produktion verloren gehen, sieht man klar

Tabelle 5

Phosphat-Phosphor $(\mu \mathrm{g} / \mathrm{l})$ im Herbst 1961

\begin{tabular}{|c|c|c|c|c|}
\hline Datum & $\begin{array}{l}\text { Mittel ges. } \\
\text { Wassersäule }\end{array}$ & $\begin{array}{l}\text { Mittel Bodenwasser } \\
\text { unter Sprungschicht }\end{array}$ & $\begin{array}{l}\mu \mathrm{g} / \mathrm{l} \text { in der } \\
\text { Oberschicht }\end{array}$ & $\begin{array}{c}\mathrm{mg} / \mathrm{m}^{2} \\
\text { Sprungschicht }\end{array}$ \\
\hline 8. 9. & 20 & 50 & 1 & 508 \\
\hline 10. 9. & 15 & 45 & 1 & 445 \\
\hline 12.9 & 18 & 51 & 1 & 666 \\
\hline 15. 9. & 20 & 44 & 4 & 696 \\
\hline 17. 9 & 28 & 66 & 2 & 854 \\
\hline 19.9 & 24 & 71 & 2 & 748 \\
\hline 20. 9. & 24 & 82 & 2 & 858 \\
\hline 28. 9. & 22 & & & \\
\hline 29. 9. & 25 & 97 & 4 & 532 \\
\hline 1.10 & 22 & 92 & 4 & 508 \\
\hline 2. 10 . & 116 & 122 & 5 & 180 \\
\hline 3. 10 & 6,8 & & & \\
\hline 4.10 & 6,3 & & & \\
\hline 6. 10 & 5,8 & & & \\
\hline 8.10 & 3,3 & & & \\
\hline 10.10. & 4,9 & & & \\
\hline 13.10. & 4,9 & & & \\
\hline
\end{tabular}


am 1. bis 3. Oktober; die euphotische Schicht erhält nur geringen Zuschuß $(5 \mu \mathrm{g} / 1 \mathrm{mehr}$ als bei der Schichtung). Der mittlere Phosphatgehalt des Bodenwassers pro 1 steigt, während die für die Wassersäule unter einem $\mathrm{m}^{2}$ Sprungschichtoberfläche $\left(\mathrm{mg} / \mathrm{m}^{2}\right.$ Sprungschicht, Tab. 5, Spalte 5) berechnete P-Menge fällt. Zwischen dem 2. und 8. Oktober beobachtete man eine Phosphatanreicherung offenbar vom Boden her. Vielleicht erreicht nun die Turbulenz bei 6 Windstärken und ausgereifter Windsee den Rest des Bodenwassers mit seinem hohen Phosphatgehalt. Der neue Wasserkörper an der Oberfläche Mitte Oktober zeichnet sich durch niedrige Phosphatwerte aus (Abb. 15a).

\section{Vertikalvertcilung des Sestons und Planktons}

In der Sestonverteilung (nicht abgebildet) zeigen sich niedrige Werte unter $1 \mathrm{mg}$, vom 14. bis 19. September sogar unter $0,5 \mathrm{mg} / 1$ in der Oberschicht, solche von 1 bis 2 , einmal über $5 \mathrm{mg} / \mathrm{lm}$ Bodenwasser. Im turbulenten Wasser Anfang Oktober finden
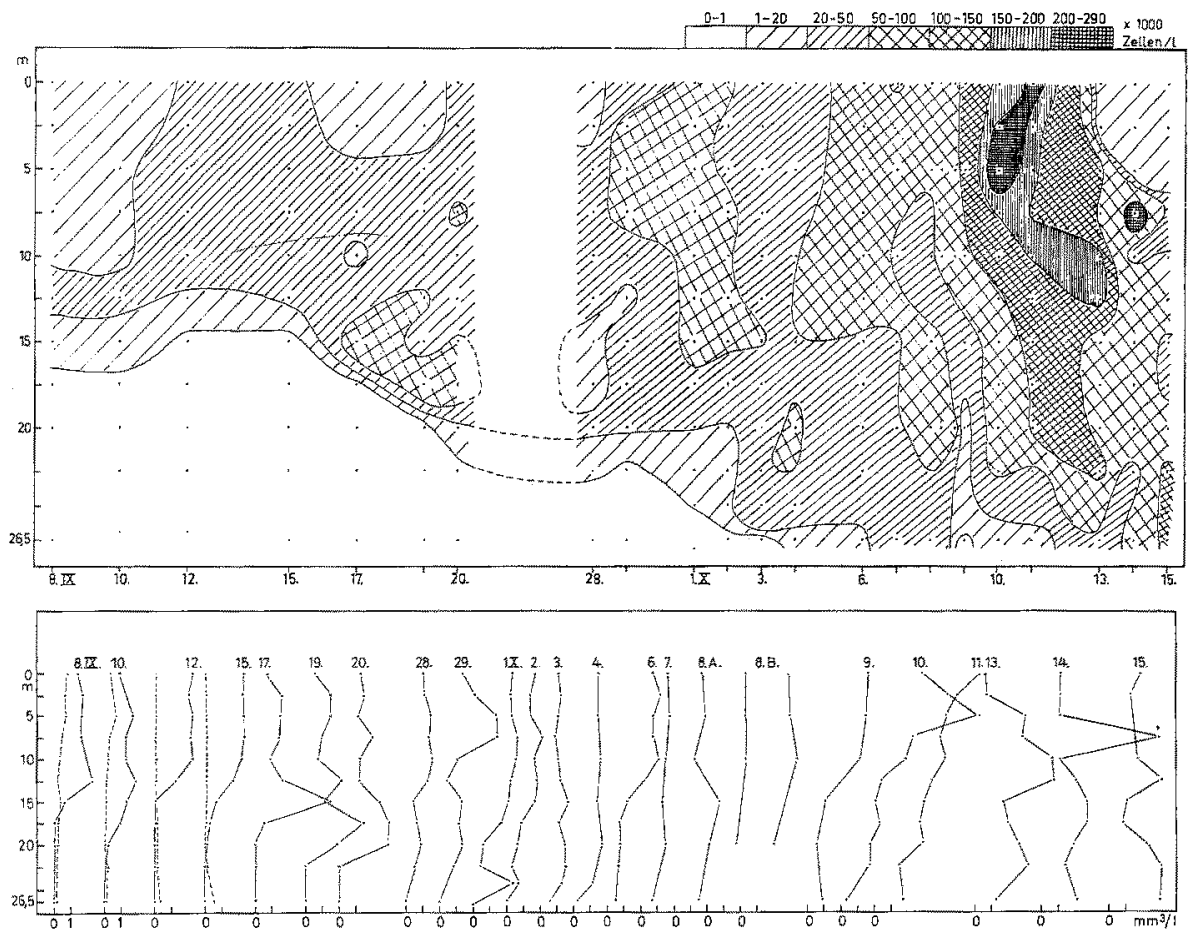

Abb. 16: (oben) Herbst 1961: Ceratium fusts. Isoplethen der Zellzahl

Abb. 17: (unten) Plasmavolumen der Ceratien, dazu bis 15. September Plasmavolumen der Diatomeen (gestrichelt)

sich 3 bis $4 \mathrm{mg} / \mathrm{l}$ in der ganzen Wassersäule. Unterschiede von $100 \%$ kennzeichnen die verschiedenen Wasserkörper am 8 . Oktober. Gegen Ende der Beobachtungszeit werden besonders im neuen Wasserkörper an der Oberfläche niedrige Werte festgestellt. 
Das Peridineenplankton dieser Untersuchungsperiode wird von nur zwei Arten beherrscht. Diese sind als Zellzahl pro 1 zur Darstellung gebracht (Abb. 16 und Abb. 18). Ceratium tripos (Abb. 18) ist am Anfang der Untersuchungszeit mit hohen Zellzahlen vertreten. Am 12. und 13. September bildet sich eine Ceratien-Wolke an
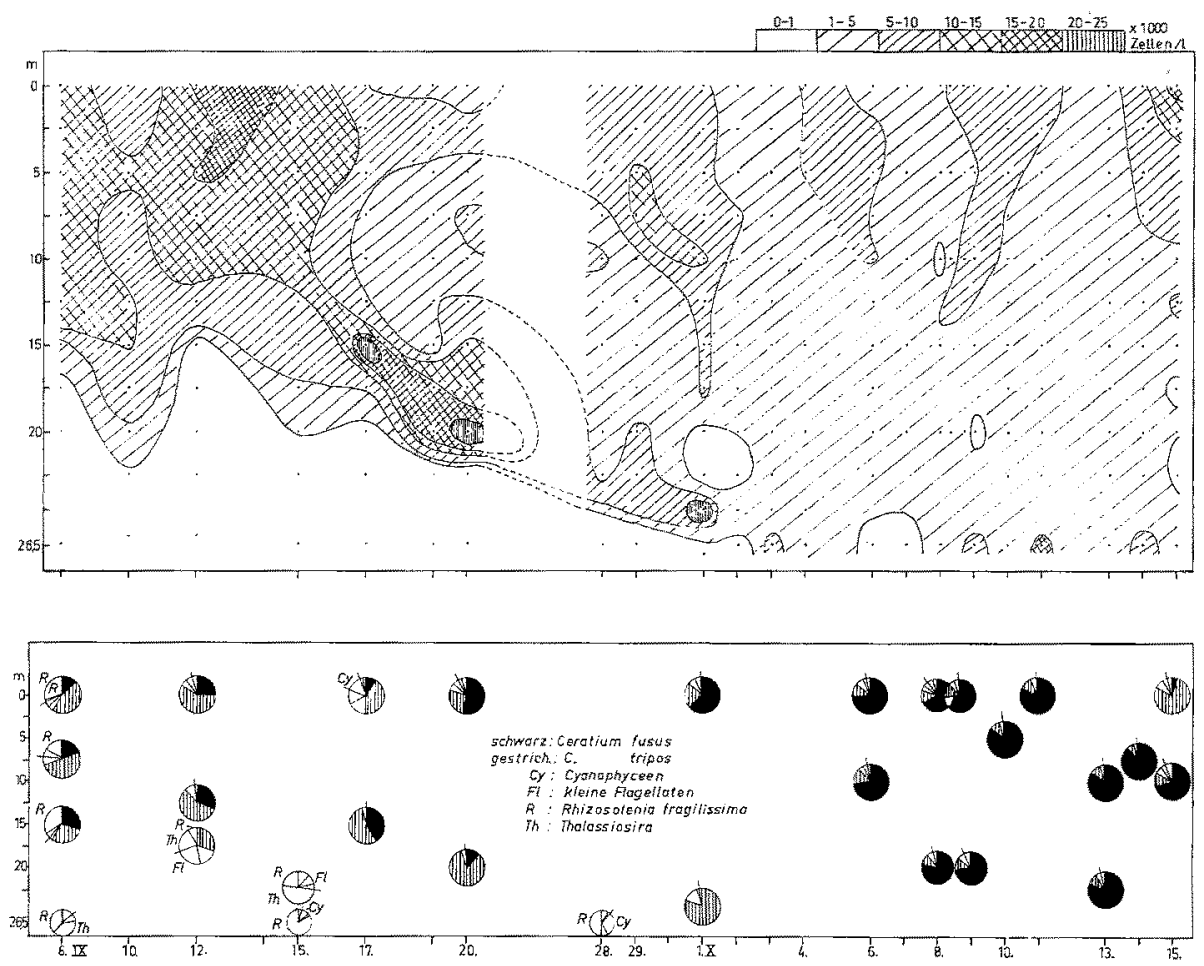

Abb. 18: (oben) Herbst 1961: Ceratium tripos. Isoplethen der Zellzahl

Abb. 19: (unten) Artzusammensetzung (Plasmavolumanteile des Phytoplanktons)

der Oberfläche, die ab 15. absinkt und am 17. die Sprungschicht erreicht hat, mit der sie weiter in die Tiefe geht. Es kommt hier zu starken Anhäufungen mit höheren Werten als an der Oberfläche, die bis zum Verschwinden der Sprungschicht in dieser verbleiben. Gegenüber diesen Werten ist Ceratium tripos im zweiten Teil der Untersuchungszeit nur noch mäßig vertreten. Interessant ist aber ihr erneutes stärkeres Vorkommen im salzarmen Wasserkörper, der Mitte Oktober von Osten einströmt. Die Zellzahlen von Ceratium fusus (Abb. 16) sind im Vergleich dazu gegensätzlich verteilt. Nirgendwo tritt diese Art im September besonders hervor, bildet aber im Oktober dann eine sehr starke Blüte mit Zellzahlen von 200 bis $290000 / 1$. Selbst wenn man bedenkt, daß die Ceratium tripos-Zelle das vierfache Volumen einer Ceratium fusus-Zelle hat, verdrängt C. fusus bei 20- bis 30 fachem Obergewicht in der Zellzahl jene mit max. 10000 Zellen pro 1 völlig. Der neue Wasserkörper ist Mitte Oktober im Gegensatz dazu wieder arm an Ceratium fusus.

Diese Unterschiede der beiden verwandten Arten scheinen sich auch etwas in der 
Verteilung von Eiweiß und Chlorophyll zu wiederholen. Die Eiweiß-Isoplethen sinken ähnlich denen von Ceratium tripos vom 8. bis 29. September ab, ohne sich aber in ihren Maxima zu entsprechen (Abb. 22a). Sehr hohe Eiweißwerte finden sich unter der

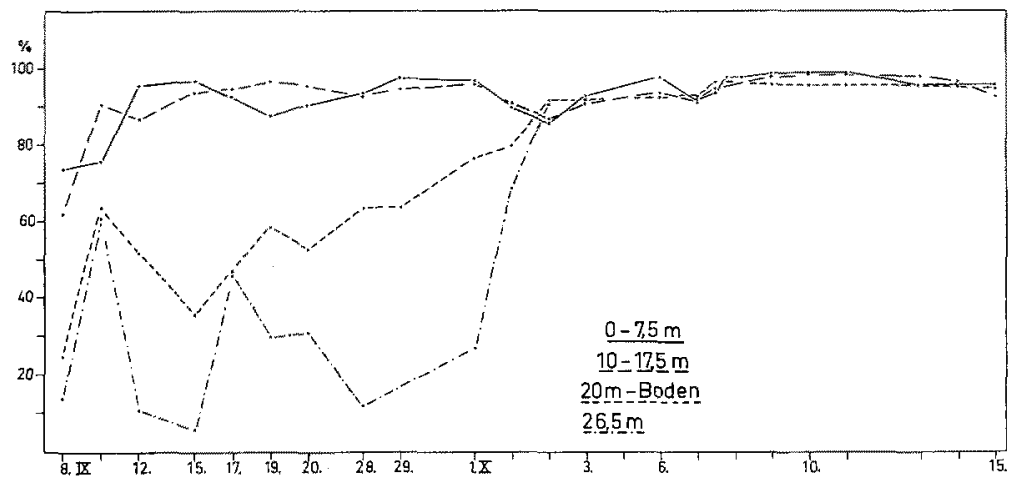

Abb. 20: Herbst 1961: Anteil (Plasmavolumen) der Perdineen am Phytoplankton

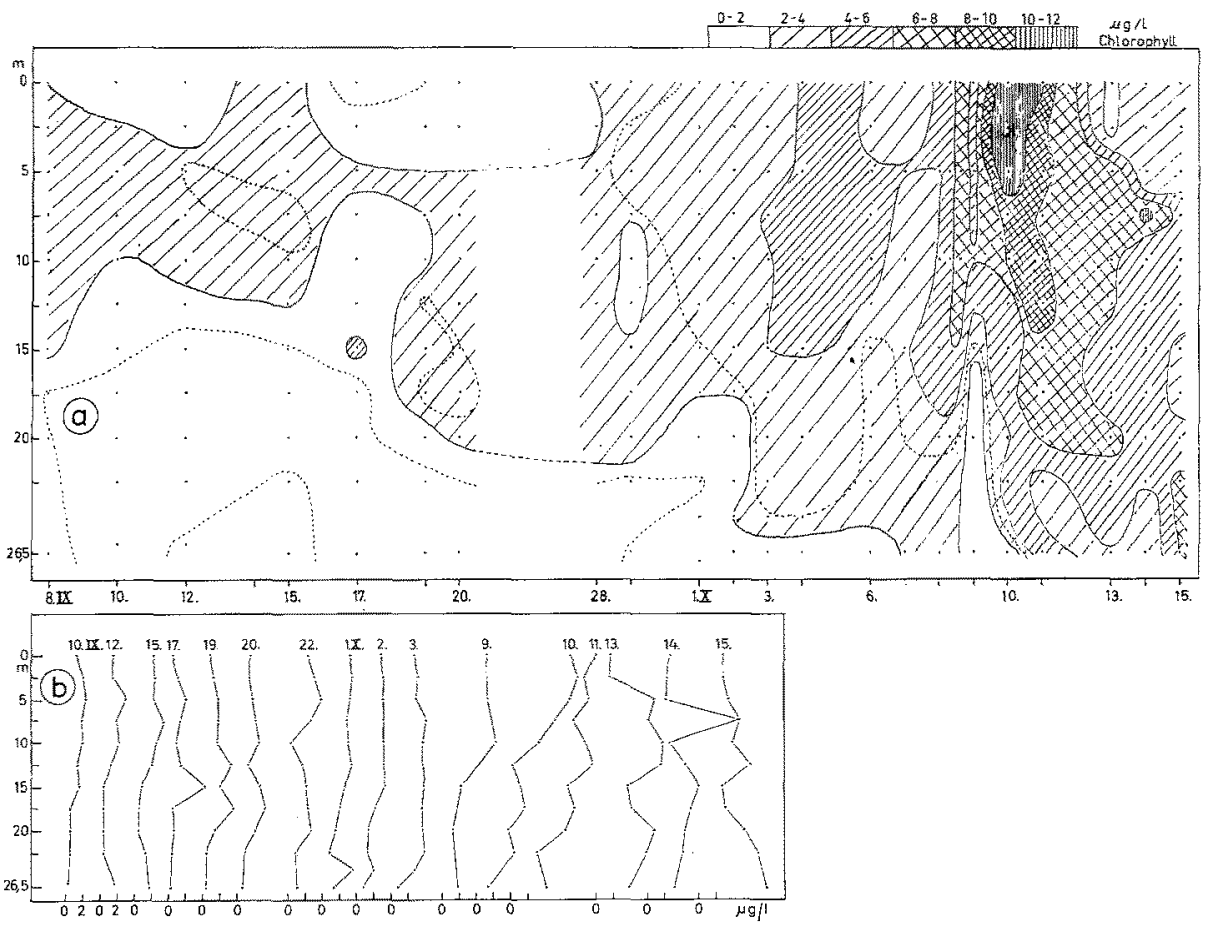

Abb. 21: Herbst 1961: (a) Chlorophyll-Isoplethen; (b) Chlorophyll-Vertikalkurven

Sprungschicht, wo sie besonders im salzreichen Bodenwasser auftreten. Ihnen entspricht kein Phytoplankton. Hohe Eiweißwerte bemerkt man auch Anfang Oktober, wo sie besonders zwischen 5 bis $15 \mathrm{~m}$ Tiefe inselartig eingestreut sind. Während der Ceratium fusus-Bluite bleibt der Eiweißwert jedoch relativ niedrig und steigt keineswegs an. 
Ein anderes Bild zeigen die Chlorophyll-Isoplethen (Abb. 21a). Ein gleichmäßig niedriger Chlorophyllgehalt (bis $3 \mu \mathrm{g} /$ ) kennzeichnet die Oberschicht in Anfang; die Ceratium tripos-Werte kommen hier nicht zum Ausdruck. Das Bodenwasser ist sehr arm an Chlorophyll. Erst ab 3. Oktober steigt der Gehalt auf 4 bis $6 \mu \mathrm{g} / 1$ und erreicht ab 8. Oktober höhere Werte, die sich mit denen von Ceratium fusus decken. Bei den Ceratium fusus-, Chlorophyll- und Eiweißisoplethen lassen sich am 9. Oktober der Durchzug eines Wasserkörpers in der Tiefe feststellen, der besonders arm an den
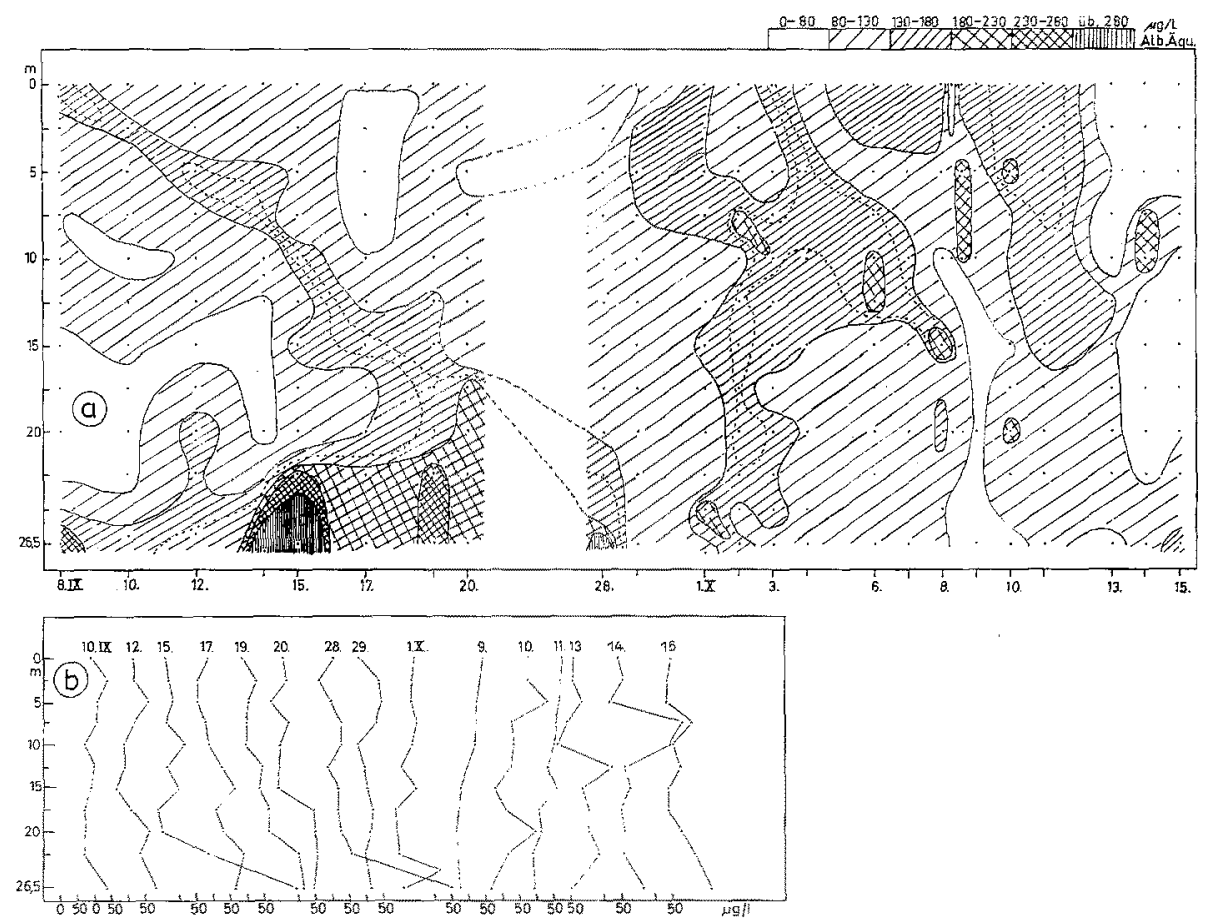

Abb. 22: Herbst 1961: (a) Eiweiß-Isoplethen; (b) Eiweiß-Vertikalkurven

genannten Werten ist und vom Boden bis in $10 \mathrm{~m}$ Tiefe reicht. Die Wucherung von Ceratium fusus und die hohen Chlorophyllwerte finden ihr Ende mit dem Erscheinen des salzarmen Wassers an der Oberfläche. Nur in der Sprungschicht werden noch inselartig hohe Ceratium fusus-, Chlorophyll- und Eiweißwerte bemerkt.

Die Vertikalkurven des Plasmavolumens aller Ceratien zeigt Abbildung 17. Bis zum 15. September sind darin noch die Diatomeen eingetragen. Am 8. und 10. bilden sie die Hältte des Planktons der Oberschicht, am 12. und 15. findet man sie im Bodenwasser, wo sie den größten Phytoplanktonanteil stellen. Das Absinken der CeratienWolken kann gut beobachtet werden. Am 29. September und 6. Oktober werden hohe Werte in der Oberschicht gefunden. Am 8. Oktober zeigt die zweite Serie nachmittags um $1 / 3$ mehr Plankton an als die erste. Am 9. Oktober beginnt dann die Blüte.

Vergleicht man die Tiefenlage der Planktonmaxima mit der Tiefe der Kompensationsintensität von $0,18 \mathrm{cal} / \mathrm{cm}^{2} / \mathrm{h}$ (Abb. 14), so findet man das Plankton bis zum 
15. September als primäre Ansammlungen in der euphotischen Schicht. Maßgebend für die Betrachtung der Peridineenverteilung muß die Lichtmenge zur Zeit der Probennahme sein, auf die sich die beweglichen Peridineen bei ruhigem Wasser ja aktiv einstellen können. Die absinkenden Ceratien-Wolken liegen unterhalb der Kompensationstiefe.

\section{Prozentanteile der Planktongruppen}

Nur am 8. und 10. September haben die Diatomeen in der Oberschicht noch einen wesentlichen Anteil am Plankton, sonst bilden die Peridineen über 90, in der zweiten Hälfte der Untersuchungszeit über $95 \%$ des Phytoplanktons (Abb. 20). Im Bodenwasser stellen die Diatomeen Mitte September oft fast das gesamte Phytoplankton (Abb. 19). Sie sind ganz überwiegend durch eine Art, nämlich Rbizosolenia fragilissima, vertreten. Ceratium tripos und fusus, hier durch ihre Plasmavolumina dargestellt, bilden im Anfang der Beobachtungszeit bis zu $85 \%$, während der Blüte $90 \%$ des gesamten Phytoplanktonbestandes. Die übrigen Peridineen haben einen kleinen, relativ konstanten Anteil (Ceratium tripos lata, Gymnodinium, Peridinium, Dinophysis). Cyanophyceen werden nur in einzelnen Proben angetroffen. Sie kommen nur im Bodenwasser vor, wo sie allerdings bis $30 \%$ ausmachen.

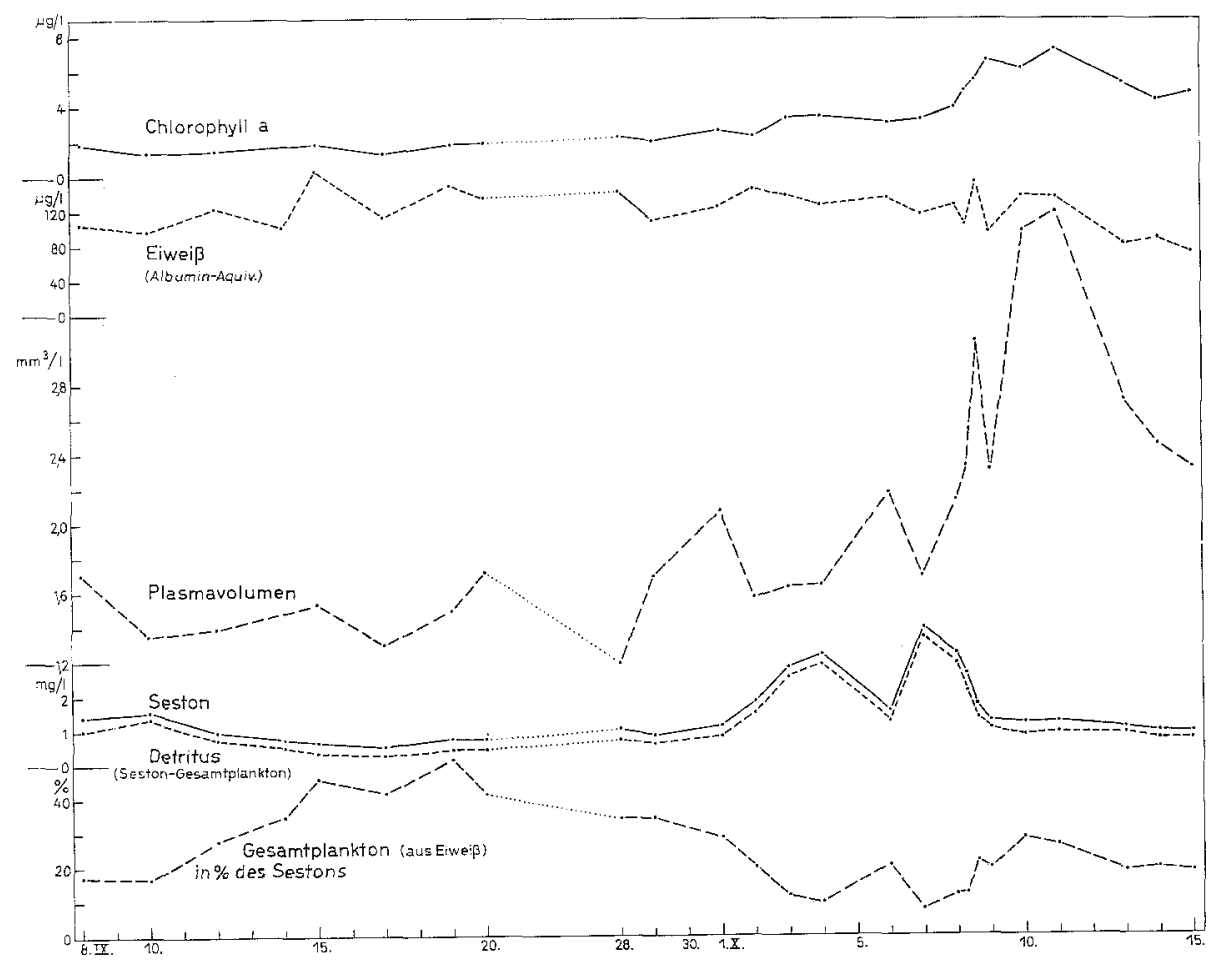

Abb. 23: Herbst 1961: Mittelwerte gemessener und berechneter Komponenten in der Wassersäule 


\section{Kurven der Mittelwerte}

Die Chlorophyllwerte überschreiten im geschichteten Wasser $2 \mu \mathrm{g} / 1 \mathrm{kaun}$. Sie bleiben auch nach dem raschen Anstieg auf 6 bis $7 \mu \mathrm{g} / 1 \mathrm{ab}$ 8. Oktober noch unter den Werten der schwachen Blüte im März 1962 (Abb. 23). Die Eiweißkurve läßt die höchsten Beträge (bis $160 \mu \mathrm{g} /$ ) zu Beginn im geschichteten Wasser durch die hohen Eiweißwerte am Boden erkennen. Während der Blüte wird auffallend wenig Eiweiß $(140 \mu \mathrm{g} / 1)$ gefunden. Bereits im geschichteten Wasser finden sich hohe Plasmavolumenwerte mit 1,3 bis $1,6 \mathrm{~mm}^{3} / 1$; ab 8 . Oktober steigt die Planktonmenge rasch und erreicht am 10. und 11. das Maximum mit 4,4 und 4,6 $\mathrm{mm}^{3} / 1$. Sie ist damit $4,5 \mathrm{mal}$ höher als bei der starken Blüte im März 1961. Entsprechend dem niedrigen Eiweißwert gleicht der berechnete Detritus dem Sestongewicht. Der Prozentsatz des Gesamtplanktons am Seston erreicht im geschichteten Wasser $50 \%$, im durchmischten dagegen meist nut 10 bis $20 \%$.

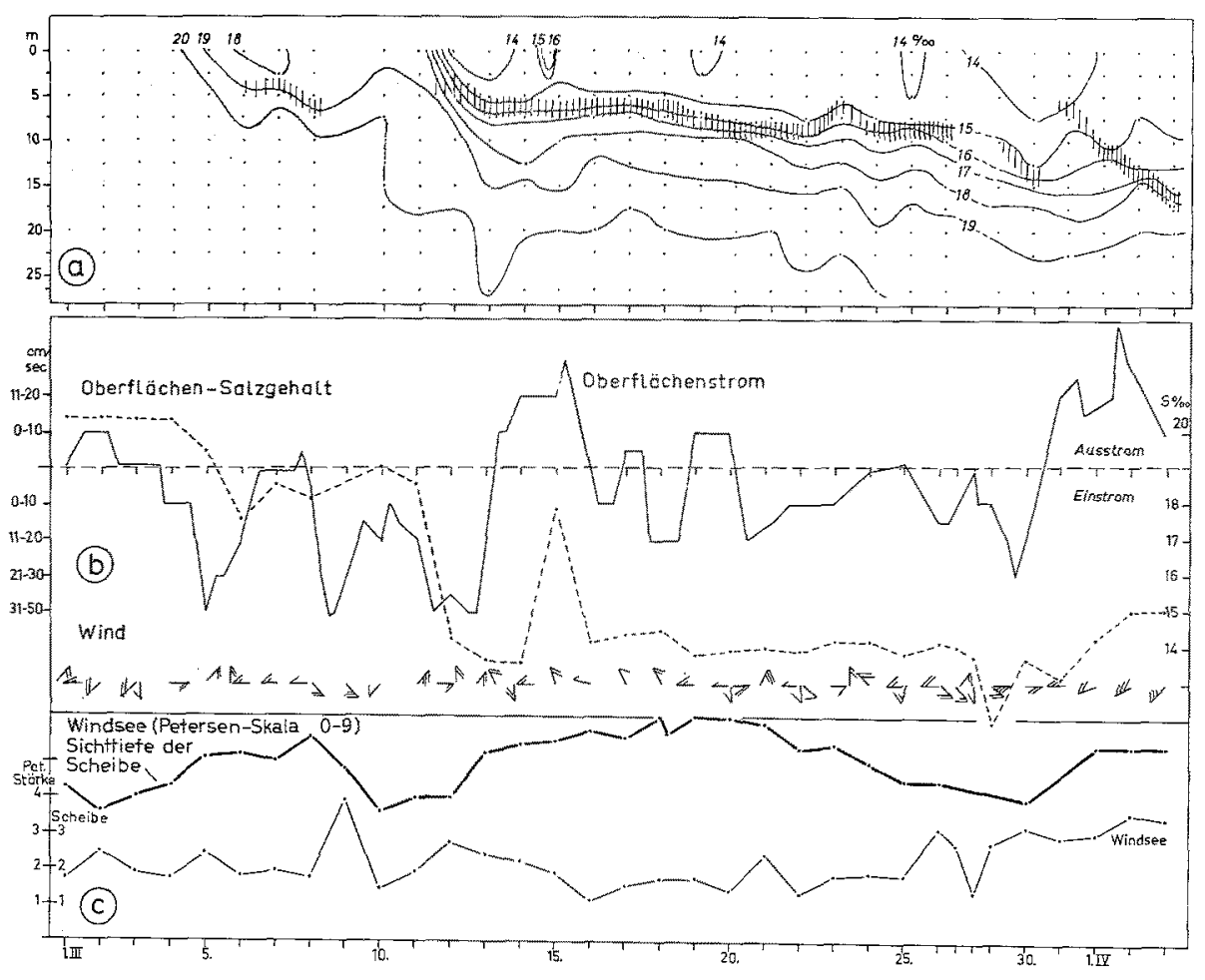

Abb. 24: März 1962: Hydrographie. (a) Isoplethen des Salzgehaltes, Sprungschichtbezeichnung wie bei Abb. 2; (b) Strom und Salzgehalt an der Oberfläche, Wind (s. Abb. 2); (c) Windsee und Sichttiefe 


\section{März 1962}

\section{Hydrograpbie}

Eine völlig homotherme und homohaline Wassersäule wird $\mathrm{zu}$ Beginn dieser Untersuchungsperiode am Anfang März angetroffen (Abb. 25a). Sie ist vermutlich durch die gründliche Mischung bei den Februarstürmen entstanden. Am 4. bis 5. März kommt bei mäßigem Ostwind und starkem Einstrom salzärmeres Oberflächenwasser in die Förde (Abb. 24a, b). Dieser erste Einschub findet am 7./8. März zunächst sein Ende. Eine haline Sprungschicht hat sich in 5 bis 7,5 m Tiefe ausgebildet. Bei frischen Winden um Nord erfolgt ab 11. März ein zweiter Einschub salzarmen Wassers. Der Salzgehalt an der Oberfläche fällt rasch um $4,5 \%$ an einem Tag bei Einstromgeschwindigkeiten bis $50 \mathrm{~cm} / \mathrm{sec}$ (Abb. 24b). Das so erneut stabilisierte Oberflächenwasser bleibt bis zum Ende des Monats.

Während der Strom am 13./14. seine Richtung ändert und am 14./15. nach Osten setzt, wird am 15. März um $8.00 \mathrm{~h}$ ein sprunghafter Anstieg des Salzgehaltes auf 17,9\% registriert (Probe der Feuerschiffbesatzung, Abb. 24a, b). Um $14.00 \mathrm{~h}$, als die eigene Probe genommen wurde, ist dieses Wasser nicht mehr zu finden, vielmehr wird es wieder salzarm $(14,9 \%$ angetroffen. Durch den Stromwechsel war offenbar das nach Westen abgedrängte salzreiche Wasser für kurze Zeit zurückgeflossen, ein Beispiel für den raschen Wechsel der hydrographischen Fronten in der Beltsee, der auch bei täglicher Probennahme oft nicht erfaßt wird. Bei schwachen Winden und geringem Strom bleibt die stabile Schichtung bis zum 29. März erhalten (Abb. 25a). Dann sinkt die Sprungschicht bei starkem Ostwind $\mathrm{ab}$ und löst sich auf. Eine neue bildet sich am

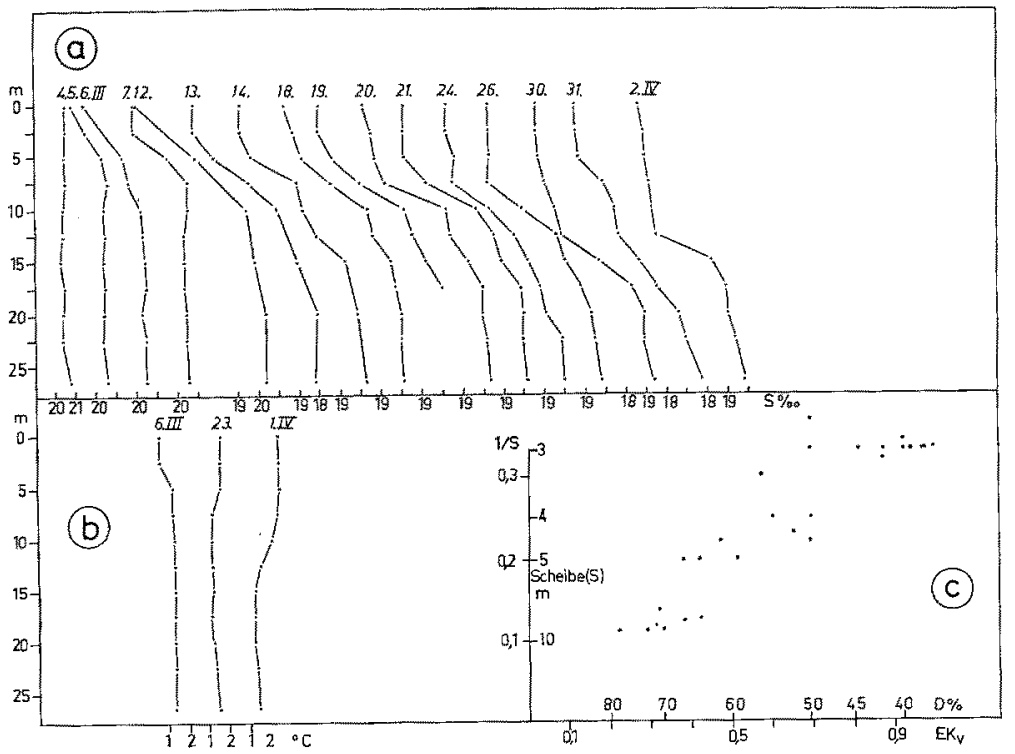

Abb. 25: März 1962: Hydrographie. (a) Salzgehalt-Vertikalkurven; (b) Temperatur-Vertikalkurven; (c) Beziehung $1 / \mathrm{S} / \mathrm{EK}_{\mathrm{v}}$ (reziproker Wert der Sichttiefe der Scheibe gegen vertikalen Extinktionskoeffizienten bzw. Durchlässigkeit aufgetragen) 
31. März nach einem Wechsel der Wind- und Stromrichtung. Sie sinkt auf 15 bis $17,5 \mathrm{~m}$ Anfang April ab.

Der März 1962 war ungewöhnlich kalt. Mitte des Monats werden die niedrigsten Luft- und Wassertemperaturen des Jahres gemessen $\left(0,2^{\circ} \mathrm{C}\right.$ an der Oberfläche). Erst Anfang April werden $2^{\circ} \mathrm{C}$ übeschritten. Die hydrographische Lage wird also in diesem Frühjahr der des Vorjahres entgegengesetzt angetroffen. Fördewasser wird mit salzarmen Ostseewasser überschichtet, was eine frühe Stabilisierung durch eine sehr hoch gelegene $(5$ bis 7,5 m) und scharfe Sprungschicht bewirkt. Da Ende Februar starke Weststürme das Wasser in der mittleren und östlichen Ostsee aufgestaut haben dürften, ist hier der kräftige Zufluß salzarmen Wassers ohne entsprechende Windwirkung wohl zu erklären. Im Gegensatz zum Vorjahre herrscht also Einstrom mit fallendem Salzgehalt an der Oberfläche (Abb. 24b).

Bei der nahezu homothermen Wassersäule kennzeichnen die Isohalinen die Wasserkörper gut (Abb. 24a). Unter der 20-0\%-Isohaline findet sich das Fördewasser vom Anfang März, über der 19-0/00-Isohaline das Wasser des ersten Einschubs von Ost, über der Sprungschicht das zuletzt eingeströmte Wasser. Der Vergleich der Oberschicht vom 16. bis 29. März scheint gut möglich, ebenfalls der des Bodenwassers, das für die Planktonproduktion aber nicht in Frage kommt. Das Wasser unter der Sprungschicht ist besonders unstabil und wird stark vermischt.

\section{Licbt}

Die Durchlässigkeit wurde hier aus Sichtscheiben-Werten nach dem in Abbildung $25 c$ dargestellten Verhältnis $1 / \mathrm{S} / \mathrm{EK}_{\mathrm{v}}$ (grün) (reziproker Wert der Sichtscheibe zu vertikalem Extinktionskoeffizienten im Bereich maximaler Transmission) errechnet,

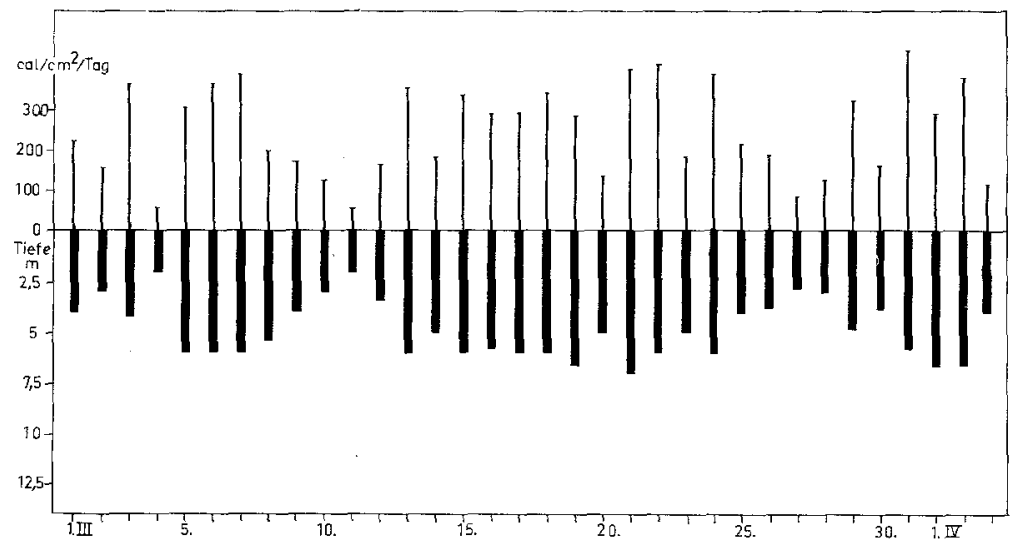

Abb. 26: März 1962: Globalstrahlung und Kompensationstiefe

wie andere Autoren bereits ihre Lichtmessungen ergänzten (JENkIN 1937). Die Kompensationstiefe für die Mittagszeit wurde hier nicht berechnet, da keine eigenen Aktinographenaufzeichnungen vorlagen. Diese Tiefen lassen sich aber nach den Werten des Vorjahres abschätzen. Die Transparenz des Wassers liegt hier zwischen der des Frühjahres 1961 und den Septemberwerten. Bei Scheibenwerten zwischen 4 bis $6 \mathrm{~m}$ 
Tiefe wird die 24-h-Kompensationstiefe bei 2 bis $7 \mathrm{~m}$, meist in 4 bis $6 \mathrm{~m}$ Tiefe gefunden (Abb. 26). Die Mittags-Kompensationstiefe dürfte 4 bis $13 \mathrm{~m}$, meist 10 bis $12 \mathrm{~m}$ betragen haben.

Die Globalstrahlungswerte, die von Wyk auf Föhr stammen, lassen drei helle Zeiträume mit Mitteln von $277 \mathrm{cal} / \mathrm{cm}^{2} /$ Tag vom 1. bis 7. März $301 \quad "$ 13. bis 24. März

und zwei dunkle mit

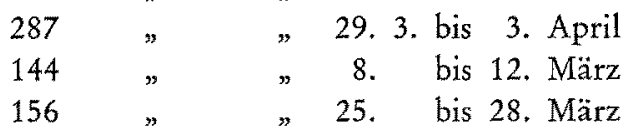

unterscheiden, wobei in den dunklen die Kompensationstiefe in 3 bis $4 \mathrm{~m}$, in den hellen bei 5 bis $6 \mathrm{~m}$ zu finden ist. Nur an den hellsten Tagen liegt die Sprungschicht im Bereich der 24-h-Kompensationstiefe. Wie im Frühjahr 1961 ist keine Abhängigkeit der Sichttiefe von der Seegangshöhe wie im Herbst zu erkennen (Abb. 24c), da das winterliche Wasser stark mit Seston angereichert ist, so daß sich durch Turbulenz dessen Menge relativ nur wenig verändert.

\section{Phosphat-Phosphor}

Hier wird die winterliche Nährstoffverteilung mit 20 bis $25 \mu \mathrm{g} / \mathrm{P} / \mathrm{l}$ noch voll erfaßt. Die Schichtung des Phosphats, wie sie sich im Laufe des März herausbildet,

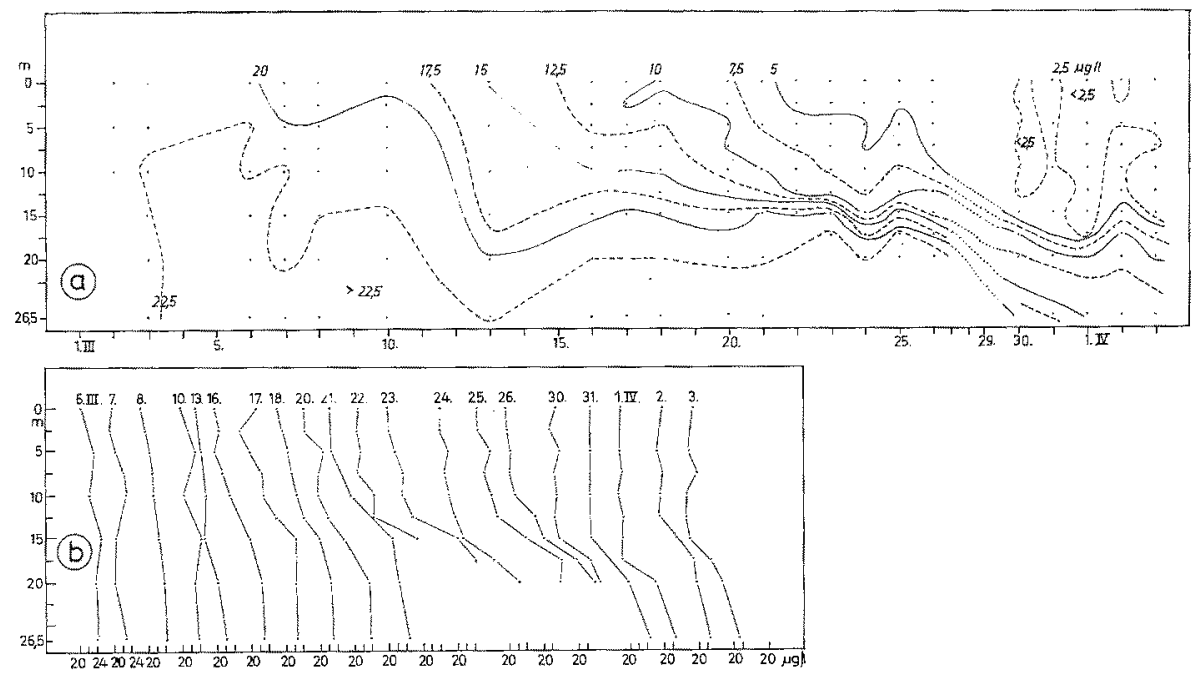

Abb. 27: März 1962: Phosphat-Phosphor. (a) Isoplethen; (b) Vertikalkurven

steht deutlich in Beziehung zur Planktonschichtung (Abb. 27a, b und Abb. 28b). Ab 22. März hat sich in 12,5 bis $15 \mathrm{~m}$ bereits ein starker Gradient der Phosphat-Verteilung herausgebildet. 


\section{Vertikalverteilung des Sestons und Planktons}

Die Sestonwerte sind Anfang März im ungeschichteten Wasser hoch; auch während der Planktonwucherung zeigt die Vertikalverteilung des Sestons (nicht dargestellt) wenig Beziehung zu den biologischen Werten. Die zunächst niedrigen Eiweißgehalte steigen kurz am 12. März in der ganzen Wassersäule in Verbindung mit dem starken Einstrom in die Förde an (Abb. 29). Erst ab 16./17. März wird dann eine kontinuier-
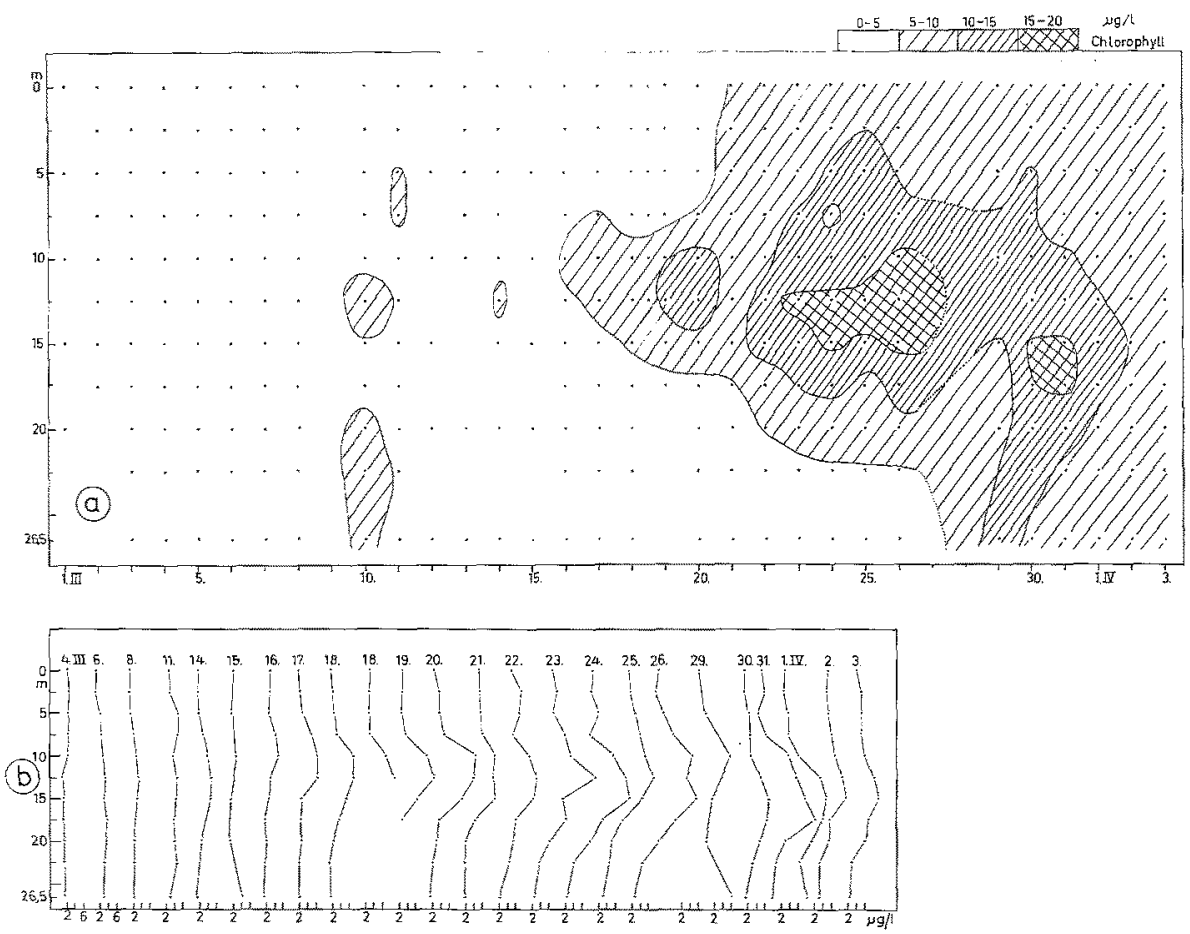

Abb. 28: März 1962: (a) Chlorophyll-Isoplethen; (b) Chlorophyll-Vertikalkurven

liche Zunahme der Eiweiß- und Chlorophyllwerte (Abb. 28) in $10 \mathrm{~m}$ Tiefe beobachtet; diese Maxima liegen also meist unter der Sprungschicht (Abb. 24a) und sind deren Einfluß auf das Absinken entzogen. Der Chlorophyllgehalt nimmt daher nach unten ab ohne starke Gradienten wie im Vorjahre bei tiefgelegener Sprungschicht. Zwei Vergleichsserien am 18. März morgens und nachmittags zeigen die tägliche Chlorophyllzunahme, die hier mit $2 \mu \mathrm{g} / 1$ in $12,5 \mathrm{~m}$ besonders ausgeprägt ist. Die Chlorophyllmaxima lassen sich nie ïber der 24-h-Kompensationstiefe feststellen. Nur während der hellsten Tagesstunden an hellen Tagen dürfte nach den errechneten Energiebeträgen noch in $10 \mathrm{~m}$ ein Stoffgewinn möglich sein, der allerdings in 24 Stunden dem Abbau nicht entgehen kann (Abb. 28b und 26).

Die höchsten Konzentrationen des Plasmavolumens liegen mehr in der Oberschicht (Abb. 30). Doch ist auch hier der Beginn inselartiger Wucherungen in $10 \mathrm{~m}$ an 3 Tagen 
gut zu erkennen. Dabei werden am 20./21. März hohe Beträge erreicht, während zur gleichen Zeit eine zweite Wucherung an der Oberfläche erscheint, sich rasch verstärkt und in die Tiefe ausbreitet. Am 29. wird über einer in 10 bis $15 \mathrm{~m}$ Tiefe absinkenden Planktonwolke ein erneutes Ansteigen der Volumenwerte an der Oberfläche gefunden.
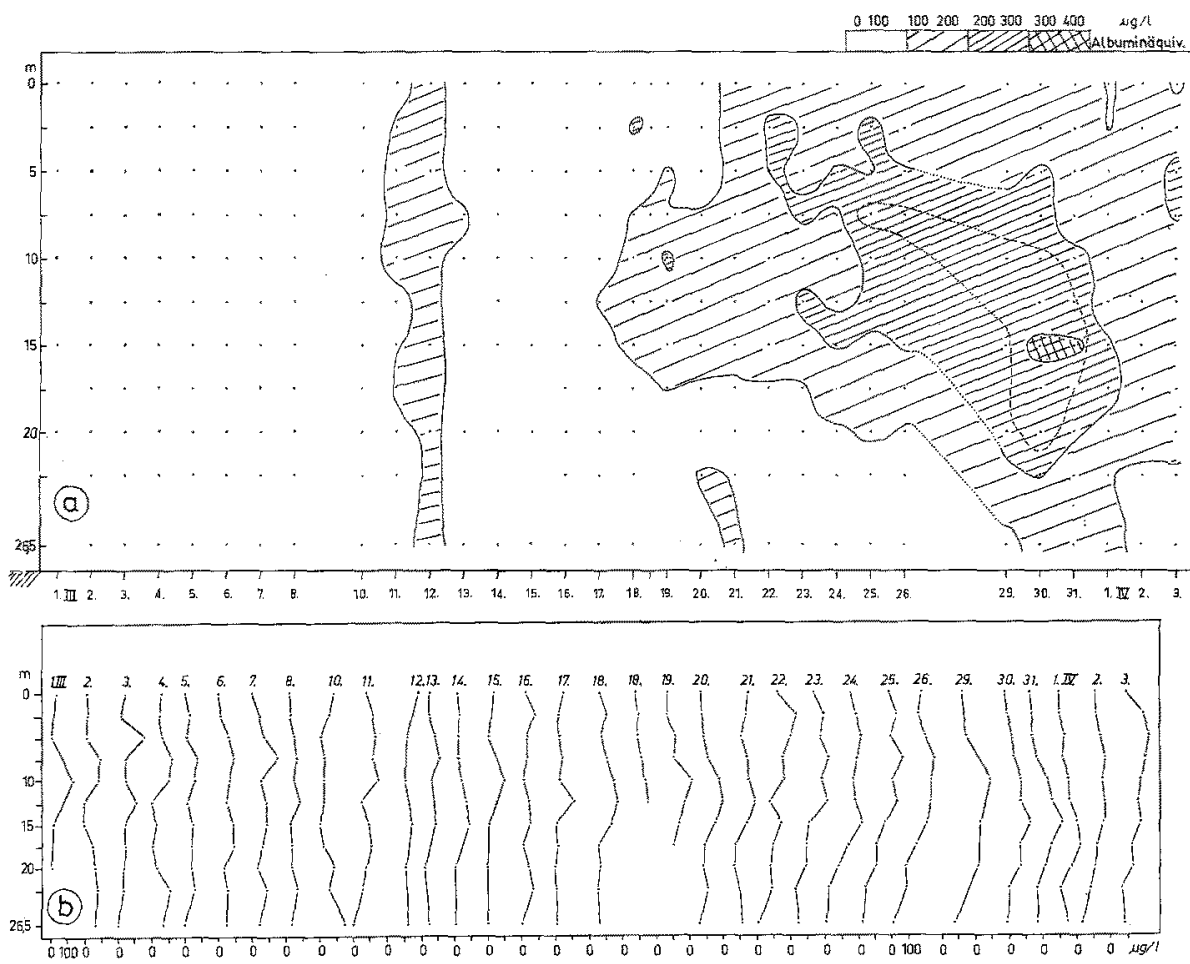

Abb. 29: März 1962: (a) Eiweiß-Isoplethen; (b) Eiweiß-Vertikalkurven

\section{Prozentanteile der Planktongruppen}

Der Anteil der Peridineen am Phytoplankton ist höher als im Vorjahre (Abb. 32). Von 30 bis $35 \%$ an 14. März fällt er langsam auf $15 \%$, steigt aber am 31 , wieder sprunghaft an. Mit dem Einstrom änderte sich also auch die qualitative Zusammensetzung des Planktons. Die Peridineen sind vertikal viel gleidumäßiger als die wolkenförmig vorkommenden Diatomeen verteilt. Jene sind auch in der Oberschicht stets relativ stärker vertreten und nehmen langsam mit der Tiefe ab. Im Prozentanteil der einzelnen Gruppen bilden Thalassiosiren zu Beginn der Wucherung meist den Hauptanteil (Abb. 31). Gegen Ende März wird Skeletonema häufiger. Es zeigt sich, daß die Planktonansammlungen in $10 \mathrm{~m}$ von Skeletonema und vor allem Thalassiosira, die an der Oberfläche ganz überwiegend von Skeletonema (bis $70 \%$ des Volumens) gebildet werden. Nur die drei dargestellten Hauptgruppen gewinnen im Plankton Bedeutung. 
Bei Ansammlungen abgesunkener Diatomeen kann sich im Einzelfall die Zusammensetzung zugunsten größerer und soliderer Zellen (Coscinodiscus am 2. April) ändern.

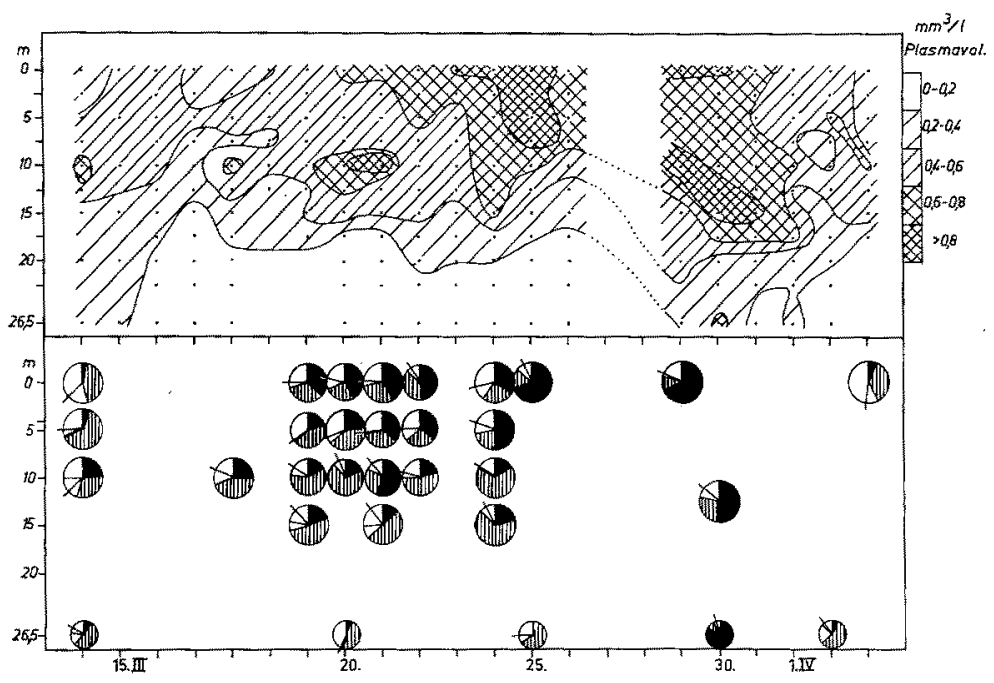

Abb. 30: März 1962: (oben) Plasmavolumen des Phytoplanktons, Isoplethen Abb. 31 : März 1962: (unten) Artzusammensetzung (Plasmavolumenanteile) des Phytoplanktons (Erklärung s. Abb. 10)

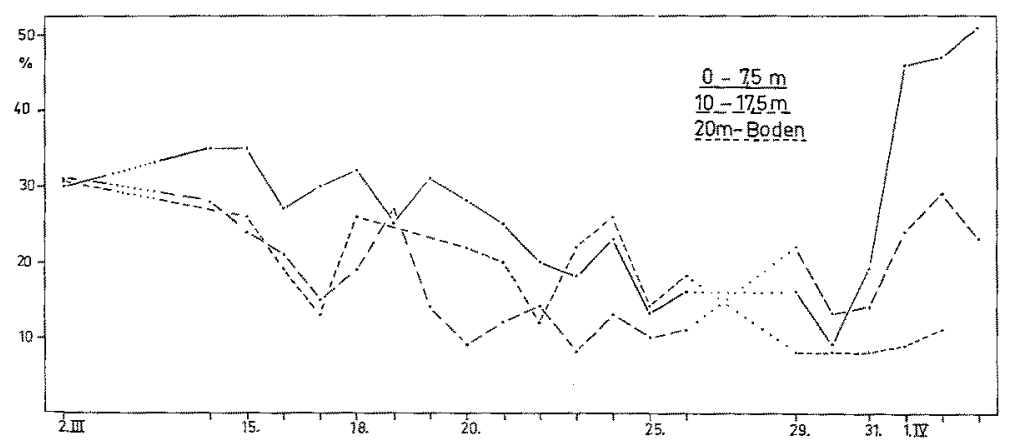

Abb. 32: März 1962: Anteil (Plasmavolumen) der Peridineen am Phytoplankton

\section{Kurven der Mittelwerte}

Die bis zum 18. März geringen Chlorophyllmengen steigen langsam auf 10 bis $12 \mu \mathrm{g} / \mathrm{lam} 24$. bis 31 . März an und fallen dann rasch auf die Hälfte ab (Abb. 33). Von Werten um 20 bis $60 \mu \mathrm{g} / 1 \mathrm{zu}$ Beginn erreicht der Eiweißgehalt des Sestons mit $280 \mu \mathrm{g} / 1$ die gleiche Höhe wie im Vorjahre. Mit $0,7 \mathrm{~mm}^{3 / 1}$ wird nur $1 / 3$ des Planktons nach Plasmavolumen im Vergleich zum Frühjahr 1961 gefunden; ähnlich ist das Verhältnis bei den Zellzahlen der kleinen Diatomeen. Der Sestongehalt fällt bei der Stabilisierung 
des Wassers am 13. März von 2 bis $4 \mathrm{mg} / 1$ auf 1 bis $2 \mathrm{mg} / 1$. Gegenüber dem Vorjahre wird also hier nur die Hältte der Sestonmenge gefunden. Der Prozentanteil des Planktons am Seston liegt um $10 \%$ bis zum 17. März, steigt dann auf 35, maximal $55 \%$ an und wird am Ende der Untersuchungsperiode noch mit $40 \%$ angetroffen.

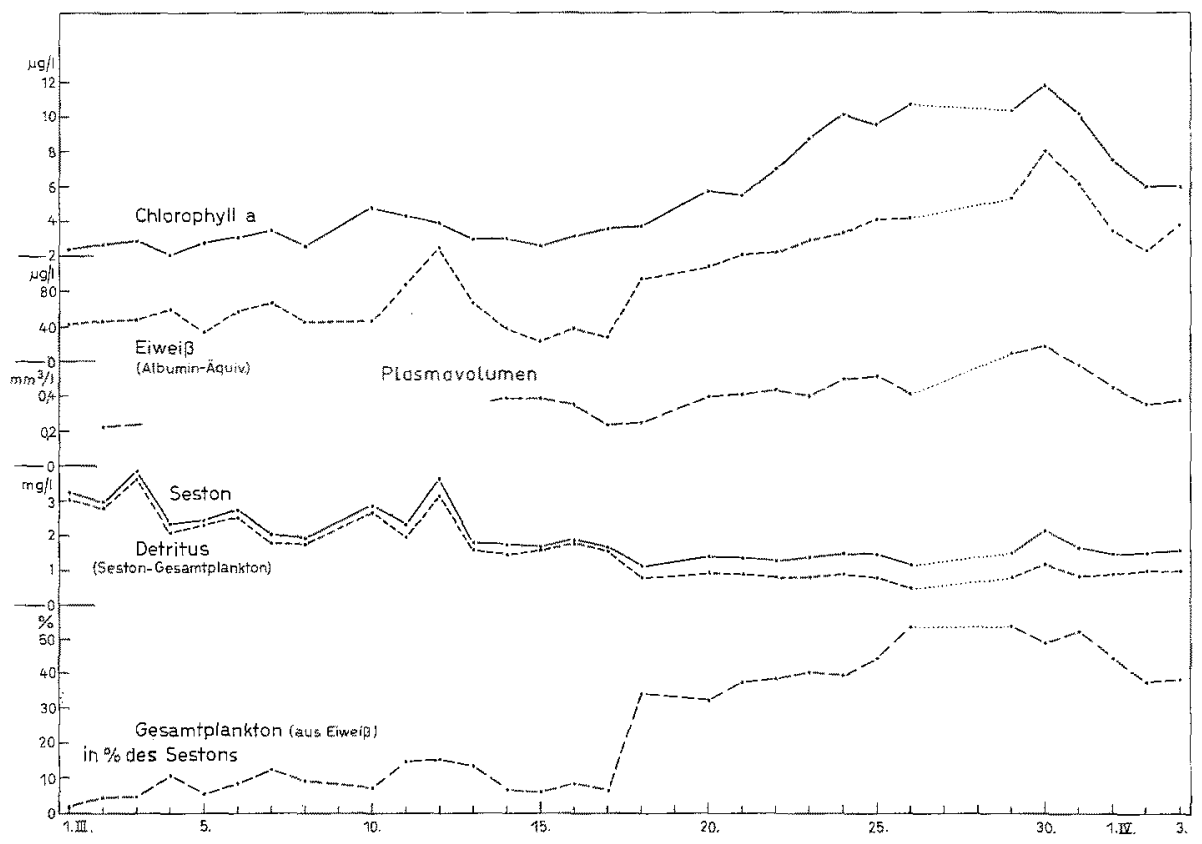

Abb. 33: März 1962: Mittelwerte gemessener und berechneter Komponenten in der Wassersäule

\section{AUSWERTUNG DER ERGEBNISSE}

\section{Berechnung der organischen Substanz des Planktons und Methodenkritik}

Im vorangehenden Teil wurden die gemessenen Komponenten des Planktons und Sestons aufgezeichnet. Für produktionsbiologische Betrachtungen muß das Ziel aber sein, die Menge - und weiterhin die Art - der organischen Stoffe und deren Veränderung im Okosystem der pelagischen Lebensgemeinschaften im Meer zu erfassen. Als Maß für die organische Substanz des Planktons kann man als aus den Analysendaten berechnete Endgröße wählen: (1) Das Volumen des Planktons (Körpervolumen oder Plasmavolumen $=$ "Rechenvolumen “). (2) Das Trockengewicht (des Gesamtplanktons mit Schalen oder der organischen Substanz). (3) Den organischen Kohlenstoff im Plankton.

Erst die Umrechnung der Analysenwerte auf eine gemeinsame Größe erlaubt den Vergleich des Planktonbestandes, wie er aus den verschiedenen gebräuchlichen Bestimmungen hervorgeht. Als berechnete Größe soll hier das Trockengewicht der organischen 
Substanz der Plankter gewählt werden; die zur Verfügung stehenden Meßwerte sind die Chlorophyll- und Eiweißanalysen des abfiltrierten Sestons sowie die mikroskopische Zählung des Phytoplanktons. Damit soll ein Einblick gewonnen werden in die Vergleichbarkeit der errechneten Substanz nach verschiedenen Bestimmungsmethoden, die aber überlagert wird von der Genauigkeit der Analysenmethodik und der Umrechnungsfaktoren. Die zur Umrechnung nötigen Angaben über die Zusammensetzung des Planktons sind seit BRANDT \& RABEN (1920) mehrfach veröffentlicht worden. HAGMEIER $(1960,1961)$ sammelt die Werte aus der Literatur, ergänzt sie und stellt nach kritischer Sichtung seine "Planktonäquivalente" zusammen. Unter Verwendung seiner Umrechnungsfaktoren gelangt man auf folgenden Wegen zum Trockengewicht der organischen Substanz, wobei die Fehler der einzelnen Umrechnungsschritte abgeschätzt und summiert werden:

(1) Aus der Zellzahl bzw. dem Plasmavolumen ( $\pm 25 \%$ )

$$
\begin{gathered}
\times 0,26=\text { Trockengewicht organischer Substanz (T.o.S.) } \\
\text { (Phytoplankton) }( \pm 32 \%)
\end{gathered}
$$

Der Ausgangswert für die Berechnung nach Planktonzählungen, das Plasmavolumen, hat bereits eine hohe relative Abweichung $( \pm 25 \%$ ), da die Umrechnung von Zellzahl auf Volumen ziemlich unsicher ist (p. 8). Das Plasmavolumen läßt sich dann ohne große Fehler auf Trockensubstanz umrechnen.

(2) Vom Eiweißwert $( \pm 10 \%)$

$$
\left.\left.\begin{array}{l}
\times 1,8 \text { für Diatomeen } \\
\times 2,2 \text { für Peridineen }
\end{array}\right\}=\begin{array}{l}
\text { T.o.S. Gesamtplankton } \\
( \pm 22 \%) \\
\times 4,4 \text { für Diatomeen } \\
\times 2,5 \text { für Peridineen }
\end{array}\right\}=\begin{aligned}
& \text { Trockengewicht Gesamtplankton } \\
& \text { mit Schale }( \pm 37 \%)
\end{aligned}
$$

Eiweiß wird recht genau bestimmt, doch ist die Umrechnung auf Trockensubstanz ziemlich ungenau, da der Eiweißgehalt der Planktongruppen schwankt. Dennoch erscheint diese Berechnung hier als die genaueste. Zudem wird die Methode kein „totes“ Eiweiß in größerem Maße miterfassen.

(3) Vom Chlorophyllwert $( \pm 2 \%$ )

$$
\left.\begin{array}{l}
\times 33 \text { für Diatomeen } \\
\times 67 \text { für Peridineen }
\end{array}\right\}=\begin{aligned}
& \text { T.o.S. Phytoplankton } \\
& ( \pm 41 \%)
\end{aligned}
$$

Die Aussagen der Chlorophyllanalyse sind besonders unzuverlässig, da nicht nur der Chlorophyllgehalt verschiedener Arten unterschiedlich ist, sondern auch innerhalb einer Art je nach physiologischem Zustand schwankt. Hinzu kommt die wahrscheinliche Anwesenheit "toten" Chlorophylls, das an Detritus gebunden ist und sich als recht langlebig erweist.

Die Planktonzusammensetzung sollte daher, besonders auch im Hinblick auf die unterschiedliche chemische Beschaffenheit der Diatomeen und Peridineen, bekannt sein. In unserem Gebiet ist die Berücksichtigung der drei Hauptgruppen des Planktons - Diatomeen, Peridineen und Copepoden - fast stets ausreichend. Der hier nicht gezählte Copepodenanteil kann aus LoHMANN (1908) und eigenen Schätzungen ermit- 
telt werden. Er kann mitunter - besonders bei der Frühjahrsblüte - vernachlässigt werden. Die Zusammensetzung des gezählten Phytoplanktons zeigen die Abbildungen $9,10,19,31,32$.

Es ergibt sich so folgende Planktonzusammensetzung als Grundlage für die Umrechnung, die nach den Prozentanteilen der Gruppen mit entsprechend differenzierten Faktoren durchgeführt wird: März 1961: Anfangs kommen bis 50\% Peridineen vor, später um $95 \%$ Diatomeen. Da geringe Zooplanktonmengen zu vermuten sind, können Umrechnungsfaktoren wie bei Diatomeen benutzt werden. Herbst 1961: Meist werden über $95 \%$ Peridineen angetroffen; im Anfang herrschen jedoch im Bodenwasser Diatomeen vor. Zooplankton wird berücksichtigt; mögliche Fehlschätzungen sind von geringer Bedeutung, weil bei der Berechnung ähnliche Faktoren zugrunde gelegt werden wie bei den Peridineen. März 1962: Neben den Diatomeen werden Peridineen berücksichtigt. Eine geringe Zooplanktonhäufigkeit ist wahrscheinlich.

Da kaum zwei natüliche Planktonpopulationen in ihrer chemischen und biologischen Zusammensetzung streng vergleichbar sind, ist die Forderung, Umrechnungsfaktoren aus einer qualitativ gleichartigen Population zu gewinnen, selten exakt zu erfüllen. Zudem basieren die Faktoren oft auf Mittelwerten aus sehr verschiedenen und in ihrer Artzusammensetzung ungenügend bekannten Planktongesellschaften. Daher ist die Benutzung von Umrechnungsfaktoren mit einigen Unsicherheiten verbunden.

Die Darstellung der Trockensubstanz-Kurven erfolgt getrennt fuir drei Wasserschichten neben der Mittelung der ganzen Wassersäule, die alleine bei der meist ausgeprägten Schichtung der Wasserkörper nur beschränkten Wert hat. Eine Aufteilung in drei Schichten läßt die qualitativen Unterschiede im Plankton besser hervortreten.

Die drei Tiefenstufen werden (für alle drei Zeiträume) nach folgenden Gesichtspunkten zusammengefaßt: Die Werte von 0 bis 7,5 m kennzeichnen die Assimilationszone; sie liegt stets über der Dichtesprungschicht. Die Werte von 10 bis $17,5 \mathrm{~m}$ charakterisieren die meist uneinheitliche Mittelschicht, in der die hydrographische Sprungschicht und oft auch die größten biologischen Gradienten liegen. Die hier noch großen - of maximalen - Planktonansammlungen sind meist schon als "sekundäre" anzusehen. Die Werte von $20 \mathrm{~m}$ bis Boden bezeichnen das Bodenwasser unter der Sprungschicht. Vergleicht man die Kurven (im folgenden oft kurz „Eiweiß-, Chlorophyll-, Plasmavolumen-Kurve") für die drei Untersuchungsperioden, so erkennt man wesentliche Unterschiede, deren Deutung hier versucht wird.

\section{März 1961}

In der Oberschicht liegt die Chlorophyll-Kurve fast stets über der für Eiweiß; dies legt die Vermutung nahe, daß bei den absolut hohen Chlorophyllwerten ein großer Anteil an Detritus gebunden ist (Abb. 34). Erst Anfang April steigt der Eiweißwert uber den Chlorophyllwert, was sich mit einem Zooplankton-Anstieg beim Abklingen der Phytoplanktonblüte erklären läßt. Die Plasmavolumen-Kurve der Oberschicht weicht von dem gleichsinnigen Verlauf der Chlorophyll- und Eiweißkurven ab. Am 11., 15. und 24. März liegen die für das Zählplankton ermittelten Werte vor der Zerstörung der Schichtung offenbar zu hoch. Gerade gegen Ende der Blüte kann man Fehler durch Mitzählen toter Zellen vermuten. 
Während in der Mittelschicht der Eiweißwert noch unter dem Chlorophyllwert liegt, ist dies im Bodenwasser umgekehrt. Hier ist größere Zooplanktonhäufigkeit verständlich. Die großen Unterschiede im Bodenwasser zeigen den Einfluß der windigen Tage auf die Planktonverteilung am 13., 18. und 27. März. Betrachtet man die ganze Wassersäule, so heben sich zwei Perioden mit höheren Werten für Chlorophyll und Eiweiß gegenüber dem Zählplankton ab. Chlorophyll wird allgemein höher gefunden als Eiweiß.

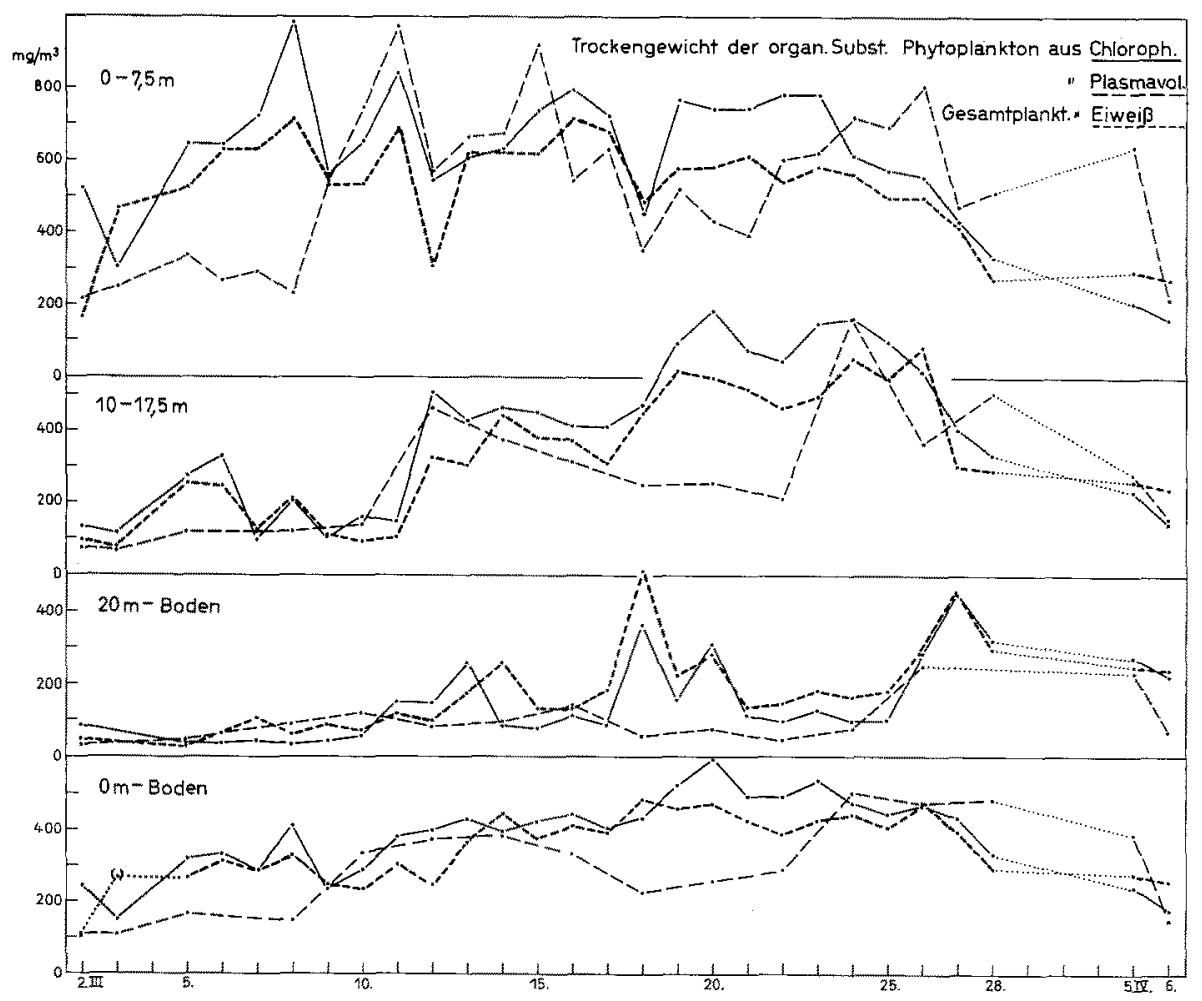

Abb. 34: März 1961: Berechnetes Trodkengewicht der organischen Substanz des Phytoplanktons aus Chlorophyllbestimmungen und Planktonzählungen (Plasmavolumen) sowie des Gesamtplanktons aus Eiweißbestimmungen

\section{März 1962}

Auffallend ist der ähnliche Verlauf der Chlorophyll- und Eiweißkurve in der Oberschicht (Abb. 35). Das Eiweißmaximum am 12. März ist durch Zooplanktoneinschub mit dem neuen Wasserkörper aus Osten erklärbar. Die Unterschätzung des Zählplanktons ab 17. März während der Stabilisierung des Wassers ist in allen Schichten offensichtlich, da auch die Eiweißkurve höher liegt. Ob hier ein sich im Laufe der Planktonentwicklung ändernder Gehalt der Plankter an Chlorophyll und Eiweiß oder Zählfehler angenommen werden dürfen, sei dahingestellt. 
Wie im Vorjahre wird mit dem Beginn einer Wucherung in der Mittelschicht der Chlorophyllgehalt relativ zu hoch gefunden, was hier die Annahme geänderten Chlorophyllgehaltes der dominierenden Diatomeen nahelegt. Der relative Chlorophyllanstieg im Bodenwasser kommt 2 bis 3 Tage später als darüber mit der absinkenden Planktonwolke. Mit dem Stromwechsel am 30./31. März und dem Abfall der Planktondichte

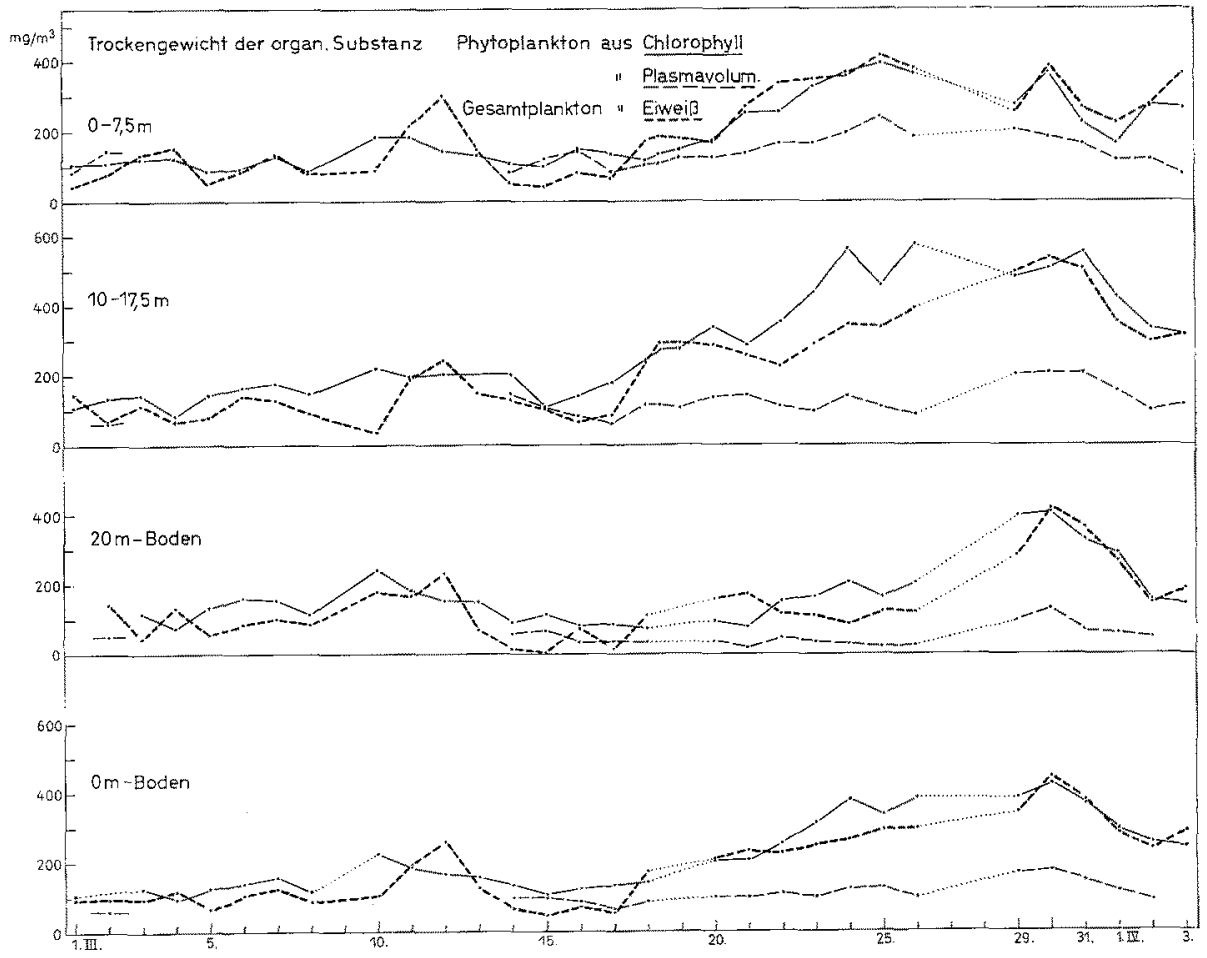

Abb. 35: März 1962: Berechnetes Trockengewicht der organischen Substanz des Phytoplanktons (s. Abb. 34)

findet sich eine gute Ubereinstimmung von Chlorophyll und Eiweiß; auf die hier vorhandene Population werden also die richtigen Umrechnungsfaktoren angewandt. Bei relativ geringer Planktondichte und langsamem Anstieg zum Ende März wird also durch Chlorophyll und Eiweiß ab 18. eine doppelt so hohe Biomasse angezeigt wie durch Planktonzählung, die hier offenbar zu geringe Werte ergibt.

\section{Herbst 1961}

Ganz abweichend von den Befunden in den Frühjahren sind die berechneten Trockensubstanz-Kurven im Herbst 1961 durch die relativ hohen Beträge der Plasmavolumen-Kurve gekennzeichnet (Abb. 36). Sie liegen in der Oberschicht 2- bis $4 \mathrm{mal}$ höher als die Eiweißkurve, 2- bis 6mal über dem Chlorophyllwert. Besonders in der 
Oberschicht ist dies ausgeprägt. Anders als im Frühjahr liegen ferner die Eiweißwerte um $1 / 3$ höher als die aus Chlorophyll, nach Beginn der Bliite allerdings um ebensoviel tiefer. Nur im Bodenwasser ist der Eiweißwert um ein Mehrfaches höher, als dem

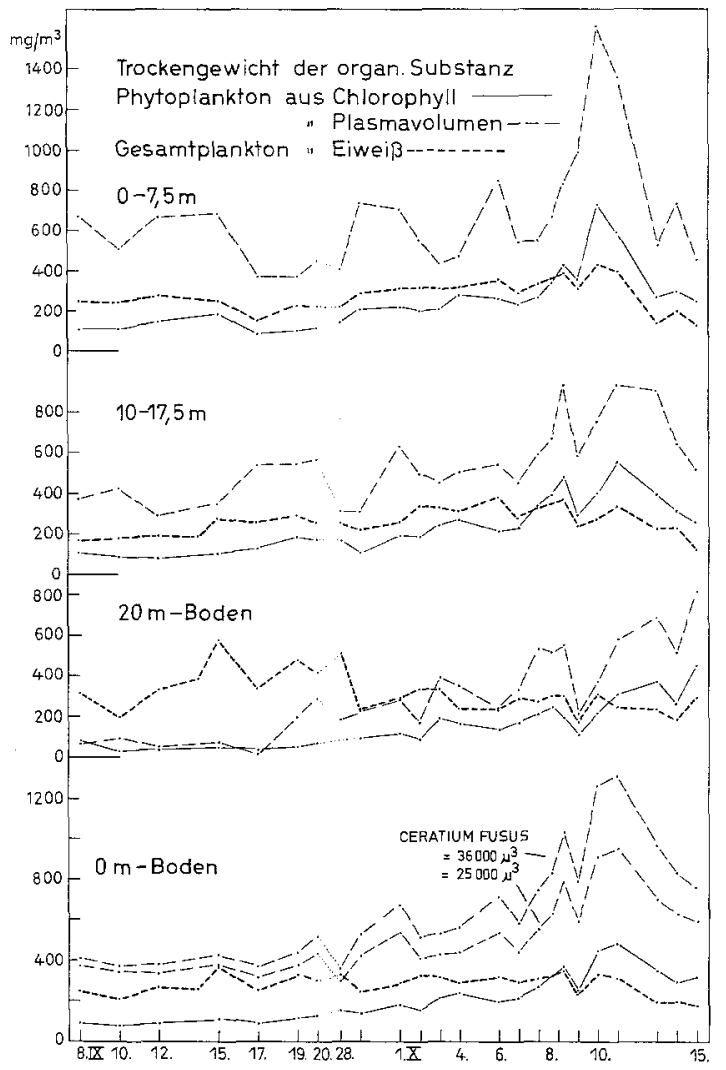

Abb. 36: Herbst 1961: Berechnetes Trockengewicht der organischen Substanz des Phytoplanktons (s. Abb. 34)

Plasmavolumen- oder Chlorophyllwert entspräche. Offensichtlich ist die starke Überschätzung des Eiweißes sowie die Übereinstimmung von Zählplankton und Chlorophyll an die Rbizosolenia-Wolke im Bodenwasser gebunden. Es müßte für die Diatomeen ein falscher Eiweiß-Umrechnungsfaktor gewählt sein, oder aber eine starke Zooplanktonpopulation im Bodenwasser existieren.

Es zeigen sich also zum Teil erhebliche Unterschiede zwischen den aus verschiedenen Bestimmungen errechneten Trockengewichten, die im Idealfall - bei fehlerfreier Gewinnung, Fixierung und Analyse des Planktons sowie genau treffenden Umrechnungsfaktoren - gleich verlaufen müßten. Jedenfalls wäre das für die Chlorophyllund Plasmavolumenwerte des Phytoplanktons zu erwarten, während in der Eiweißbestimmung das Zooplankton mitenthalten ist.

Besonders auffallend sind die Unterschätzung des Zählplanktons in den Früh- 
jahren und die zu geringen Eiweiß- und Chlorophyllwerte im Herbst. Die Fixierung von Diatomeen mit Lugolscher Lösung ist oft nicht befriedigend und kommt als Fehlerquelle in Betracht. Diatomeenketten zerbrechen leicht, wodurch die Artbestimmung sehr erschwert wird (Thalassiosira, Chactoceras). Es werden bisweilen auch Lösungserscheinungen an den Kieselpanzern zarter Diatomeen beobachtet. Viele Autoren halten daher Formolfixierung für besser (BRAarud 1958, PAasche 1960). Eine Trennung von toten und lebenden Zellen konnte bei der schnellen Zählung am fixierten Material nicht durchgeführt werden. LuND et al. (1958) halten den Fehler daraus für klein und vernachlässigen ihn gegenüber der natürlichen Heterogenität. $\mathrm{Da} ß$ er auch größer werden kann, zeigt GrIM (1939). In den Frühjahrsproben könnten diese beiden Fehlerquellen eine Rolle spielen, daneben auch die Anwesenheit von Detritus-Chlorophyll und wechselnde chemische Zusammensetzung der Diatomeen im Verlaufe der Blüte.

Im Herbst sind die großen. Unterschiede in der Abschätzung des Planktons durch Chlorophyll- und Planktonzählung klar an das Vorherrschen der Ceratien gebunden; sie werden nicht im Bodenwasser vom 8 . bis 18 . September beobachtet, wo Rhizosolenia dominiert. Zählfehler können diese Unterschiede nicht erklären, weil die Lugolfixierung, für Diatomeen oft nur mäßig brauchbar, für Peridineen besonders günstig ist, was sich auch in der guten Erhaltung der Ceratien bestätigen ließ. Die Ermittlung der Zellzahl ist bei den großen, einzeln liegenden Ceratien besonders zuverlässig. Auch deren Volumina sind innerhalb einer Art recht konstant; dies und das Fehlen der großen Vakuole wie bei Diatomeen läßt eine befriedigende Umrechnung von Zellzahl auf Volumen zu, so daß bei den Umrechnungsfaktoren der Fehler nicht gesucht werden kann. Für die beiden hier allein entscheidenden Ceratienarten werden folgende Volumina angegeben:

$$
\begin{array}{lrl}
\text { Ceratium tripos } & 100000 \mu^{3} & \text { alle Autoren ibereinstimmend } \\
\text { Ceratium fusus } & 36000 \mu^{3} & \text { LOHMANN (1908) } \\
& 25000 \mu^{3} & \text { HAGMEIER (1960) }
\end{array}
$$

Hagmerer gibt die Abmessungen der Plankter an, deren Volumen er ermittelt hat. Da sie mit den hier gefundenen Zellgrößen übereinstimmen, fand HAGmEIERs Faktor Verwendung (die Berechnung mit dem höheren. Wert von. LoHmanN ist in Abbildung 36 zum Vergleich eingetragen).

Daß Fehler durch Mitzählen toter Zellen im Herbst entstanden sind, ist unwahrscheinlich, da deren Anteil gerade zum Beginn der Planktonblüte am kleinsten ist (GRIM 1939). Vielmehr ist gut denkbar, daß die dickbepanzerten Ceratien bei der Chlorophyll- und Eiweißbestimmung nicht vollständig extrahiert werden. Die Literaturangaben machen dies wahrscheinlich. Richards \& THOMpson (1952) fanden bei der Chlorophyllextraktion in 90prozentigem Aceton nach 24 Stunden keine nachträgliche Lösung mehr; Gardiner (1941) stellte aber bei mikroskopischer Kontrolle fest, daß zwar Diatomeen vollständig, Dinophyceen jedoch unvollständig extrahiert werden. Ober die Vollständigkeit der Hydrolyse des Planktoneiweißes mit $\mathrm{NaOH}$ in den dickschaligen Ceratien kann hier leider noch keine Aussage gemacht werden.

Die unvollständige Extraktion wird hier als Hauptgrund für die niedrigen Werte von Chlorophyll und Eiweiß angesehen. Doch muß auch der Gehalt der Ceratien an Eiweiß und besonders Chlorophyll diskutiert werden, der je nach Lichtangebot, Ernährungsweise und anderen physiologischen Bedingungen gerade bei Peridineen stark 
schwankt (Yentsch \& Ryther 1957). Von den Peridineen, gerade auch den Ceratien, ist die Fähigkeit zur mixo- und heterotrophen Ernährungsweise bekannt, die sich auf den Chlorophyllgehalt auswirken muß. Die Tiefenlage der Planktonwolken und deren Anlehnung an die Sprungschicht (Abb. 18) sprechen für eine solche Ernährung besonders für Ceratium tripos.

Eine niedrige photosynthetische Aktivität scheint die geringe $\mathrm{PO}_{4}$-Zehrung der Ceratien und ein offenbar extrem niedriger Chlorophyllgehalt während der doch recht erheblichen Planktonwucherung anzuzeigen. Doch werden für Ceratium fusus die primären Maxima in der Oberschicht nicht durch heterotrophe Lebensweise erklärt. Daß gerade während der Blüte der Eiweißgehalt so niedrig bleibt und sogar noch abfällt, dürfte hier am abfallenden Zooplanktonanteil liegen; die hier häufigsten Copepoden filtrieren ja weniger die großen Phytoplankter (wie Ceratien), sondern vielmehr nur die kleinsten Formen und Detritus ab. Im Herbst 1961 wird man es hier wahrscheinlich mit sowohl mangelhafter Extraktion der Planktonzellen, als auch deren niedrigem Gehalt an Chlorophyll zu tun haben. Die Unsicherheit der Aussagen in diesem Kapitel wird man erst nach Versuchen über die Extraktion dickschaliger Peridineen im verschiedenen physiologischen Zustand und der $\mathrm{NaOH}-\mathrm{Hydrolyse}$ an getrocknetem und frischem Peridineenplankton beseitigen können.

Die gefundenen Unterschiede erscheinen für die Produktionsbiologie des Planktons unseres Gebietes sehr wichtig, gibt es doch eine Reihe von widersprüchlichen Befunden über die relative Höhe des Frühjahrs- und Herbstmaximums, die ihre Ursache in der Methode haben dürften. LoHMANN (1908) findet mit sorgfältigen, quantitativen Planktonfängen vor Laboe (Ausgang der Kieler Förde) nach Umrechnung auf Plasmavolumen zwar hohe Werte im Frühjahrsmaximum, noch höhere aber im Herbst (September). STEEMANN NiELSEN (1958) stellt bei Primärproduktionsmessungen über mehrere Jahre im nahen Großen Belt ebenfalls ein Maximum im Herbst fest. KREY (1961) und BANSE \& KREY (1962) dagegen finden mit chemischen Methoden in langjährigen Beobachtungen bei Boknis Eck, dem Ausgang der Eckernförder Bucht, das Maximum dieser Werte meist im Frühjahr, ebenso wie GILLBRICHT beim F.S. „Flensburg" mit gleicher Methode.

BANSE \& KREY (1962) erklären die gegensätzlichen Befunde mit verschiedener Methodik so, daß hier mit Eiweißbestimmungen auch Bakterien erfaßt wurden, bei LoHMANNs Zählungen nicht. Gerade bei hohen Detritusmengen kann der Eiweißgehalt der anhaftenden Bakterien durchaus eine Rolle spielen und wird gerne zur Erklärung herangezogen. Zeitzschel (1964) findet in Sinkstoffen, die er in der Eckernförder Bucht kurz über dem Boden auffing, sowie an der Sedimentoberfläche oft nennenswerte Eiweißmengen mit der Biuret-Methode. Nicht nur verschiedene Bakteriendichten, sondern auch deren unterschiedliche Aktivität bei der im Herbst gegenüber dem Frühjahr $10^{\circ}$ bis $15^{\circ} \mathrm{C}$ höheren Temperatur werden diskutiert. Auch ZeITzSCHEL erklärt durch die höhere Zersetzungsgeschwindigkeit die Unterschiede zwischen Zellzahl and chemischen Werten.

StEEMANN Nielsen (1940) findet bei dänischen Feuerschiffen in Kurven vom Plasmavolumen und Chlorophyll große Schwankungen und keinen parallelen Verlauf. HAGMEIER (1960) beobachtet mehrfach nur geringe Übereinstimmung berechneter Trockengewichte mit den verschiedenen Methoden. Unsere Untersuchungen scheinen 
geeignet, diesen Punkt näher zu beleuchten, da hier alle drei in Frage kommenden Bestimmungsarten verglichen und durch ihren zeitlichen Ablauf in verschiedenen Tiefen analysiert werden konnten.

\section{Begrenzende Faktoren der Planktonentwicklung derdrei Untersuchungsperioden}

Für die drei Untersuchungsperioden sollen hier die wichtigsten Faktoren, die man als begrenzend für die Planktonentwicklung kennt, zusammen mit den Planktonwerten in ihrer zeitlichen Veränderung aufgetragen und diskutiert werden (Abb. 37 bis 39). Stabilität und Strom werden aus dem hydrographischen Teil ersehen. Vertikalturbulenz (durch Windseehöhe angedeutet), Licht (Globalstrahlung nach Aktinographenwerten) und Phosphat werden neben der Plankton-bzw. Chlorophyllkurve für die euphotische Schicht dargestellt.

Das Kapitel über den Vergleich berechneter Trockensubstanzwerte zeigt, daß nicht alle drei Bestimmungen (Chlorophyll, Eiweiß, Planktonzählung) gleichzeitig die wirklich vorhandene Planktonpopulation treffend charakterisieren, sondern of große Unterschiede in der absoluten Höhe und sogar im relativen Verlauf der Kurven auftreten können. Es sollte die Möglichkeit geben, zu entscheiden, welche Kurven die Population am besten beschreiben. Dies wird jeweils hier zu Beginn der Besprechung einer Untersuchungsperiode vermerkt.

\section{März 1961}

Die Schäden durch Lugolfixierung des Zählplanktons dürften hier am größten gewesen sein. Die Berechnung aus Plasmavolumen zeigt oft einen etwas unwahrscheinlichen Verlauf. Chlorophyll und Eiweiß, das hier praktisch ganz vom Phytoplankton stammen dürfte, gehen dagegen meist parallel und sind gut vergleichbar. Sie geben hier ein besseres Plankton-Maß ab. Es wird daher die Chlorophyllkurve der gemittelten Werte 0 bis $7,5 \mathrm{~m}$ als Bezug gewählt (Abb. 37).

Die Blüte war zu Beginn der Beobachtungszeit wohl nur wenige Tage alt. Die starken Gradienten zeugen von der geringen vertikalen Mächtigkeit der entstandenen Planktonwolken, wie sie bei einer so dünnen Assimilationszone erwartet werden müssen. Zur Erklärung sind die Verhältnisse Ende Februar zu beachten: Bis zum 22. Februar war es sehr ruhig, am 22. kam Südostwind 3 bis 4 auf, am 23./24. herrschte starker Einstrom bei 6 Windstärken. Ab 26. Februar fand man bei schwachen Westwinden kräftigen Ausstrom bis Ende des Monats. Hier mag, bei starker Sonneneinstrahlung vom 25 . bis 27 , der Beginn der Blïte vermutet werden, wobei allerdings diese durch Planktoneinschub aus küstennahen Gebieten oder der Innenförde durch den Ausstrom beschleunigt sein kann.

Im März ist mehrfach der Einfluß der beiden wichtigsten begrenzenden Faktoren - Turbulenz und Lichtangebot - auf die Planktonverteilung zu erkennen. Die hellen Tage 8 . und 15. bis 17. März haben bei gleichbleibender, der 19. bei abfallender Wind- 
see ein Ansteigen des Chlorophylls zur Folge. Die Windtage 12. und 18. März lassen den Planktongehalt in der Assimilationszone abfallen, indem sie ihn in der Wassersäule verteilen und der euphotischen Zone entziehen. Der Lichtabfall am 18. und 12. März ist nur gering, könnte aber schon die hemmende Wirkung der Turbulenz auf die Produktion verstärken. Da die windigen Tage besonders bei Westwind oft stark bewölkt sind, summieren sich hier zwei negative Wirkungen auf das Plankton und können bei Vernachlässigung des einen eine zu große Wirkung des anderen Faktors vortäuschen (z. B. bei fehlenden Lichtmessungen). Am 18. März reicht die Durchmischung

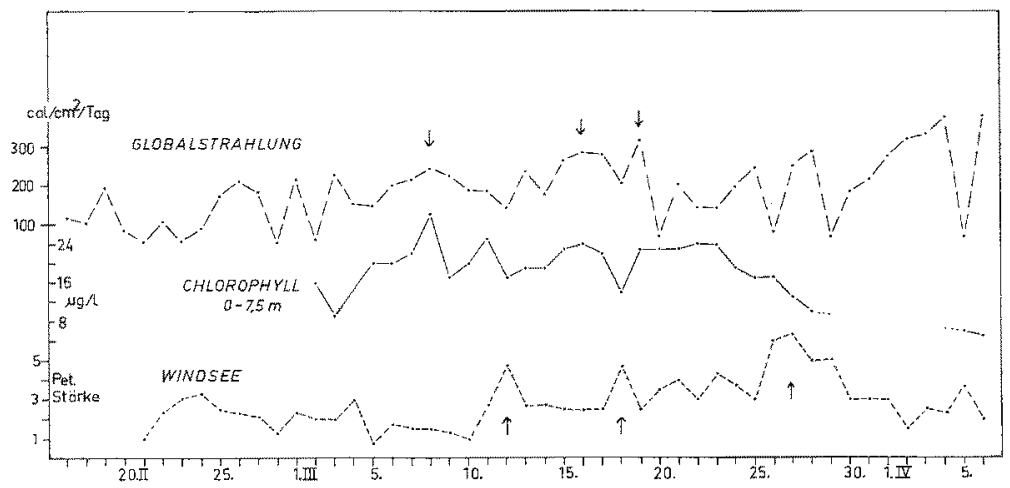

Abb. 37: März 1961: Phytoplanktonentwicklung (Chlorophyllwert) und die wichtigsten Umweltfaktoren

bis zur Sprungschicht $(20 \mathrm{~m}$ ), was durch die homogene Vertikalverteilung des Planktons wahrscheinlich gemacht wird. Daß diese Tiefe hier ähnlich der kritischen Tiefe werden kann, ist anzunehmen, da die 24-h-Kompensationstiefe bei $2,5 \mathrm{~m}$ gefunden, die kritische Tiefe auf 5- bis $8 \mathrm{mal}$ höher, also 12,5 bis $20 \mathrm{~m}$ geschätzt wird. Nach der Vermischung des Planktons und dem dadurch bedingten Abfall des Bestandes in der euphotischen Zone am 18. März können sich bei der tiefreichenden Turbulenz bis zur Sprungschicht keine Planktonmaxima in der euphotischen Schicht ausbilden. Die Absinkverluste scheinen durch die Sprungschicht niedrig zu sein, so daß sich hier ein ansehnlicher Bestand halten und noch etwas vergrößern kann, obwohl die Mischungstiefe nur wenig geringer als die kritische Tiefe ist.

Da der Abfall der Planktonmenge in der Gesamtwassersäule am 20., der in der Oberschicht am 23. und in der Mittelschicht am 24. März beginnt, also vor dem Einsetzen des starken Windes, kommen nur Lichtmangel und Nährstofferschöpfung als Erklärung in Frage. Man findet in diesem Frühjahr bei stetigem Ausstrom ein Aufsteigen von salzreichem Tiefenwasser während des ganzen März, wie der Oberflächensalzgehalt deutlich zeigt (Abb. 2b). Diese ständige Beimischung des nährstoffreichen, aufquellenden Tiefenwassers dürfte die Nährstofferschöpfung sehr verlangsamen. Zudem gelangt in der Mischungszone durch dauernde Turbulenz stets das in Sprungschichtnähe remineralisierte Phosphat sicher wieder nach oben. Wahrscheinlicher ist, 'daß für diese Phase das Licht die Planktonentwicklung begrenzt, das ab 20. bis 26. 
März viel niedriger als in der Woche vorher gefunden wird. Eine geringe Anderung der Kompensationstiefe muß bei diesen Verhältnissen bei gleichbleibender Mischungstiefe schon entscheidende Wirkung haben (SVERDRup 1953, GILlBRICHT 1955). Während sich die Plankton-Vermischung durch Turbulenz sofort bemerkbar macht, geschieht die Beeinflussung durch Licht langsamer. Da aber die Schöpfproben am Nachmittag genommen wurden, kann sich das Lichtmaximum des gleichen Tages schon ausgewirkt haben. Es scheint also eine Gegenüberstellung der Werte des gleichen Tages gerechtfertigt. Das „natürliche" Ende der Blüte läßt sich nicht verfolgen, da der Wind ab 25. besonders 26. März, die Schichtung zerstört und das Plankton in der Wassersäule verteilt. Trotz starken Lichtangebots am 27./28. fallen Chlorophyll und Eiweiß weiter. Hier kann Nährstofferschöpfung nicht mehr begrenzen, da die Turbulenz das Bodenwasser erreicht.

Während der Tage ohne Beobachtungen mag durch ansteigendes Strahlungsangebot und fallende Turbulenz ein neuer, kurzer Produktionsanstieg stattgefunden haben, der sicher aber nicht stark war, da am 5. April ohne vorherige Windstörung niedrige Chlorophyll- und Eiweißwerte gefunden werden. Die beiden Beobachtungstage 5. und 6. April lassen keine Schlüsse auf die Weiterentwicklung des Planktons zu. Keine der drei gemessenen Komponenten Chlorophyll, Eiweiß und Zählplankton zeigt hier eine zu erwartende Reaktion auf die beiden Lichtextreme und die Windsee. Es ist nicht ausgeschlossen, daß sich eine zweite Blüte nach einer hier schon beginnenden Stabilisierung ausbildet. Die hydrographische Lage - Ausstrom an der Oberfläche und Nachfließen salzreichen Bodenwassers - macht dies sogar wahrscheinlich.

\section{März 1962}

Die Plasmavolumenwerte drücken sich ab 18. März nicht mehr im Chlorophyllgehalt aus. Sie werden hier für die Oberschicht getrennt ausgewertet. Neben den Kurven der Windsee-Höhe, des Lichtangebotes und des Phosphats kommen also die Plasmavolumen-Mittel von 0 bis $7,5 \mathrm{~m}$ und die Chlorophyll-Mirtel von 10 bis $17,5 \mathrm{~m}$ zur Darstellung (Abb. 38).

Daß der Beginn von zunächst inselartigen Wucherungen der Diatomeen in $10 \mathrm{~m}$ nicht an der Oberfläche bei optimalem Lichtangebot gefunden wird, ist keineswegs zu erwarten. Eine solche Gedeihtiefe ist selbst bei der Annahne, daß es sich hier um ausgesprochenes Schattenplankton (Winterende!) handelt, aus den Lichtwerten (Abb. 26) nicht zu verstehen. Im Gegensatz zum März 1961 ist diese Zeit sehr hell, an hellen Tagen nämlich stets über 300 bis $400 \mathrm{cal} / \mathrm{cm}^{2} /$ Tag. Fehler können durch Übernahme der Werte von Wyk/Föhr und der Schätzungen der Durchlässigkeit entstanden sein. Sie werden jedoch keine große Bedeutung haben und rechtfertigen kaum die Annahme einer viel höheren Kompensationstiefe. Fehler in der Schätzung der Kompensationsenergie können durch die Unterschiede der Literaturangaben bei dem hier gefundenen trüben Wasser nicht zur Erklärung ausreichen.

Der Chlorophyllanstieg in der ganzen Wassersäule am 10. März kann nur in Verbindung mit dem kräftigen Einstrom und der steil abfallenden 20\%-Isohaline gedeutet 
werden (Abb. 24a), zumal das Licht am 8. bis 12. März besonders schwach ist (Abb. 26). Es scheint hier allochthones Plankton mit dem Gegenstrom unter der Sprungschicht aus Westen gekommen zu sein; ähnliches darf man wohl auch von den folgenden Planktonwolken in $10 \mathrm{~m}$ Tiefe annehmen. Da ein besonders planktonreicher Wasserkörper am Feuerschiff nicht festgestellt wurde, könnte man die Herkunft dieser Planktonwolken aus Küstennähe vermuten, wo sie beim Erscheinen des salzarmen Wassers aus Osten unter die Sprungschicht gelangen konnten. Es ist dann damit zu rechnen, daß durch

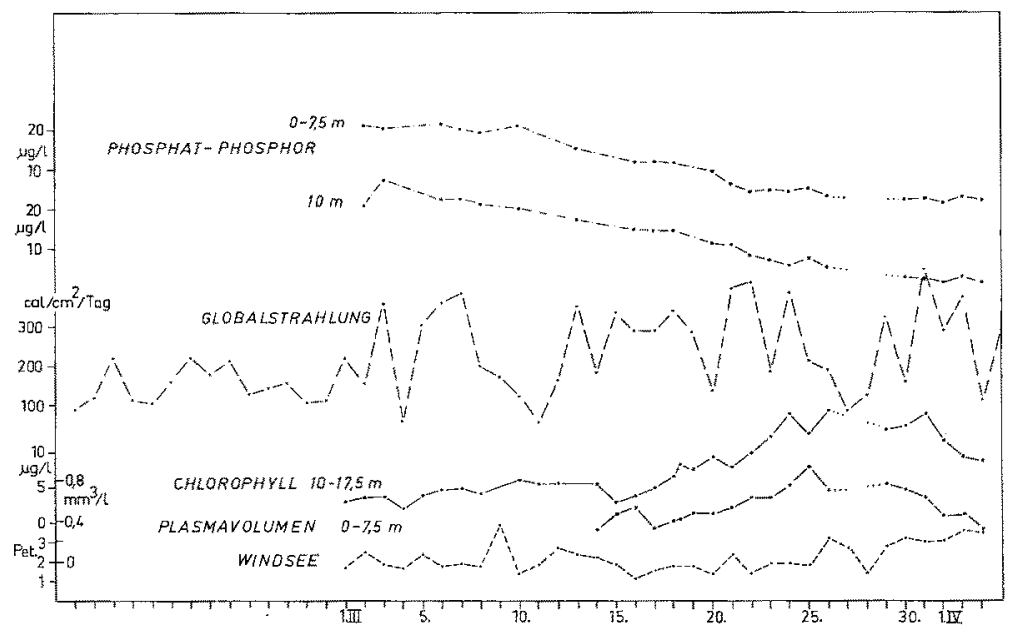

Abb. 38: März 1962: Phytoplanktonentwicklung (Chlorophyllwert, Plasmavolumen) und die wichtigsten Umweltfaktoren

entgegengesetzt übereinanderfließende Strömungen Wirbel entstehen, welche die Plankter festhalten und vor dem Absinken bewahren (WYTRKI 1950). Damit wäre allerdings höchstens ein gleichbleibender, nicht aber ein kräftig wachsender Bestand erklärt, der wahrscheinlich durch kontinuierlichen Zustrom immer planktonreicheren Wassers vorgetäuscht wird.

Der salzarme Wasserkörper, der an der Oberfläche von Osten eingeströmt war (Abb. 24), ist offenbar sehr arm an Plankton. Trotz des großen Lichtangebotes entwickelt sich in der stabilisierten Oberschicht zunächst keine Blüte, obwohl bei Verhinderung der Vertikalkonvektion durch die hochgelegene Sprungschicht optimale Lichtenergie und noch genügend Nährstoffe verfügbar sein müßten (Abb. 27). Erst ab 20. März wird durch Planktonzählung der Beginn einer Wucherung an der Oberfläche festgestellt, was sich auch im schnellen Abfall des Phosphats in der Oberschicht ausdrückt. Allerdings läßt die Phosphat-Kurve bereits am 12. März, also dem Beginn der Stabilisierung, einen höheren Verbrauch ersehen (Abb. 27), als nach dem Planktonbestand zu vermuten wäre. Das Lichtangebot steigt zwar am 21. stark an, doch ist darin kaum die Ursache der Wucherung zu sehen, da schon vorher bei gleicher hydrographischer Bedingung ebensoviel vorhanden war, und sich nachher ein Lichtabfall beim Plankton nicht bemerkbar macht. 
Der Einfluß der meist sehr niedrigen Windsee läßt sich nur am 26. März nachweisen, wo er für die Oberschicht wichtig wird. Den Abfall der Planktondichte erkennt man am 30./31. März in Verbindung mit einem raschen Stromwechsel, wobei der Anstieg der Windturbulenz und Abfall der Sprungschichthöhe diese Entwicklung erklärt. Der sprunghafte Anstieg des Peridineenanteils (Abb. 32) kommt durch die horizontale Zufuhr einer Population, die weiter westlich lebte, zustande. Der Ausstrom von maxi$\mathrm{mal} 720 \mathrm{~m} / \mathrm{h}$, meist wohl nur die Hältte, bringt also rasch eine andere Population zum Feuerschiff, was wieder für die inhomogene Verteilung der Plankter in diesen Gewässern spricht.

\section{Herbst 1961}

Bei der Auswertung der Trockensubstanz-Kurven stellt sich für diese Periode das Plasmavolumen der Peridineen als die sicherste gemessene Größe des Planktons heraus (Abb. 39). Beim abfallenden Lichtangebot im Herbst ist der Lichtfaktor als Begrenzung beim Beginn der Blïte meist sicher nicht anzunehmen. Immerhin ist in Einzelfällen nach dunklen Tagen bei sonst adäquaten Bedingungen eine Auslösung der Wucherung durch einsetzende stärkere Strahlung denkbar. Im allgemeinen ist es das Nährstoffangebot,

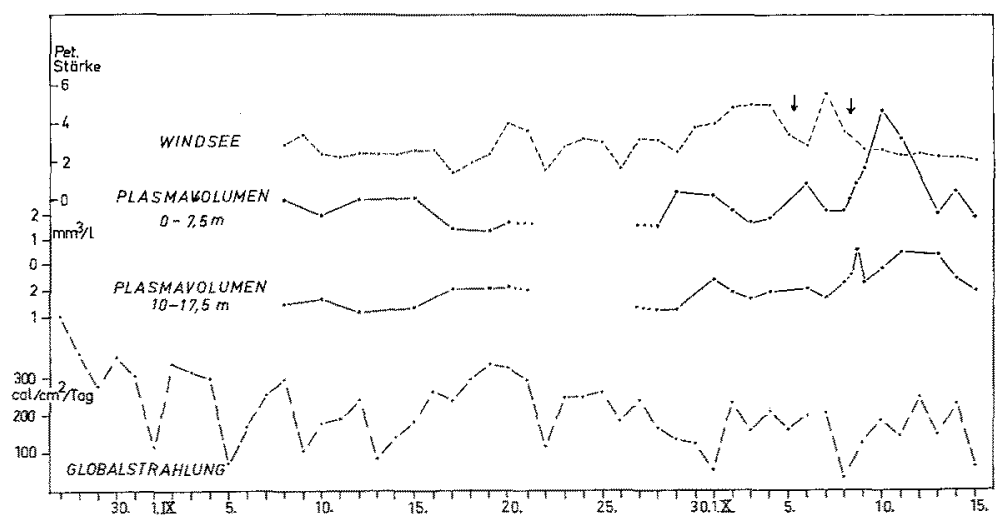

Abb. 39: Herbst 1961: Phytoplanktonentwicklung (Plasmavolumen) und die wichtigsten Unweltfaktoren

das im Herbst als wichtigster begrenzender Faktor anzusehen ist. Daher werden die Betrachtungen des Phosphathaushaltes hier eingehender durchgeführt. Es zeigte sich, daß nur geringer Phosphatgehalt für das Planktonwachstum zur Verfügung stand. Die $\mathrm{PO}_{4}$-Isoplethen lassen aber trotz der hohen Planktonzahlen keine deutliche PhosphatZehrung erkennen (Abb. 15).

Der Vergleich mit der Turbulenztiefe, die hier bei homogenem Wasser gut durch die Höhe der Windsee - die ja bereits Windrichtung und -stärke in einem Kurvenzug vereinigt - dargestellt wird, gibt dagegen Aufschluß über die Auslösung der Wucherung. Am 29. September ist die Oberschicht bereits etwas mit $P O_{4}$ angereichert 
(Abb. 15). Trotz des abfallenden Lichtangebotes steigt der Planktonbestand wohl durch verringerte Turbulenztiefe. Diese nimmt dann wieder zu und verhindert ein Weiterwachsen des Planktons, was aus den gegenläufigen Kurven am 2. bis 4. Oktober deutlich wird. Nach einem Ansteigen und erneutem Abfallen der Windstärke beginnt die starke Wucherung sofort am 8. Oktober. Hier muß allerdings die erwähnte Störung beachtet werden, die am 8. die Deutung der Verhältnisse erschwert. Da sich der Wasserkörper aber in seinen hydrographischen Daten nicht von denen an den vorigen und folgenden Tagen unterscheidet, sondern diese nur in den optischen Eigenschaften verschieden sind, scheint die Erklärung als kurzer Zustrom von Wasser, das über dem Kalkgrund oder an der Gelting Birk mit Seston angereichert wurde, gerechtfertigt. Dieses Wasser enthielt bereits mehr Plankton, das sich im flachen Wasser wohl rascher entwickeln konnte. Es muß also getrennt werden zwischen der Zufuhr von Plankton, die bei dem bereits vorhandenen hohen Bestand aber nicht als entscheidend angesehen werden darf, und dem Weiterwachsen am 9., 10. und 11. Oktober. Dieses Wachstum in der euphotischen Schicht beweist, daß die Bedingungen jetzt adäquat geworden sind für eine Blüte. Dies erklärt sich zwanglos aus der stark abgefallenen Windsee.

Die Beendigung der Blüte kann nicht durch Phosphatmangel verursacht worden sein, wie Isoplethen und Mittelwerte zeigen. 4 bis $6 \mu \mathrm{g} P / 1$ sind vorhanden, kaum weniger als vorher beim Beginn der Blüte. Dazu folgende Mittelwerte (Tab. 6).

Tabelle 6

$\mathrm{PO}_{4}$-Mittelwerte im ungeschichteten Wasser $(\mu \mathrm{g} \mathrm{P} / \mathrm{l})$

\begin{tabular}{|cccccccccccc|}
\hline \multirow{2}{*}{ Wassertiefe } & \multicolumn{2}{c}{ September } & \multicolumn{2}{c}{ Oktober } & & & & & & & \\
& 28. & 29. & 1. & 2. & 3. & 4. & 6. & 8. & 10. & 11. & 13. \\
\hline $0-7,5 \mathrm{~m}$ & 0 & 3,3 & 2,7 & 4,7 & 5,8 & 5,9 & 5,1 & 6,1 & 4,4 & 4,2 & 3,6 \\
$10-17,5 \mathrm{~m}$ & & & & 4,9 & 5,6 & 6,4 & 6,3 & 6,5 & 5,2 & 4,9 & 4,6 \\
\hline
\end{tabular}

Der neue Wasserkörper (Abb. 12a), schon hinreichend als Ostseewasser charakterisiert (plankton- und $\mathrm{PO}_{4}$-arm), iberschichtet das Wasser mit der Ceratienblüte. Dic starke Sprungschicht riegelt das Plankton vom Oberflächenwasser ab, und läßt, da sie rasch tiefer sinkt und die euphotische Zone einnimmt, die Blüte an Lichtmangel zugrunde gehen. Interessant sind die starken Planktonkonzentrationen in der Sprungschicht, wo Ceratien sich offenbar halten können oder aktiv hinschwimmen und dort noch genïgend Licht erhalten. In der Sprungschicht (7,5 bis $10 \mathrm{~m}$ ) wird mit Sicherheit das Licht zum begrenzenden Faktor (die 24-h-Kompensationstiefe liegt am hellen 14. Oktober bei $6 \mathrm{~m}$ ). Immerhin ist dort, besonders bei aktiver Zuwanderung von unten, die Ceratienansammlung am 14 . Oktober in 7,5 $\mathrm{m}$ nicht $\mathrm{zu}$ verwundern. Dennoch scheint diese Planktonwolke am 15 . bereits abgesunken zu sein und in 12,5 $\mathrm{m}$ die euphotische Zone verlassen zu haben. Die Ceratien durchwandern aber nicht die Sprungschicht, um in besseren Lichtgenuß zu kommen. Man kann hier natürlich nicht sagen, ob sie der Salzgehaltsgradient oder der Nährstoffmangel dieses Wasserkörpers daran hindert. 


\section{DISKUSSION}

\section{Räumlicher und zeitlicher Abstand der Probennahme}

Daß man für Planktonproben noch immer auf eine punktförmige Entnahme angewiesen ist, erweist sich gerade im geschichteten Wasser bei der großen Heterogenität der Planktonverteilung als nachteilig. Fänge mit dem Planktonrecorder vermögen nur großräumige Unterschiede in der horizontalen Verteilung zu erfassen. Nur uber optische Registrierungen kam man zu wertvollen Aufschlüssen über die Feinverteilung von Partikelansammlungen, wie gerade für unsere Gewässer WYRTKI (1950) zeigt. Auch JosePH (1950) und KREY $(1952,1954)$ beobachten durch Messungen des physikalischen Extinktionskoeffizienten mit dem D-Gerät erstaunliche Gradienten in der Trübungsverteilung, die meist von abiogenen Teilchen, besonders feinster mineralischer Trübe $<10 \mu \varnothing$, verursacht wird. Es fehlt nicht an Versuchen, über optische Messungen zur Abschätzung der Sestonzusammensetzung im Meer zu gelangen (GILlbRICHT 1959). Bei Durchlässigkeitsmessungen in landfernen Meeresgebieten, wo praktisch alle Schwebstoffe vom Plankton stammen, läßt sich bis zum gewissen Grade die gefundene Extinktion auf bestimmte Partikelgrößen oder gar Planktongruppen beziehen. Man kann so eine spezifische Extinktion für Zoo- und Phytoplankton, große und kleine Formen, oder Detritus finden.

Die in unserem Gebiet meist übliche Probennahme mit $5 \mathrm{~m}$ Tiefenabstand muß für biologische Untersuchungen in den meisten Fällen als unzureichend angesehen werden. Dies zeigen unsere Werte mit 2,5 m Abstand besonders bei wolkenförmiger Verteilung des Planktons im März und im Herbst 1961, wo bei $5 \mathrm{~m}$ Abstand starke Maxima der Beobachtung entgangen wären. In Verbindung mit den geringen Tiefen der euphotischen Schicht wundert es auch nicht, wenn Planktonwolken von nur 1 bis $2 \mathrm{~m}$ Dicke anzutreffen sind. Leider war die Verarbeitung von mehr als $2 \times 11$ Proben täglich auf dem Feuerschiff nicht möglich, weswegen sich ein noch engerer Probenabstand verbot. Nur bei stark turbulentem Wasser genügen meist Proben in $5 \mathrm{~m}$ Abstand.

Wie aus den hydrographischen Untersuchungen in der Flensburger Förde hervorgeht, kann hier auch eine tägliche Probennahme manchmal kein zutreffendes Bild der Planktonsequenz liefern. Tägliche Beobachtungen gehören zu den intensivsten bisher langfristig vorgenommenen. Kurzfristige Untersuchungen auf Ankerstationen und von Feuerschiffen wurden in unserem Gebiet von GILIBRICHT und WYRTKI durchgeführt. GILLBRICHT (1951) zeigt die Veränderung von Planktonwolken bei dreistündlicher und täglicher Probennahme, WYRTKI (1950) ähnliches für die Trübungsverteilung. GILIBRICHT findet dabei isolierte Planktonwolken von nur einigen 100 bis wenige $1000 \mathrm{~m}$ Länge (siehe auch BaInbridge 1957, KIERst'EAd \& SlobodkIn 1953). Uber kurzfristige Anderungen in der Produktionsleistung und im Chlorophyllgehalt des Planktons im Tagesgang berichten MCALLISTER (1963) und YENTSCH \& RYTHER (1957).

\section{Zusammensetzung von Seston, Detritus und Plankton}

Der Begriff "Seston" wurde von Kolkwrtz (1912) in die Limnologie und von KREY (1949) für die Meeresforschung eingeführt und bezeichnet „alles Absiebbare aus 
dem Wasser". Schwieriger ist die Definition des Detritus, der nach KREY alle ungelösten Zersetzungsprodukte der Organismen und mineralische Partikel enthält, wogegen STRICKLAND (1960) ihn als "schwebendes Material organischer Herkunft, das dauernd zur Reproduktion unfähig ist", definiert, mineralische Partikel also ausschließt.

Unsere Methoden können organischen nicht vom anorganischen Detritus trennen. Zieht man - wie hier geschehen - das Planktongewicht, wie es sich aus Eiweißbestimmungen errechnet, vom Sestongewicht ab, erhält man einen „Detritus“-.Wert nach KREY, der biologisch stark wechselnde Bedeutung hat, je nachdem, ob das Seston viel (Landnähe) oder wenig mineralische, abiogene Teilchen enthielt. Im ersten Fall kann das Sestongewicht weitgehend dem Gewicht kleiner Sand- und Tonteilchen, im zweiten dem des Planktons und seiner Abbauprodukte entsprechen. Nur im letzten Fall berechnet man also den organischen Detritus, der biologisch besondere Bedeutung hat wegen seines Nährwertes für flitrierende Organismen und wegen seines vieldiskutierten Bakterienaufwuchses. Diese Bakterien könnten bei der Biuret-Methode der Eiweißbestimmung die Werte erhöhen, ohne daß sich mit mikroskopischen Planktonzählungen gleichhohe Beträge an organischer Substanz finden ließen. Mineralische Partikel können gelöste organische Stoffe adsorbieren und somit zu solchen Konzentrationen anreichern, daß Bakterien sie ausnutzen können. Neben dieser biologischen Bedeutung mineralischer Teilchen als Träger eines Mikroflora-Aufwuchses dürfte jedoch die indirekte über die Beeinflussung des Lichtklimas im Wasser für produktionsbiologische Fragen in unseren Gewässern wichtiger sein.

BANSE (1962) betont die Notwendigkeit der Kombination chemischer und biologischer Planktonuntersuchungen. Auf die Kenntnis der Artzusammensetzung zu verzichten, wie es bei der Zusammenzählung von Chlorophyll- und Eiweißgehalten naheliegend ist, hält er nicht für zulässig. BANSE findet auch, daß die Summierung der Plankter über das Plasmavolumen sinnvoll ist; der Jahresgang des Plasmavolumens und der Assimilation im Großen Belt (STEEMANN Nielsen 1958) entsprechen sich, was nicht selbstverständlich ist, da verschiedene Arten ja unterschiedlich aktives Plasma haben könnten.

\section{Vertikalverteilung des Planktons}

Der Einfluß der Sprungschicht auf die Planktonvertikalverteilung wird von mehreren Autoren erwähnt. Sorokin (1960) zeigt Vertikalkurven mit und ohne Sprungschicht, Gessner (1948) an Seen solche, bei denen die maximale Produktion über oder unter der Sprungschicht stattfand, wobei sich ähnliche Vertikalkurven wie bei den hier vorgelegten Untersuchungen vom März 1961 und 1962 finden. Nicht nur die Absinkhemmung, sondern auch höhere Teilungsraten durch Nährstoffzufuhr von unten durch die Sprungschicht oder Planktonzerfall wurden für die Maxima in der Sprungschicht verantwortlich gemacht. Stets wurde ein Anstieg der Photosynthese in der Sprung-1 schicht beobachtet.

WYRTKI (1950) stellt die dynamische Erklärung von Trübschichten in der Sprungschicht für unser Gebiet in den Vordergrund. Nach STOMMEL (1949, zit. nach WYRTKI) bilden sich an der Grenzschicht zweier Wasserkörper, die sich in verschiedener Richtung 
übereinanderbewegen, Konvektionszellen, welche die Partikel, die einmal dort hineingeraten sind, festhalten. Ahnlich stellt sich bereits GRIM (1939) die Anreicherung des absinkenden Planktons im Bodensee in der thermischen Sprungschicht vor. GRIM beschreibt in seiner umfangreichen Studie uiber das Bodenseeplankton die Ausbildung primärer und sekundärer Maxima in der Vertikalverteilung, wie sie besonders gut nach Tagen mit starker Turbulenz erkannt werden können, wenn sich die Partikel je nach spezifischem Gewicht in bestimmten Horizonten anreichern. Ohne Schichtung wird nur das oberste Maximum primär, also durch verstärktes Zellwachstum bei günstigen Lebensbedingungen entstanden sein, während bei hydrographischer Schichtung zwei und mehr Maxima primär sein können. GRIM weist auch auf die Unmöglichkeit sauberer Trennung zwischen beiden Arten der Entstehung solcher Maxima hin, z. B. wenn sich Peridineen mixotroph in sekundären Maxima ernähren.

LENZ (1963) findet bei seiner Untersuchung der Echostreuschichten der westlichen Ostsee ebenfalls of Anreicherungen von Peridineen und kleinen Flagellaten in der Sprungschicht, also der kinetischen, zur heterotrophen Ernährung befähigten Formen, nicht aber von Diatomeen. GrLlbricht (1951) zeichnet eine Ceratium tripos-Wolke bei F. S. "Flensburg" in $17,5 \mathrm{~m}$, die nicht absinkt, die aber weit unterhalb des Kompensationspunktes liegen dürfte.

Die Fähigkeit zur Eigenbewegung der Peridineen wird yon RYTTER-HAsLE (1954) untersucht. Dinoflagellaten bewegen sich 5 bis $10 \mathrm{~m}$ pro $12 \mathrm{~h}$ vertikal. Ceratium fusus kann nach Peters (1929) $1 \mathrm{~mm}$ in 4 bis $6 \mathrm{sec}$, Ceratium tripos nach TsCHrn (1920) $1 \mathrm{~mm}$ in 4 bis $8 \mathrm{sec}$ schwimmen. Auch in unserem Gebiet kann also damit gerechnet werden, daß die Ceratienansammlungen im Herbst zum Teil auf Lokomotion zurückgehen.

Das Verhältnis lebender zu toter Zellen im Plankton wurde bereits angeschnitten. GrIM (1939) findet im Bodensee bis zu 50 bis $75 \%$ toter Zellen im Plankton der obersten $30 \mathrm{~m}$. Mit steigender Planktondichte fällt der Prozentsatz der toten Zellen, ein Minimum wird zu Beginn der Blüte, ein. Maximum kurz vor dem Tiefstand einer Art beobachtet. Wichtig ist, daß tote Zellen rascher als lebende absinken, was natürlich besonders bei Peridineen von Bedeutung ist, da nur tote wirklich sekundäre Maxima bilden.

\section{Populationsdichten während der Planktonblüten}

Vergleicht man die absolute Populationsdichte der Frühjahrs- und Herbstwucherungen des Phytoplanktons, so ergeben sich erhebliche Unterschiede. Findet man bei verschiedenen Autoren auch unterschiedliche Angaben über die relative Höhe des Planktonbestandes im Frühjahr und Herbst in der westlichen Ostsee, so liegen, wie erwähnt, methodische Ursachen nahe. Um die Unterschiede in der Dichte der Populationen zu beleuchten, mögen hier die langjährigen Beobachtungen des Planktonbestandes betrachtet werden, die KREY (1961b) an zwei Stationen in der Beltsee, nämlich "Boknis Eck" am Ausgang der Eckernförder Bucht und „Breitgrund“ (10 sm südöstlich vom Feuerschiff „Flensburg" entfernt) durchgeführt hat. Zwar wurde hier meist nur einmal im Monat eine Vertikalserie mit $5 \mathrm{~m}$ Probenabstand genommen, doch ergibt 
sich beim Vergleich der Mittelwerte in der Wassersäule in 7 Jahren eine Übersicht über die mittlere Planktonmenge und die Zeiträume ihres Vorkommens.

Der Planktonbestand wird hier ebenfalls durch Eiweiß- und Chlorophyllanalysen erfaßt, wobei die gleiche Methodik Verwendung fand. Die Frühjahrsgipfel der Jahreskurven werden von März bis April gefunden, die Herbstgipfel ganz überwiegend im September bis Oktober. Die Höhe der mittleren Eiweißwerte beträgt in den Frühjahrsgipfeln 90 bis $185 \mu \mathrm{g} / 1$ Albuminäqu. bei Station "Boknis Eck" und 135 bis $210 \mu \mathrm{g} / 1$ bei Station „Breitgrund“. Die entsprechenden Chlorophyllwerte (nur von 3 Jahren) sind 9 bis $13 \mu \mathrm{g} / /$ bei „Boknis Eck" und 7 bis $25 \mu \mathrm{g} / 1$ bei "Breitgrund". In den Herbstgipfeln werden auch von $\mathrm{K}_{\mathrm{REY}}$ nur die relativ geringen Werte von 70 bis $150 \mu \mathrm{g} / 1$ Albuminäqu. beobachtet. In der Chlorophyll-Jahreskurve sind nur im Frühjahr Maxima ausgeprägt. Doch wird ein langsamer Anstieg der Chlorophyllwerte von 2 bis $4 \mu \mathrm{g} / 1 \mathrm{im}$ September auf 5 bis $9 \mu \mathrm{g} / \mathrm{l}$ im November festgestellt. Messungen des Frühjahrsplanktons in den verschiedenen Jahren ergeben also ein Verhältnis der Mittelwerte von $1: 2$ bis $1: 3$, womit die wirklich vorhandenen Schwankungen allerdings nur stark gedämpft wiedergegeben sein dürften.

Die vergleichbaren Werte aus den eigenen Untersuchungen beim Feuerschiff „Flensburg “ lassen ähnliche Populationsdichten erkennen. Der mittlere Eiweißgehalt in der Wassersäule liegt hier im März 1961 bei $200 \mu \mathrm{g} / \mathrm{l}$, maximal $260 \mu \mathrm{g} / \mathrm{l}$ Albuminäquivalente, im März $1962120 \mu \mathrm{g} / \mathrm{l}$, maximal $160 \mu \mathrm{g} / \mathrm{l}$ und von Mitte September bis Mitte Oktober $120 \mu \mathrm{g} / \mathrm{l}$, maximal $140 \mu \mathrm{g} / 1$. Die mittleren Chlorophyllwerte betragen im März $196112 \mu \mathrm{g}$, maximal $16 \mu \mathrm{g} / \mathrm{l}$, im März $19626 \mu \mathrm{g}$, maximal $10 \mu \mathrm{g} / 1$ und im Oktober $19614 \mu \mathrm{g}$, maximal $6 \mu \mathrm{g} / \mathrm{l}$.

Die Zellzahlen in den hier beschriebenen Planktonblüten sind zwar hoch, erreichen aber nicht die Werte, die in anderen Meeresgebieten vorkommen. In den Frühjahren 1961 und 1962 werden in der Flensburger Förde 65 bis $100 \times 10^{5}$, maximal $150 \times 10^{5}$ beziehungsweise 15 bis $35 \times 10^{5}$, maximal $45 \times 10^{5}$ Skeletonema costatumZellen pro Liter gefunden. MARshall \& ORR (1929/30) zählten im Loch Strivan in Schottland $260 \times 10^{5}$, Grlbricht (1959) in der Irminger See sogar $300 \times 10^{5}$ Skeletonema-Zellen pro Liter.

\section{Ursachen des Blütebeginns}

In den Jahren 1935 bis 1940 wurde heftig über die Gründe der Entstehung der Planktonblüten besonders im Frühjahr debattiert. Es wurde deutlich, daß dafür nicht nur eine Ursache in Frage kam. AtKins (1928) nahm das Licht als kontrollierenden Faktor an. Marshall \& ORR (1928) sahen in der Tageslänge den wichtigsten Faktor (neben Strahlungsmenge und Stabilisierung). FøYN (1929) und GRAN (1932) fanden den Beginn der Blüte im stabilisierten Küstenwasser früher als weiter draußen und schrieben dies dem Nährstoffgehalt des Schmelzwassers zu. BraArud \& KLEM (1931) konnten diese Erklärungsmöglichkeit aber nicht bestätigen. Brgelow, LILLICK \& SEARS (1940) fanden ähnliche Unterschiede im Blütenbeginn im Gulf of Maine: Hier kam meist die Stabilisierung als Ursache in Frage. Den Einfluß der Abnahme der Strahlung in hohen geographischen Breiten (KImBaLL 1928) auf den Blïtebeginn erwähnten 
BraArud, GaARder \& Nordli (1958). Riley (1941, 1942) erkannte, daß eine kombinierte Wirkung von abnehmender Turbulenz und steigender Einstrahlung die Ursache der Frühjahrsblüte sein mußte. Er korrelierte Plankton und Stabilität des Wassers und fand eine Abhängigkeit. Die wichtige Arbeit von Sverorup (1953) behandelt das Problem theoretisch. Die kritische Tiefe ist maßgebend für die Blüte, sie muß gröRer als die Mischungstiefe sein. Seine Theorie stimmmte mit der Praxis bei Untersuchungen am Wetterschiff „M“ überein. Nach der "Stabilisation“ - der Unterdrückung der Turbulenz in der Wassersäule - hängt die Schnelligkeit des Anwachsens der Population von der Größe des Unterschieds der Mischungstiefe und der kritischen Tiefe ab. SvERDRup fand, daß der erste Wachstumsschub im Frühjahr bei Wetterschiff „M" durch die Vergrößerung der Kompensationstiefe, nicht durch Stabilisierung bedingt wurde, die dagegen die zweite Blïte verursachte.

CusHing (1962) unterschied drei Fälle der Wirkung von Energieeinstrahlung und Mischungstiefe auf den Produktionsverlauf im Frühjahr: (1.) Strahlung konstant (Kompensationstiefe und mögliche Produktionsrate konstant), Mischungstiefe verringert sich; (2.) Mischungstiefe konstant, Strahlungsenergie steigt (damit Kompensationstiefe und Produktionsrate); (3.) Strahlungsangebot steigt, während Mischungstiefe sich verringert. Bei ozeanischen Verhältnissen macht die meist große kritische Tiefe einen wesentlichen Teil der Mischungstiefe aus, die Anderung der Produktionsrate bleibt damit gering. Im ,trüben Küstenwasser dagegen ist die kritische Tiefe sehr klein. Hier kann zwar die Mischungstiefe ebenfalls sehr klein bleiben, besonders wenn die Möglichkeit haliner Schichtung besteht wie bei uns, kann jedoch auch viele Male größer werden. Die Produktionsrate kann sich also in trübem Wasser viel mehr ändern als in klarem. So läßt sich die starke Dynamik der Planktonentwicklung und die Anfälligkeit gegen schon geringe Turbulenzänderungen bei den hier untersuchten Perioden zwanglos erklären. Besonders bei Abwesenheit einer halinen Schichtung wundert es nicht, wenn bereits mäßige Windstärken trotz der windgeschïtzten Lage der Flensburger Förde die Planktonproduktion hier unterbinden oder abschwächen. Zudem wird ja gerade dann das Lichtklima schlechter durch Sestonaufwirbelung, was die Wirkung der Turbulenz noch wieder verstärken muß, da die Kompensationstiefe geringer wird. Es kommt ferner in unseren Gewässern die Heterogenität der Planktonverteilung hinzu, die Sverdrups schematischen Voraussetzungen eines homogen verteilten Planktons in den seltensten Fällen entspricht, wodurch wirkliche Änderungen der Produktion schwerer erkannt werden können.

Besonders deutlich werden diese Vorstellungen bei den Arbeiten von GILLBRICHT $(1955,1956)$, der die Planktonblüte in einem abgeschlossenen, brackigen Hafenbecken untersuchte, wo er die Schwierigkeiten der Identitätsbeweise eines Wasserkörpers, wie er sie früher auf F.S. „Flensburg“ kennengelernt hatte, umgehen konnte. Er wies eindeutig die Begrenzung des Planktonwachstums durch Turbulenz nach, die in diesem trüben Hafenwasser die Lage besonders instabil werden ließ. In seiner Arbeit beschreibt er auch ein Diatomeen-Maximum in einer neu entstandenen Sprungschicht, dessen primäre Natur wahrscheinlich gemacht wird, obwohl das Licht zur positiven Produktionsbilanz hier nicht mehr ausreicht. Dies legt Vergleiche mit den im März 1962 gefundenen Verhältnissen nahe.

Als Modellfall der Stabilisierung einer Wassersäule kann eine solche durch Zufluß 
von Schmelzwasser ins Meer gelten. Man erkannte daher an der norwegischen Küste im Frühjahr bald dieses Phänomen des Blütebeginns nach dem Einsetzen des Abtauens der Schnee- und Eismassen (Gran 1929). Ebenso ist dies aus der Arktis oft beschrieben, wo der Blütebeginn auffällig an den abschmelzenden Eisrand gebunden ist (MARSHALL 1958).

Conover (1956) untersuchte im Long Island Sound, der mit unseren Gewässern vergleichbar ist, den Eintritt der Frühjahrsblüte mit dem Lichtangebot und der Stabilitätsänderung. Im Frühjahr 1953 wurde die Blüte hauptsächlich von Skeletonema, im folgenden Jahre von Thalassiosira nordensköldii gebildet. Beim Vergleich von Licht und Temperaturansprüchen der beiden Arten zeigte sich, daß Thalassiosira mit geringeren Lichtansprüchen auskam als Skeletonema. Bei ähnlichen Stabilisations- und Strahlungsverhältnissen in den beiden Frühjahren 1953 und 1954 konnte sich Thalassiosira wegen ihrer Lichtgenügsamkeit schon 3 Wochen früher (bei $2^{\circ} \mathrm{C}$ kälterem Wasser) als Skeletonema entwickeln. Hier ist ein Vergleich zum Frühjahr 1962 in der Flensburger Förde angebracht, wo Thalassiosira-Arten bei sehr geringer Lichtintensität in $10 \mathrm{~m} \mathrm{zu}$ finden sind, wogegen Skeletonema später im stark durchleuchteten Oberflächenwasser dominiert.

In jedem Falle überwiegen bei den beschriebenen Diatomeenblüten die kleinen Formen. Nach PAASche (1960) nimmt die organische Substanz einer Population kleiner Arten schneller zu als die von großen. Offenbar wirkt sich dieser Unterschied in der Beltsee stark aus (BANSE 1962), wo stets die kleinen Skeletonema- und ThalassiosiraZellen in der Überzahl gefunden wurden.

Bei der Beobachtung einer reinen Skeletonema-Blüte im Loch Strivan fanden MARSHALl \& ORR. (1929/30) ein Ansteigen des Kompensationspunktes von 10 bis $20 \mathrm{~m}$ Ende März auf 2 bis $5 \mathrm{~m}$ Anfang April im Gipfel der Blüte, wo also durch Beschattung durch die Planktonwolke in dieser sehr hellen Periode dem Plankton weniger Licht zukam als vorher. Die Verhältnisse in diesem Gewässer sind aber insofern ungewöhnlich, als kaum Detritus zugegen war, der in der Flensburger Förde aber eine große Rolle spielt. Beherrschte also bei den Untersuchungen von MARshall \& ORR das Diatomeenplankton das Lichtklima im Wasser, so findet man in der Beltsee ganz andere Verhältnisse. Hier tragen nicht die relativ großen, durchsichtigen Plankter zur Lichtschwächung viel bei, sondern eher die meist großen Detritusmengen. Nach WYRTKI (1950) haben die feinsten Teilchen der mineralischen Partikel $(<10 \mu \varnothing)$ die höchste spezifische Extinktion.

\section{ABSCHLIESSENDE BETRACHTUNGEN}

Im hier untersuchten Gebiet ist man selten in der Lage, einen der komplex zusammenwirkenden Umweltfaktoren für das Plankton außer Betracht lassen zu können. Dazu wäre die Gunst der hydrographischen Bedingungen notwendig, nämlich einerseits die eines Seegebiets mit sehr gleichförmigen Umweltfaktoren (wie sie z. B. für manche Binnenseen angenommen werden dürfen), andererseits die eines Gewässers mit extremen, dabei aber konstanten und gut definierbaren Lebensbedingungen des Planktons, wie sie z. B. GiLlbricht (1955) in dem von ihm untersuchten Hafenbecken vorfand, 
oder wie sie Ryther (1954) von stark eutrophierten Buchten des Long Island Sound beschrieb. Im ersten Fall könnte der ungestörte Ablauf der Planktonentwicklung „im Normalfall" beim Zusammenwirken aller Umweltfaktoren beobachtet werden. Im zweiten wäre die Situation eines Versuchs im Freiland gegeben, wobei ein oder mehrere Faktoren in ihrer begrenzenden Wirkung auf das Planktonwachstum vernachlässigt werden und somit die Wirkung der verbleibenden einfacher und sicherer erkannt werden könnten.

In unserem Gebiet mit seinen besonders komplizierten Produktionsbedingungen eines geschichteten, flachen Brackwassermeeres werden quantitative Planktonuntersuchungen noch dadurch erschwert, daß sich identische Wasserkörper meist nicht lange an einem Ort halten, sondern horizontal verschoben werden und mancherlei Veränderungen unterliegen. In den drei hier untersuchten Zeiträumen erlaubte keine besonders ruhige hydrographische Situation, eine Planktonblite von Anfang bis Ende bei ungestörten Verhältnissen zu verfolgen. Daher konnten die Planktonpopulationen auch nur unter den Einschränkungen verglichen werden, die sich aus den hydrographischen Beobachtungen zur gleichen Zeit ergaben. Es muß als ein günstiger Umstand erscheinen, daß unter den drei nicht "gezielt" in Beobachtung genommenen Planktonblüten zwei Frühjahrswucherungen, die unter ganz verschiedenen hydrographischen Bedingungen stattfanden, und eine interessante Entwicklung des Planktons im Herbst angetroffen wurden.

Der sehr früh und stark einsetzenden Blüte im Frühjahr 1961 steht eine drei Wochen später beginnende und schwächer ausgebildete im März des folgenden Jahres gegenüber, wobei der Einfluß einer tief (März 1961) und sehr hoch (März 1962) gelegenen Sprungschicht $\mathrm{zu}$ aufschlußreichen Unterschieden in der Planktonbevölkerung führte. Hier, wie besonders im Oktober 1961 beim Beginn der Herbstblüte nach dem Verschwinden der thermohalinen Schichtung, ließ sich die entscheidende Wirkung der Turbulenz auf den Produktionsverlauf erkennen. Inwieweit die gefundenen Größen der Planktonbestände für die Beltsee als repräsentativ angesehen werden dürfen, kann durch den Vergleich mir den Werten von KREY (p. 57) abgeschätzt werden, der ähnliche Eiweiß-und Chlorophyllwerte mit vergleichbaren Unterschieden der einzelnen Jahre an zwei Stationen am Ausgang der Flensburger Förde und der Eckernförder Bucht fand.

Nach den Ergebnissen der hier vorgelegten Arbeit ist es recht wahrscheinlich, daß auch im Frühjahr weniger die Nährstofferschöpfung eine entscheidende Rolle bei der Produktionsbegrenzung in der Beltsee spielt, sondern vielmehr die Turbulenztiefe, die den Lichtgenuß der Planktophyten durch die verschiedene Länge ihres Aufenthaltes in der euphotischen Schicht bestimmt. Dies entspricht nicht den Produktionsbedingungen der Weltmeere, wo ja - mit Ausnahme der hohen Breiten - die Nährstoffe die Planktonproduktion begrenzen (STEEMANN Nielsen 1958).

Spricht man von der Frühjahrs- oder Herbstblüte des Phytoplanktons, so sollte man berücksichtigen, daß es sich meist wohl um zwei oder mehr einzelne Wucherungen handelt, die in wechselnder Stärke und unterschiedlichen Abständen aufeinander folgen und für die jeweils verschiedene Umweltfaktoren maßgebend sein und begrenzend wirken können. Bei den vorliegenden Untersuchungen dürfte im Frühjahr 1961 und 1962 nur die erste Wucherung erfaßt worden sein; alles spricht dafür, daß bei der an- 
getroffenen hydrographischen Situation weitere folgten. Auch KrEYs Beobachtungen bei Boknis Eck und Breitgrund lassen einen hohen Planktonbestand 1 bis 2 Monate lang im Frühjahr erkennen. Würde nur die Nährstofferschöpfung begrenzen, könnte eine Blüte nur eine kurze, in den verschiedenen Jahren ungefähr gleichlange Zeit von vielleicht 1 bis 2 Wochen andauern, da in unseren Gewässern am Winterende stets nur rund 20 bis $30 \mu \mathrm{g} / 1 \mathrm{PO}_{4}-\mathrm{P}$ in der Wassersäule anzutreffen sind, die von einer rasch anwachsenden Diatomeenpopulation bald verbraucht werden.

Sind aber über 4 bis 6 oder gar 8 Wochen hohe Planktondichten zu finden, muß man wiederholte Turbulenzeinwirkung annehmen. Die Möglichkeit der Nährstoffbegrenzung würde ja ungestörte hydrographische Verhältnisse bis zum Eintreten dieses Mangels voraussetzen, was aber in unserem Gebiet gerade im Frühjahr und Herbst nicht die Regel ist. Windige Tage (März 1961) greifen meist vorher in den Produktionsablauf ein, indem dann die Turbulenz die entstandenen Planktonwolken in der Wassersäule verteilt und das mittlere Lichtangebot für die Plankter so verringert, daß die Höhe des Bestandes abfällt. Auch in der geschichteten Wassersäule kann dies der Fall sein, je nach Tiefenlage der Sprungschicht und der Größe des vertikalen Extinktionskoeffizienten. Der Unterschied zwischen Sprungschichttiefe ( = Mischungstiefe) und kritischer Tiefe entscheidet dann über die Produktionsbilanz. Bestimmt die Windturbulenz die Planktonproduktion, müssen unregelmäßig lange und starke Wucherungen die Folge sein. Sie sind dann - im Gegensatz zu nährstoffbegrenzten Blüten - nicht oder nur im Rahmen der Windvorhersage vorauszuberechnen.

Im Herbst ist die Wahrscheinlichkeit der Begrenzung durch Turbulenz größer als im Frühjahr, weil bei Zerstörung der Schichtung dann Sedimentaufwirbelung und damit Erhöhung der Lichtextinktion und abfallende Sonnenhöhe gleichsinnig das Planktonwachstum noch anfälliger gegen geringe Turbulenzschwankungen machen. So erklärt sich die langanhaltende Periode sehr unterschiedlicher Herbstwucherungen.

Betrachtet man die ganze Beltsee, so nimmt der Einfluß der Windturbulenz mit der Entfernung vom Land im Mittel zu. In den Förden herrschen in dieser Hinsicht also gemilderte Verhältnisse. Andererseits wird die Lichtextinktion im Wasser mit zunehmender Landferne meist schwächer, die Kompensationstiefe also größer. Dies vermindert die Empfindlichkeit gegenüber Turbulenzschwankungen sehr. Beide Effekte wirken also gegenläufig und können, je nach dem Überwiegen des einen oder anderen, zu einer regional ubberaus verschiedenen Planktonproduktion in der Beltsee zur gleichen Zeit auch bei gleichen Schichtungsverhältnissen führen. Es mag dann eine Planktonverteilung zustande kommen, die man mit "Wolkenfeldern“ vergleichen kann.

\section{ZUSAMMENFASSUNG}

1. Im Übergangsgebiet zwischen Nord- und Ostsee, der Beltsee, wurden Untersuchungen über Beginn, Dauer und begrenzende Faktoren der Phytoplanktonblüten durchgeführt. Vom Feuerschiff „Flensburg“ (Flensburger Außenförde) aus wurden tägliche Vertikalserien mit 2,5 m Probenabstand durchgefïhrt und die gewonnenen Proben anschließend bearbeitet. Chlorophyll- und Eiweißgehalt wurden neben Planktonzählungen zur Charakterisierung des Planktongehaltes benutzt. Nach eigenen Be- 
leuchtungsmessungen wurde die Strahlungsenergie in den verschiedenen Wassertiefen berechnet. Ferner dienten hydrographische Untersuchungen und Messungen des Phosphatgehaltes zur Beschreibung der abiotischen Umwelt der Plankter. Die Beobachtungen fanden jeweils 5 bis 6 Wodhen lang im März bis April 1961 und 1962 sowie im September und Oktober 1961 statt.

2. Der Beginn der Blüte war Ende Februar 1961 an geringe Turbulenztiefen bei ruhigem Wetter und relativ hohe Wassertemperaturen $\left(3,5^{\circ} \mathrm{C}\right)$ gebunden. Im folgenden Frühjahr begann die Planktonwucherung drei Wochen später bei niedrigen Temperaturen $\left(1^{\circ} \mathrm{C}\right)$ nach einsetzender Stabilisierung der Wassersäule durch eine hochgelegene Sprungschicht. Im Herbst 1961 ermöglichte nachlassende Windeinwirkung nach einer vorhergegangenen Anreicherung der euphotischen Schicht mit Nährstoffen den Beginn der Blüte.

3. Unterschiedliche Lichtansprüche erklären das Wachstum zweier getrennter Populationen yon Skeletonema costatum an der Oberfläche und von Thalassiosira in $10 \mathrm{~m}$ Tiefe zur gleichen Zeit im Frühjahr 1962. Verschiedene Nährstoff- und Lichtansprüche machen im Herbst 1961 die getrennte Besiedlung des phosphatarmen Oberflächenwassers durch Ceratium tripos und des phosphatreicheren vermischten Wassers durch Ceratium fusus erklärlich.

4. Das Ende der beobachteten Frühjahrsblüten wurde durch Windturbulenz herbeigeführt. Phosphaterschöpfung ließ sich in den 6 Beobachtungswochen in keinem Falle erkennen. Beim Zusammenwirken der die Planktonblüten begrenzenden Faktoren -w winderzeugte Turbulenz, Stabilität der Wassersäule, Nährstoffangebot und Fraß durch Zooplankton - kommt in der Beltsee weniger der Nährstofferschöpfung die Hauptrolle zu, als vielmehr der Einwirkung der Turbulenz. Hoher Sestongehalt beherrscht als feine mineralische Trube die Lichtextinktion im Wasser. Die geringen Kompensationstiefen (Frühjahr 1961: 2 bis $4 \mathrm{~m}$; Frühjahr 1962:2 bis 7 m; Herbst 1961: 1,5 bis $11 \mathrm{~m}$ ) bewirken eine große Anfälligkeit der Planktonentwicklung gegenüber schon geringer Erhöhung der Turbulenztiefe, die das Plankton leicht unter die "kritische Tiefe" bringen kann.

5. Statt einer "Frühjahrs"- und "Herbstblüte" des Phytoplanktons ist eine Folge unterschiedlich starker Wucherungen während mindestens 4 bis 6 Wochen im Frühjahr und 8 Wochen im Herbst anzunehmen. Diese Wucherungen dauern weit länger als dies bei Nährstoffbegrenzung allein der Fall wäre, da an windigen Tagen das Planktonwachstum gehemmt und gleichzeitig die Nährstoffmenge in der Oberschicht ergänzt wird.

6. Starke regionale Schwankungen der Turbulenz- und Kompensationstiefe führen in der Beltsee zu einer sehr inhomogenen horizontalen Planktonverteilung. Im Zusammenhang mit Strömungen erschwert dieser Umstand die Untersuchung der Planktonsukzession an einem Ort, weil die Sequenz meist miterfaßt wird. Man sollte daher besser die Sukzession in einem markierten, individuellen Wasserkörper untersuchen. Fragen der Licht- und Nährstoffbeeinflussung der hier beobachteten Populationen bedürfen noch dex Klärung durch das Kulturexperiment.

Meinem verehrten Lehrer, Herrn Prof. Dr. J. Krey, sage ich für die Anregung zu dieser Arbeit und seine Förderung herzlichen Dank. 


\section{ZITIERTE LITERATUR}

Antia, N. G., Mcallister, C. D., Parsons, T. R., Stephens, K. \& Strickland, J. D. H., 1963. Further measurements of primary production using a large-volume plastic sphere. Limnol. Oceanogr. 8 (2), 166-183.

Atkins, W. R. G., 1928. Seasonal variations in the phosphate and silicate content of seawater during 1926 and 1927 in relation to the phytoplankton crop. J. mar. biol. Ass. U.K. 15, 191-205.

- \& Poole, H. H., 1933. The photoelectric measurement of the penetration of light of various wave-lengths into the sea and the physiological bearings of the results. Phil. Trans. R. Soc. (Ser, B) 222, 129 ff.

- - 1936. The photoelectric measurement of the diumal and seasonal variations in daylight and a globe integrating photometer. Pbil. Trans. R. Soc. (Ser. A) $235,245 \mathrm{ff}$.

BAINBRIDGE, R., 1957. The size, shape and density of marine phytoplankton concentrations. Biol. Rev. 32 (1), 91-115.

BANSE, K., 1957. Ergebnisse eines hydrographisch-produktionsbiologischen Längsschnitts durch die Ostsee im Sommer 1956. 2. Die Verteilung von Sauerstoff, Phosphat und suspendierter Substanz. Kieler Meeresforsch. 13, 186-201.

- 1962. Chemie und Autökologie bei produktionsbiologischen Untersuchungen des Planktons. Kieler Meeresforsch. 18 (3), 132-135.

- \& Krey, J., 1962. Quantitative Aspekte des Kreislaufs der organischen Substanz in Meere. Kieler Meerestorsch. 18 (3), 97-106.

BEOBACHTUNGEN auf den deutschen Feuerschiffen der Nord- und Ostsee im Jahre 1961 und 1962. Deutsches Hydrographisches Institut, Hamburg.

Bigelow, H. B., Lrllick, L. C. \& Sears, M., 1940. Phytoplankton and planktonic protozoa of the offshore waters of the Gulf of Maine. Trans. Am. phil. Soc. 31 (3), 149-191.

BraARUd, T., 1958. Counting methods for determination of the standing crop of phytoplankton. Rapp. P.-v. Réun. Cons. perm. int. Explor. Mer 144, 17-19.

- \& KLEM, A., 1931. Hydrographical and chemical investigations in the coastal waters off More and the Romdalsfjord. Hvalradets Skr. Norske Vidensk. Akad. 1, 1-88.

- GaArder, K. R. \& Nordi, O, 1958. Seasonal changes in the phytoplankton at various points off the Norwegian West Coast. Fisk Dir. Skr., Ser. Havundersøkelser 12 (3), 1-77.

BRANDT, K. \& RABEN, E., 1920. Zur Kenntnis der chemischen Zusammensetzung des Planktons und einiger Bodenorganismen. Wiss. Meeresunters. Abt. Kiel 19, 175-210.

Conover, S. A. M., 1956. Oceanography of Long Island Sound. 1952-54. 4. Phytoplankton. Bull. Binghom. oceanogr. Coll. 15, 62-112.

Cushing, D. H., 1962. An alternative method of estimating the critical depth. J. Cons. int. Explor. Mer 27 (1), 131-140.

DIETRICH, G., 1950. Die natürlichen Regionen von Nord- und Ostsee auf hydrographischer Grundlage. Kieler Meeresforsch. 7 (2), 35-69.

FøYN, B. R., 1929. Investigations of the phytoplankton at Lofoten, March-April, 1922-27. Skr. norske Vidensk-Akad. 1928 (10).

Gardiner, A., 1941. Measurement of phytoplankton by the pigment extraction method. $/$. mar. biol. Ass. U. K. 25,739-744.

GEssner, F., 1948. The vertical distribution of phytoplankton and the thermocline. Ecology $29(3), 386-389$.

- 1960. Die Photosynthese des Phytoplanktons. In: Handbuch der Pflanzenphysiologie. Hrsg. von W. Ruhland (u. a.). Springer, Berlin, Bd 5, T. 2.

GrLlbricht, M., 1951. Produktionsbiologische Untersuchungen in der Kieler Bucht. (Auf Grund eigener Messungen beim Feuerschiff „Flensburg" 1949 und 1950.) Diss. Kiel, $92 \mathrm{pp}$ u. Anhang.

- 1955. Wucherungen von Phytoplankton in einem abgeschlossenen Hafenbecken. Helgoländer wiss, Meeresunters. 5 (2), 141-168.

- 1956. Der Einfluß der Turbulenz auf die Planktonproduktion in einem Hafenbecken. Kurze Mitt. Inst. FischBiol. Univ. Hamb. 6, 1-9. 
- 1959. Die Planktonverteilung in der Irminger See im Juni 1955. Ber. dt. wiss. Komm Meeresforsch. 15 (3), 260-275.

- 1962. Ober das Auszählen von Planktonschöpfproben. Helgoländer wiss. Meeresunters. 8 (2), 203-218.

GRAN, H. H., 1929. Investigations of the production of plankton outside the Romdalsfiord 1926-27. Rappp. P.-v. Réun. Cons. perm. int. Explor. Mer 56, 1-112.

- 1930. The spring growth of the plankton at Møre in 1928-29 and at Lofoten in 1929 in relation to its limiting factors. Skr. norske Vidensk-Akad. (mat. nat. Kl.) 5.

- 1932. Phytoplankton. Methods and problems. J. Cons. perm. int. Explor. Mer 7 (3), 343-358.

- B BraArud, T., 1935. A quantitative study of the phytoplankton in the Bay of Fundy and the Gulf of Maine. J. biol. Bd Can. 1, 279-467.

GrIM, J., 1939. Beobachtungen am Phytoplankton des Bodensees (Obersee) sowie deren rechnerische Auswertung. Int. Revne ges. Hydrobiol. Hydrogr. 39, 193-315.

HagmeIer, E., 1960. Untersuchungen über die Menge und die Zusammensetzung von Seston und Plankton in Wasserproben von Reisen in die Nordsee und nach Island. Diss. Kiel, $168 \mathrm{pp}$ u. Anhang.

- 1961. Plankton-Aquivalente. Kieler Meeresforsch. 17 (1), 32-47.

Höglund, H. \& Landererg, S., 1936. Further investigations upon the photosynthesis of phytoplankton by constant illumination. Rapp. P.-v. Rém. Cons. perm. int. Explor. Mer 95, $31-33$.

JenKIN, P. M., 1937. Oxygen production by the diatom Coscinodiscus excentricus in relation to submarine illumination in the English Channel. J. mar. biol. Ass. U. K. 22, 301-342.

JerLov, N. G., 1951. Optical studies of ocean waters. Rep. Swed. deep Sea Exped. 3 (1), 1-60.

- 1955. Factors influencing the transparency of the Baltic waters. Medd. oceanogr. Inst. Göteborg 25, 1-19.

Josepr, J, 1946. Uber die Extinktion des Lichtes im Meerwasser und ihre Messung. Diss. Hamburg.

- 1949. Uber die Messung des „Vertikalen Extinktionskoeffizienten“. Dt. bydrogr. Z. 2 (6), 255-267.

- 1950. Durchsichtigkeitsregistrierungen als ozeanographische Untersuchungsmethode. Dt. bydrogr. Z. 3 (2), 69-77.

- \& WaTtenberG, H., 1944. Untersuchungen über die optischen Verhältnisse im Meere. In: Mitt. Hydrogr. Dienst, 1944.

KäNDLER, R., 1951. Der Einfluß der Wetterlage auf die Salzgehaltsschichtung im Öbergangsgebiet zwischen Nord- und Ostsee. Dt. hydrogr. Z. 4, 150-160.

- 1963. Hydrographische Untersuchungen über die Abwasserbelastung der Flensburger Förde. Kieler Meeresforsch. 19 (2), 142-157.

Kierstead, H. \& Stobodkin, L. B., 1953. The size of water masses containing plankton blooms. 7. mar. Res. 12, 141-147.

Kimball, H. H., 1928. Amount of solar radiation that reaches the surface of the earth on the land and on the sea, and methods by which it is measured. Mon. Weath. Rev. U.-S. Dep. Agric. 56, 393-399.

KolkwiTz, F, 1912. Plankton und Seston. Ber. dt. bot. Ges. 30 (6), 334-346.

KREY, J., 1939. Die Bestimmung des Chlorophylls in Meerwasser-Schöpfproben. J. Cons. perm. int. Explor. Mer 14 (2), 201-209.

- 1949. Uber Art und Menge des Sestons im Meere. Zool. Anz. (Suppl. Bd) 14, 295-301.

- 1950. Eine neue Methode zur quantitativen Bestimmung des Planktons. Kieler Meeresforsch. 7 (1), 58-75.

- 1952a. Die Untersuchung des Eiweißgehaltes in kleinen Planktonproben. Kieler Meeresforsch. 8, 164-172.

- 1952b. Die Charakterisierung von Wasserkörpern durch optische Messungen. Arch. Hydrobiol. $40(6), 1-14$.

- 1954. Beziehungen zwischen Phytoplankton, Temperatursprungschicht und Trübungsschirm in der Nordsee im August 1952. Kieler Meeresforsch. 10 (1), 3-18. 
- 1961. Beobachtungen über den Gehalt an Mikrobiomasse und Detritus in der Kieler Buche 1958-60. Kieler Meeresforsch. 17 (2), 163-175.

- Banse, K. \& Hagmeier, E., 1957. Über die Bestimmung von Eiweiß im Plankton mittels der Biuret-Reaktion. Kieler Meeresforsch. 13 (1), 35-40.

Lenz, J., 1963. Zur Ursache der an die Sprungschicht gebundenen Echostreuschichten in der westlichen Ostsee. Diss. Kiel, 79 pp \& Anhang.

Lund, J. W. G., Kipling, C. \& Le Cren, E. D., 1958. The inverted microscope method of estimating algal numbers and the statistical basis of estimations by counting. Hydrobiologia 11, 143-170.

Lohmann, H., 1908. Untersuchungen zur Feststellung des vollständigen Gehaltes des Meeres an Plankton. Wiss. Meeresunters. Abt. Kiel 10, 129-370.

Marshall, P. T., 1958. Primary production in the Arctic. J. Cons. perm. int. Explor. Mer $23(2), 173-177$.

Marshald, S. M. \& ORR, A. P., 1928. The photosynthesis of diatom cultures in the sea. J.mar. biol, Ass. U. K. 15, 321-360.

- 1929/30. A study of the spring diatom increase in Loch Strivan. J. mar. biol. Ass. U. K. $16(3)$.

MCAllister, C. D., 1963. Measurements of diurnal variations in productivity at ocean station “P”. Limnol. Oceanogr. 8 (2), $289-292$.

- Stephens, K. \& Strickland, J. D. H., 1961. Measurements of primary production in coastal sea water using a large-volume plastic sphere. Limnol. Oceanogr. 6, 237-258.

PaAsche, E., 1960. On the relationship between primary production and standing stock of phytoplankton. J. Cons. perm. int. Explor. Mer 26 (1), 33-48.

Peters, N., 1929. Uber Orts- und Geißelbewegung bei marinen Dinoflagellaten. Arch. Protistenk. 67 (2/3), 291-321.

Petterson, H., Höglund, H. \& Landegrg, S., 1934. Submarine daylight and the photosynthesis of phytoplankton. Meddn Göteborgs Högsk. oceanogr. Inst. 6(Ser. B) 3, 1-17.

Pomeroy, L. R., Haskin, H. H. \& Ragotzkie, R. A., 1956. Observations on dinoflagellate blooms. Limnol. Oceanogr. 1 (1), 54-60.

Poole, H. H., 1938. The effect of surface condition on the intensity and angular distribution of submarine daylight. Rapp. P.-v. Réun. Cons. perm. int. Explor. Mer 108 (1), 4-6.

Rabinowitch, E. I., 1951. Photosynthesis and related processes. Wiley, New York, 2 (1), $1-620$.

Ragotzkie, R. A. \& Pomeroy, L. R., 1957. Life history of a dinoflagellate bloom. Limnol. Oceanogr. 2 (2), 62-69.

Richards, F. A. \& Thompson, T. G., 1952. The estimation and characterization of plankton populations by pigment analysis. II. A spectrophotometric method for the estimation of plankton pigments. J. mar. Res. 11, 156-172.

Riley, G. A., 1941. Plankton studies, 4. Georges Bank. Bull. Bingham oceanogr. Coll. 7 (4), $1-73$.

- 1942. The relationship of vertical turbulence and spring diatom flowerings. J. mar. Res. 5, 67-87.

- 1943. Physiological aspects of spring diatom flowerings. Bull. Bingham oceanogr. Coll. 7 (4), $1-53$.

- 1947. Factors controlling phytoplankton population on Georges Bank. J. mar, Res. 6, 54-73.

Ryther, J. H., 1954. The ecology of phytoplankton blooms in Moriches Bay and Great South Bay, Long Island, N. Y. Biol. Bull. mar, biol. Lab., Woods Hole 106, 198-209.

- 1956. Photosynthesis in the ocean as a function of light intensity. Limnol. Oceanogr. 1 (1), $61-70$.

- Yentsch, C. S., Hulburt, E. M. \& Vaccaro, R. F., 1958. The dynamics of a diatom bloom. Biol. Bull. mar. biol. Lab., Woods Hole 115 (2), 257-268.

RytTer Hasle, G., 1954. More on phototactive diurnal migration in marine dinoflagellates. Nytt Mag. Bot. 2. 
SaUberer, F., 1962. Empfehlungen für die Durchführung von Strahlungsmessungen an und in Gewässern. Mitt. int. Verein. theor, angew. Limnol. 11, 1-77.

SoRokin, J. I., 1960. Vertical distribution of phytoplankton and the primary organic production in the sea. J. Cons. perm. int. Explor. Mer 26 (1), 49-56.

Steemann Niflsen, E., 1940. Die Produktionsbedingungen des Phytoplanktons im Übergangsgebiet zwischen der Nord- und Ostsee. Meddr Kommn Danm. Fisk. - og Havunders., Ser. Plankton $3(4), 1-55$.

- 1958a. Light and organic production in the sea. Rapp. P.-v. Réun. Cons. perm. int. Explor. Mer 144, 141-148.

- 1958b. A survey of recent Danish measurements of the organic productivity in the sea. Rapp. P.-v. Réun. Cons. perm. int. Explor. Mer 144, 92-95.

- \& Hansen, V. K., 1959. Light adaptation in marine phytoplankton populations and its interrelation with temperature. Physiologia Pl. 12, 353-370.

- - 1961. Influence of surface illumination on plankton photosynthesis in Danish waters $\left(56^{\circ} \mathrm{N}\right)$ throughout the year. Pbysiologia Pl. 14, 595-613.

Stommes, $\mathrm{H}$., 1949. Trajectories of small bodies sinking slowly through convection cells. J. mar. Res. 8 (1), 24-29.

STRICKLAND, J. D. H., 1958. Solar radiation penetrating the ocean. A review of requirements, data and methods of measurements, with particular reference to photosynthetic productivity. J. Fish. Res. Bd Can. 15 (3), 453-493.

- 1960. Measuring the production of marine phytoplankton. Bull. Fish. Res. Bd Can. 122, $1-172$.

Sverorup, H. U., 1953. On conditions for the vernal blooming of phytoplankton. J. Cons. perm. int. Explor. Mer 18, 287-295.

Tschirn, E., 1920. Biologische Studien an Ceratien der Kieler Förde. Diss. Kiel.

UTERMöHL, H., 1958. Zur Vervollkommnung der quantitativen Phytoplanktonmethodik. Mitt. int. Verein. theor. angew. Limnol. 9, 1-38.

Wattenberc, H., 1937. Methoden zur Bestimmung von Phosphat, Silikat, Nitrit, Nitrat und Ammoniak im Seewasser. Rapp. P..v. Réun. Cons. perm. int. Mer 103, 5-26.

- 1941. Uber die Grenzen zwischen Nord- und Ostseewasser. Annln Hydrogr. Berl, 9, 265 bis 279 .

- 1949a. Entwurf einer natürlichen Einteilung der Ostsee. Kieler Meeresforsch. 6, 10-15.

- 1949b. Salzgehaltsverteilung in der Kieler Bucht und ihre Abhängigkeit von Strom- und Wetterlage. Kieler Meeresforsch. 6, 17-30.

WeIdemanN, H., 1948. Über periodische und unperiodische Erscheinungen im Wasseraustausch der Beltsee. Diss. Kiel, 43 pp. u. Anhang.

WyRTKI, K., 1950. Über die Verteilung der Trübung in den Wassermassen der Beltsee und ihren Zusammenhang mit den hydrographischen Faktoren. Diss. Kiel.

YENTSCH, C. S. \& RYTHER, J. H., 1957. Short-term variation in phytoplankton chlorophyll and their significance. Limnol. Oceanogr. 2 (2), 140-142.

Zetтzschel, B., 1964. Zur Sedimentation Yon. Seston; eine produktionsbiologische Untersuchung von Sinkstoffen und Sedimenten der Westlichen und Mittleren Ostsee. Diss. Kiel, 106 pp. u. Anhang. 